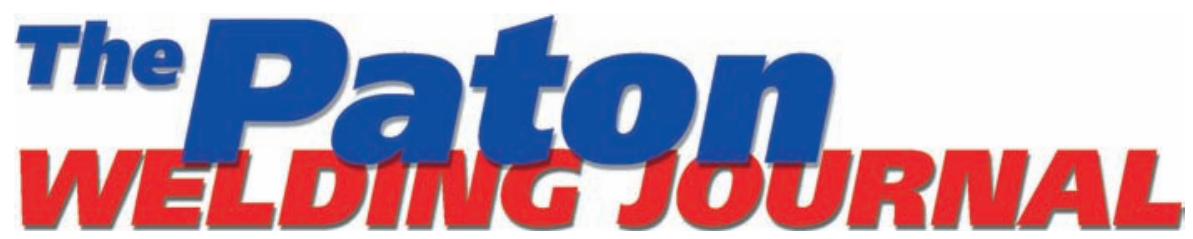

November 2017 No. 11

Published since 2000

English translation of the monthly «Avtomaticheskaya Svarka» (Automatic Welding) journal published in Russian since 1948

\section{EDITORIAL BOARD \\ Editor-in-Chief B.E. Paton}

Scientists of PWI, Kiev S.I. Kuchuk-Yatsenko (vice-chief ed.), V.N. Lipodaev (vice-chief ed.),

Yu.S. Borisov, G.M. Grigorenko A.T. Zelnichenko, V.V. Knysh,

I.V. Krivtsun, Yu.N. Lankin, L.M. Lobanov, V.D. Poznyakov, I.A. Ryabtsev, K.A. Yushchenko

Scientists of Ukrainian Universities V.V. Dmitrik, NTU «KhPI», Kharkov V.V. Kvasnitsky, NTUU «KPl», Kiev V.D. Kuznetsov, NTUU «KPI», Kiev

\section{Foreign Scientists}

N.P. Alyoshin

N.E. Bauman MSTU, Moscow, Russia Guan Qiao

Beijing Aeronautical Institute, China A.S. Zubchenko

DB «Gidropress», Podolsk, Russia M. Zinigrad

Ariel University, Israel V.I. Lysak

Volgograd STU, Russia

Ya. Pilarczyk

Welding Institute, Gliwice, Poland U. Reisgen

Welding and Joining Institute, Aachen, Germany G.A. Turichin

St. Petersburg SPU, Russia

Founders

E.O. Paton Electric Welding Institute, NASU International Association «Welding» Publisher

International Association «Welding» Translators

A.A. Fomin, O.S. Kurochko, I.N. Kutianova Editor

N.G. Khomenko

Electron galley

D.I. Sereda, T.Yu. Snegiryova Address

E.O. Paton Electric Welding Institute, International Association «Welding»

11 Kazimir Malevich Str. (former Bozhenko Str.), 03150, Kiev, Ukraine

Tel.: (38044) 20060 16, 2008277

Fax: (38044) 20082 77, 2008145

E-mail: journal@paton.kiev.ua

www.patonpublishinghouse.com

State Registration Certificate

KV 4790 of 09.01 .2001

ISSN 0957-798X

doi.org/10.15407/tpwj2017.08.01

Subscriptions

$\$ 348,12$ issues per year

air postage and packaging included.

Back issues available. All rights reserved.

This publication and each of the articles contained herein are protected by copyright.

Permission to reproduce material contained in this journal must be obtained in writing from the Publisher.

\section{CONTENTS}

Interview with A.V. Stepakhno - Director General of the

E.O. Paton Electric Welding Institute PPWE 2

\section{INDUSTRIAL}

Shlepakov V.N., Kotelchuk A.S. and Gavrilyuk Yu.A.

Modern flux-cored wires for welding of low-alloy steels

of increased and high strength

Nesterenkov V.M., Orsa Yu.V., Khripko K.S. and Gusev Yu.V.

Restoration repair of elements and units of gas turbine

engines

Tsaryuk A.K., Elagin V.P., Rozumenko G.A., Pasechnik A.I.

and Peretyatko V.A. Selection of technology for repair

welding of parts of turbine units

Poznyakov V.N., Dyadin V.P., Davydov E.A., Maksimenko A.A.

and Klapatyuk A.V. Evaluation of technical condition and

repair of casing of catalytic cracking regenerator R-202

Mazur A. A., Lipodaev V.N., Pustovojt S.V. and Petruk V.S.

State-of-the-art of welding equipment and consumables

market in Ukraine

\section{INFORMATION}

Pilot Plant of Welding Consumables …................................... 37

Production of Titanium Alloy Ingots ........................................ 38

Training and Qualification Centre _.......................................... 39 


\section{Interview with A.V. Stepakhno - Director General of the E.O. Paton Electric Welding Institute PPWE}

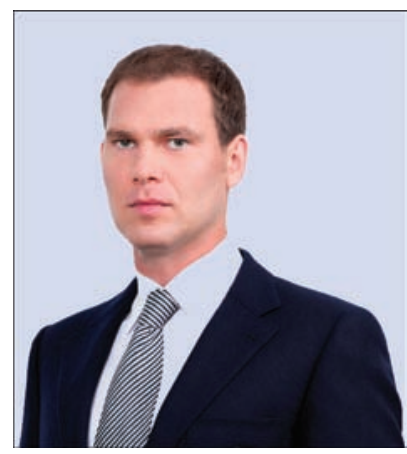

Pilot Plant of Welding Equipment is the leading production facility of Science-Technology Complex «E.O. Paton Electric Welding Institute». From the moment of the start of its operation in 1959, the main objective of the Plant was optimization of the technology of manufacturing new welding equipment, developed by scientists of the Electric Welding Institute.

Over the past years, the Plant produced a lot of unique equipment - from high-precision small-sized units used for welding in space, up to high-power automated machines of «Styk», "Sever» type, for instance for flash-butt welding of large-diameter pipes, for welding longitudinal welds of pipes under the conditions of automated manufacturing, etc. At present the Plant focuses on manufacturing reliable welding equipment fit for operation under any production conditions.

Today manufacturing of special-purpose welding and surfacing equipment, including automatic equipment, by special orders from major users takes up a considerable share of production. PPWE was the first to master batch production of inverter equipment in Ukraine. The Plant has good prospects of economic, and production development, and its products enjoy high consumer demand.

Your enterprise has been successfully developing over the recent years. What promoted or contributed to beginning of intensive growth?

Strategy of enterprise development was elaborated for long-term perspective. Our goal was to become the leaders in the production of welding equipment in Eastern Europe. To reach this goal, radical reconstruction of the Plant capacities was performed, modern market of welding equipment was analyzed, and priorities in the range of manufactured products were determined.

Starting from the moment of its founding up to 1990, the Plant serially produced classical welding equipment (transformers, semi-automatic machines, rectifiers). Over all these years, hundreds of thousands of equipment pieces were manufactured for enterprises from almost all continents of the world.

Over the next years, despite the instability of economic situation in the country, the Plant management always invested into enterprise development and brought together a team of professionals, literally «living in their business»». This brought its results and today we occupy a significant part of the market of welding equipment and consumables in Ukraine and outside it. Over the last decade, production volumes increased almost

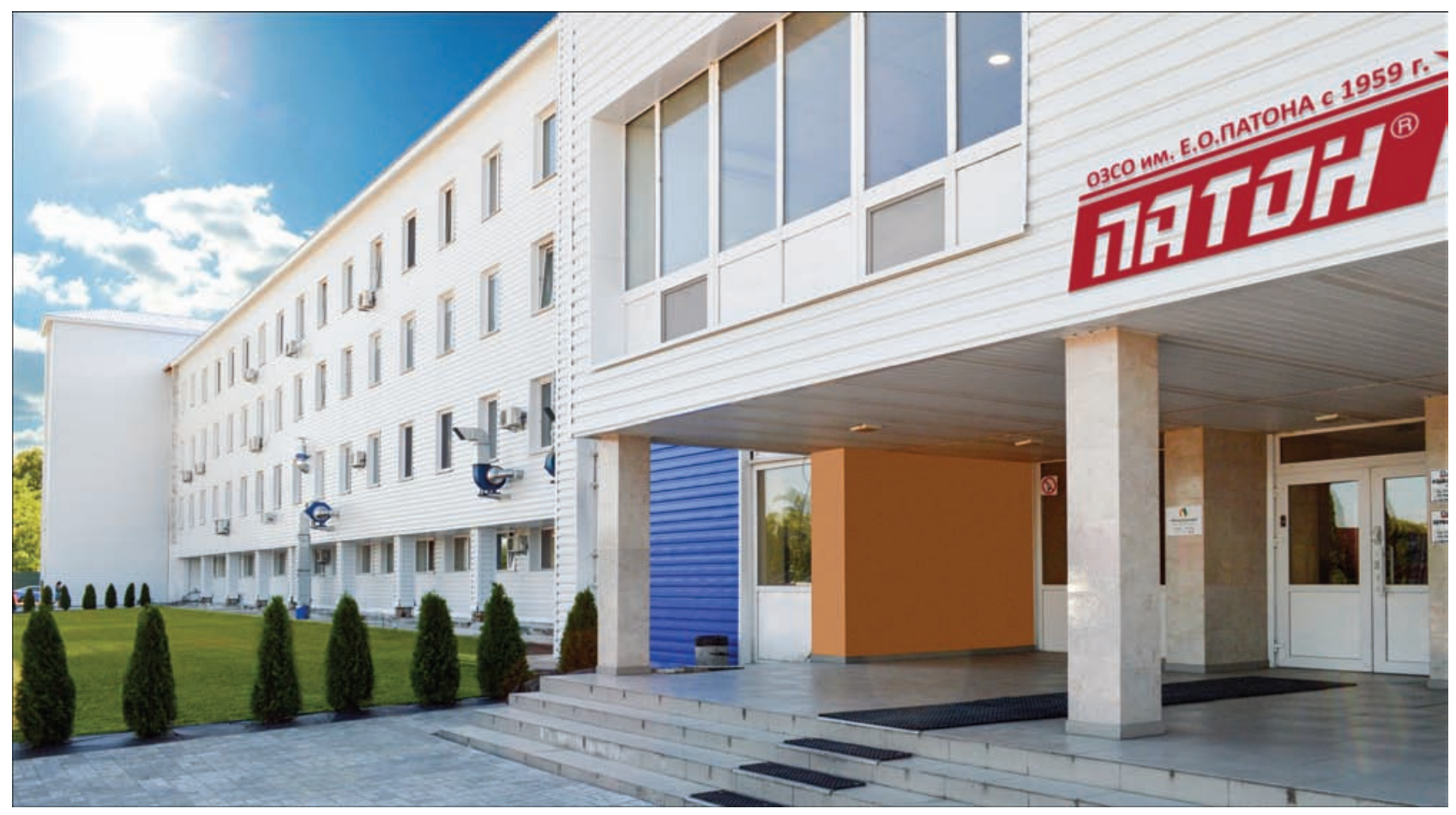


100 times. In 200650 pieces of inverter equipment and about one hundred transformer pieces were produced per month. Planned output for this year is equal to 50 thousand inverters and more than 2 thousand pieces of classical equipment. We are optimistic about the annual plan, as these are the real indicators of the current capabilities of the Plant.

It is known that during the period of independent Ukraine, the market of arc welding equipment in the country was developing actively, and became quite saturated. What niche in the extensive product range have you planned for PWI PPWE?

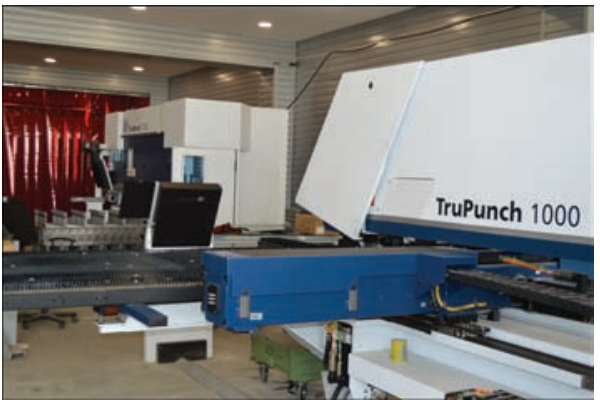

During the period of formation of independence of Ukraine the Plant, was on the brink of survival, similar to many other enterprises. However, in 1998 serial production of the most sought classical equipment was resumed. Advance of technology markedly influenced the welding equipment sector: all the units were modified to save energy, and transformer equipment was gradually moving out of the consumption segment. We had to look for something new. We began studying the experience of technologically advanced countries. Plant specialists visited the enterprises and industrial exhibitions of Europe, China and CIS countries, where the vector of development of welding equipment manufacturers was determined. We chose the direction of design and manufacture of welding inverters.

The enterprise changed its course to production of inverter equipment, designed for mass segment of the market: private shops on repair of electric equipment, household appliances, and production of furniture, household farms; service stations; construction companies; manufacturing enterprises and utility companies.

In 2005 an experimental section was set up for manufacturing inverter welding machines, which now are sales leaders. By 2008 the Plant was already manufacturing small batches of inverters for manual arc welding of three modifications for 120,160 and 200 A currents. Today the inverter line includes 25 models for currents from 140 up to $315 \mathrm{~A}$, and by the end of the year models for up to 500 A current will be introduced.

\section{What did reconstruction of production facilities include?}

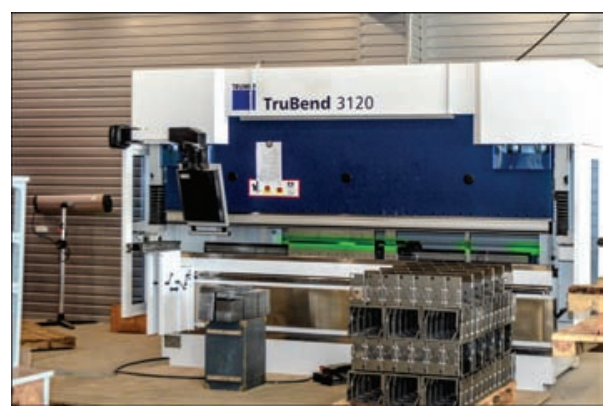

Today the Plant has well-fitted production facilities, including shops for manufacturing classical and inverter equipment, and shops for metalworking with high-tech TRUMPF machines-tools as well as production site for electrode manufacturing.

Launching our own metalworking shop allowed a considerable lowering of the cost of manufactured welding machines and attracting orders from other companies for producing various metal products. In addition to production facilities, administrative, office and storage premises of the Plant have been upgraded.

\section{Transformations, probably, also involved the changes of enterprise personnel policy?}

All the Plant shops and sections are staffed with highly qualified personnel. Plant staff is unique: as welding professionals they share their experience with promising young specialists under the actual production conditions.

Plant management continuously invests into development of its employees. Training and internship are conducted regularly not only in Ukraine, but also abroad. Plant specialists visit leading industry exhibitions in Essen, Beijing and CIS countries, so as to keep abreast of the latest innovations and trends in the industry. Students from the National Technical University of Ukraine «Igor Sikorsky KPI» also do internships at the Plant. Thus, the Plant promotes sharing scientific experience and revival of technical potential of our country.

Has the geography of equipment supplies expanded today?

After the Plant has taken up a significant share of Ukrainian market, we began to deal with export. Foreign consumers gradually responded and new partners appeared.

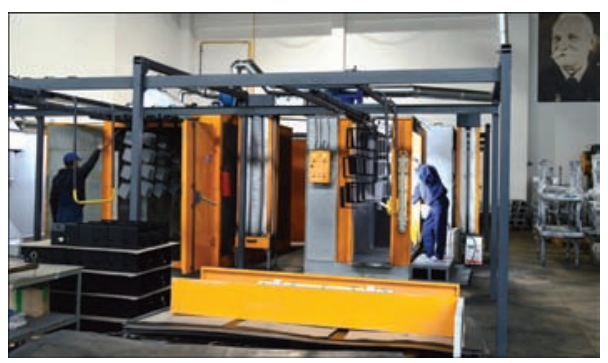


In 2012 the first export delivery of welding inverters was made to Equatorial Guinea. Starting from 2013 welding units began to be exported to Georgia, Moldova and Azerbaijan. In Georgia a distribution network has been actively working for three years now, and a service center has been established.

In 2014 we received the European certification CE for inverters, and this year we have confirmed it for the entire line of currently manufactured inverters. And this opened up new opportunities for us.

In 2015 PATON welding equipment was presented in the markets of Czech Republic, Uzbekistan, United Arab Emirates and Myanmar, in 2016 — in those of Korea, Belarus, Kazakhstan, Estonia, Poland and Bulgaria. This year we began exporting welding electrodes and machines to Latvia, Lithuania, Rumania and Iran.

Today, export geography covers more than 20 countries. Our products are in good demand, as we are in the middle price segment, and approach such known manufacturers as ESAB, Fronius and Kemppi as to equipment characteristics.

In terms of production diversification PWI PPWE also mastered production of coated electrodes. What prospects do you see for the enterprise in the market in this connection?

Mastering electrode production provides our customers with a whole range of services. Each of them can immediately obtain the welding machine and electrodes he needs. Due to quality electrodes, their range and technical support, we are creating a wide client base. Our goal is to provide the market with consumables of our own production, corresponding to EC requirements.

Your connections with the Electric Welding Institute are traditional. Can you give examples of effective recent cooperation?

Yes, the Plant continues to work closely with the Electric Welding Institute and Experimental Design and Technological Bureau on development of specialized welding equipment.

As examples, we can note the following projects on the national and international scale performed over the recent years:

- in 2013 development of welding technology and equipment for manufacturing combined welded rotors by automatic submerged-arc welding by the order of OJSC «Turboatom» was completed;

- in 2014 a project was fulfilled for State Oil Company of Azerbaijan Republic (SOCAR) on separation of two pontoons from a block by the method of directed explosion at construction of an off-shore stationary platform No.7 at Guneshli field in the Caspian Sea;

- in 2015 a project for State Company «Ukrspetzexport» on development and manufacturing of a batch of welding equipment for tropical climate was completed. Equipment with improved characteristics and increased reliability was supplied to one of the shipyards of South-East Asia;

- in 2016 we performed two joint contracts for East European machine-building plant for electroslag welding of up to 200 and up to 450 mm thick metal;

- in 2016 the Plant together with EDTB developed multistation welding rectifiers VDU-1202P, which were used for refitting SCB Foundry - a Car-Building Plant of CKD Kutna Hora a.s. Group (Czech Republic);

- also in 2016 a project was completed for State Company «Ukroboronservis» on development of an automatic mortar coordination system. A plate was designed and its folding system was developed. The developed complex allows aiming the mortar on the target automatically. The project was presented with success at XIII International Specialized Exhibition «Armament \& Safety-2016».

At present all the Plant units are staffed by qualified personnel, fitted with modern equipment and demonstrate their readiness to implement projects of varying complexity.

It is known that the enterprise uses PATON brand for their products. What does it imply?

This, primarily, obliges us to manufacture products of exceptionally high quality.

Quality control is carried out at all stages of production: from purchasing materials and raw materials up to testing each welding unit in special stands. Final product control is performed directly before shipment to the client. In addition, if required, the Plant provides advisory and engineering support to product buyers.

It is known that as a result of privatization many enterprises have completely disappeared from the market, or are at the stagnation stage in our country. The case of PWI PPWE is different. Please name three main principles of leadership, realized at the enterprise for its successful development. 
The basic principles of leadership are laid down in our motto — «Reliability. Quality. Traditions».

We manufacture welding units, the reliability of which has been confirmed by 5 year guarantee, and their quality - by European certificates CE. Traditions are passed on from experienced welding professionals to promising young specialists of the Plant in practical operation.

We continuously invest funds into production and technical base of the enterprise, purchasing up-to-date equipment, and in personnel development - as a guarantee of future success of our enterprise. I believe that production is the main driver of the country's economy. Development of the industry largely depends not only on the selected strategy of its leaders, but also on the possibility to invest into the innovative developments and directions.

The Plant always puts the customer first, seeking the most competitive solutions and trying to reach the highest product level. And for many years now Plant products have enjoyed well-earned popularity in different countries, due to their reliability and quality.

\section{We would like to thank you, Mr. Stepakhno, for interesting and detailed information on the activities of Pilot Plant of Welding Equipment, and to wish your enterprise further successes for the benefit of Ukraine.}

The interview was recorded by A.T. Zelnichenko, V.N. Lipodaev

\section{STAGES OF DEVELOPMENT OF PWI PPWE}

1959-1969

- In January, 1959 E.O. Paton Electric Welding Institute Pilot Plant was established. Development and manufacturing of submerged-arc welding machines and tractors of TC-17 type began.

- Electroslag welding machines and power sources of TShS type for 1000 and 3000 A current were put into production.

- Semi-automatic $\mathrm{CO}_{2}$ welding machines of A547 type were put into production.

- Batch production of small-sized welding transformer STSh-250 began in 1968.

- Special units and machines for flash-butt welding and surfacing were developed and put into production.

- «Vulcan» unit for welding in space was produced.

\section{0-1980}

- Welding machines were manufactured for VAZ and KAMAZ plants.

- Special welding machines for KUF-8 combine harvesters for agriculture were put into production.

- Batch-production of multistation rectifier VMG-5000 for $\mathrm{CO}_{2}$ welding began in 1973.

- «ARAKS» apparatus for Soviet-French space experiment was produced.

- The first sample of a unique powerful in-pipe machine K-700 for flash-butt welding of pipes of oil and gas pipelines in the conditions of the North was manufactured.

- In 1974 the State Quality Mark of the USSR was awarded for the first time within the Ukr.SSR AS to three batch-produced units: STSh-250 transformer, VMG-5000 rectifier, A1114M semi-automatic machine.

- From 1975 till 1980 more than 50 sets of unique welding machines were supplied to the USA, FRG, Sweden and Japan.

- In February 1979 the Plant celebrated its $20^{\text {th }}$ jubilee.

\section{1-1990}

- Equipment for Khartsyzsk and Vyksa Pipe plants was manufactured.

- «Isparitel» unit for deposition of protective coatings in space was produced.

- Export supplies to Austria, Bulgaria, East Germany, India, Canada and Japan begin to be made. 
- In 1981 State Quality Mark of the USSR was awarded for the second time to STSh-250, VMG-5000 and A1114M units.

- In July, 1984 cosmonauts Svetlana Savitskaya and Vladimir Djanibekov successfully performed the operations of cutting, welding, brazing and spraying of metal plates in open space using portable electron beam unit URI in orbital scientific-research complex «SALUT-7».

- Unique apparatuses and units were produced for various welding processes.

\section{1-2000}

- Machines for welding fuel tanks of «Zhiguli» car and tank cars were manufactured for Neftekamsk car plant.

- Batch-production of STSh type transformers for 250, 315 and 400 A currents, VD type rectifiers for 250, 315 and 400 A currents and upgraded semi-automatic machines of PS type for 180, 250 and 315 A currents is started.

\section{1-2010}

- Unique vacuum chambers were produced for electron beam welding of critical products.

- A unique transformer with square-wave current for welding longitudinal welds of large diameter pipes for Khartsyzsk Pipe Plant was developed and put into production.

- In 2004 the name of PATON - academician E.O. Paton, the founder of the E.O. Paton Electric Welding Institute, was added to the name of equipment, manufactured by the Plant.

- In December 2004 official presentation of the first inverter power source VDI-160M was conducted.

- In 2006 surfacing machines were manufactured and introduced at «Krivorozhstal» Combined Works, OJSC «Azovmash», OJSC «ZSMK» at Novokuznetsk.

- Production of high-efficient ploughs for agricultural sector was mastered.

- In 2008 the first salon-shop «Svarka» with a wide range of welding equipment and consumables was opened.

- Production of the first batches of VDU type inverters for manual arc welding for currents of 120,160 and 200 A was started.

- In 2009 the Plant marked its 50 ${ }^{\text {th }}$ jubilee; Plant veterans were awarded Diplomas of the government of Ukraine and Kiev City Administration.

- In 2010 new samples of inverter power sources were put into production: VDI for manual arc welding; ADI for argon-arc welding and PSI for semi-automatic welding.

\section{1 - up to now}

- Serial production of classical power sources is going on: STSh transformers for 250, 315 and 400 A currents, VD-310N, VD-400 and VS-650SR rectifiers.

- Production of high power sources TShS-3000-1 and TShP-10000-1 for electroslag technologies was resumed.

- In 2012 the first export delivery of welding inverters to Equatorial Guinea was made.

- Since 2013 welding units have been exported to Georgia, Moldova and Azerbaijan.

- In 2014 a contract was completed with State Oil Company of Azerbaijan Republic (SOCAR) on separation of two pontoons from the block by the method of directed explosion at construction of off-shore stationary platform No.7 in Guneshli field in the Caspian Sea. New methods, technologies and equipment for deep-water and ground welding and cutting were developed.

- In 2014 a unique complex of equipment for narrow-gap welding of large turbine rotors was manufactured for OJSC «Turboatom».

- Starting from 2014 5-year guarantee for welding inverters of ADI and VDI series has been introduced for the first time in CIS.

- In 2014 the Plant as the leading national manufacturer of welding equipment started rendering support to the state in the ATO zone.

- In 2014 European certification CE of all the manufactured inverters was obtained.

- In June 2015 the first batch of new welding inverters VDI of EKO series for 160, 200 and 250 A currents was produced, which has become the sales leader. 
- In 2015 batch-production of ballast resistors RPB-304 for welding current regulation in multistation welding, as well as all-purpose welding rectifiers VDU-6303P and VDU-1202P began.

- In November, 2015 the car-building plant of CKD Kutna Hora a.s. Group of Companies, Czech Republic, was reequipped with the following Plant equipment: all-purpose rectifiers VDU-1202P, multistation rectifiers VDM-1202P, rectifiers VS-650SR, ballast resistors RBP-302, semi-automatic machines PS-351.2 and argon-arc inverters ADI-200S.

- In December 2015 the Plant started manufacturing completely digital welding inverters of VDI Professional series, as well as semi-automatic machines PSI-250S and PSI-250R with a new control panel and digital adjustment of parameters.

- In December, 2015 the Plant was awarded the Certificate of Appreciation of SC «Ukroboronprom» for fruitful cooperation and professional assistance in solving the problems of upgrading the combat and special equipment for detachments and units of the Armed Forces of Ukraine.

- In 2015 a batch of welding machines of tropical modification was produced for a shipyard in Myanmar: VS650SR rectifiers with BP-608 feed units, and VDI-200R inverters.

- In 2015 the foreign markets of welding units and electrodes were extended to Czech Republic, Uzbekistan, United Arab Emirates and Myanmar.

- At the beginning of 2016, our Plant supplied to a machine-building plant a batch of specialized equipment for electroslag welding of metal up to $450 \mathrm{~mm}$ thick: all-purpose rail welding machine A535 in a set with transformer TShS-1000-3 and self-propelled welding units ASh115 in a set with VDU-1202P rectifiers.

- Welding units are supplied to armor plants of SC «Ukroboronprom»: inverters of VDI series, semi-automatic machines of PS series, feed units BP, as well as welding electrodes.

- In February 2016, the first batch of VDI-mini units - the smallest size welding units in the world for rated powder of $3.5 \mathrm{kV} \cdot \mathrm{A}$ was produced.

- In April, 2016 the Plant started manufacturing welding electrodes by the classical formulation: ANO-21, ANO-36, ANO-4, UONI 13/45, UONI 13/55, MR-3, special electrodes T-590, TsCh-4, OZL-8 and TsL-11, as well as electrodes of Elite series by an improved formulation: Elite ANO-36, Elite MD6013, Elite ANO-21.

- In July 2016 the first batch of welding inverters of ADI, VDI and PSI series was supplied to Korea.

- In October 2016, a project was completed for SC «Ukroboronservis» on development of an automatic system of mortar coordination.

- In 2016 welding units and electrodes were exported to Belarus, Kazakhstan, Estonia, Poland and Bulgaria.

- Production of welding machines exceeded 50 thou units per year.

- Volume of electrode production is more than 600 tons per month.

- At the beginning of 2017, a shop for manufacturing cases for welding machines was put into production. It is fitted with high-tech equipment of TRUMPF model and a powder coating line.

- Starting from 2017, welding electrodes and machines have been supplied to Latvia, Lithuania, Rumania and Iran.

- In September 2017, the line of inverters of VDI Standard and VDI Professional, PSI Standard and PSI Professional series was complemented by units for higher current values of 315, 400 and $500 \mathrm{~A}$.

- In 2017 overhauling of all the office, production and storage premises was performed.

Geography of export supplies: Austria, Azerbaijan, Armenia, Belarus, Bulgaria, Hungary, Germany, Georgia, India, Iran, Kazakhstan, Canada, Korea, Latvia, Lithuania, Moldova, Myanmar, United Arab Emirates, Poland, Rumania, Slovakia, Turkey, Uzbekistan, Finland, Czech Republic, Equatorial Guinea, Estonia, Japan.

Objective of Pilot Plant of Welding Equipment of the E.O. Paton Electric Welding Institute remains unchanged - to become a leader in manufacturing welding equipment and consumables in Eastern Europe. 


\title{
MODERN FLUX-CORED WIRES FOR WELDING OF LOW-ALLOY STEELS OF INCREASED AND HIGH STRENGTH
}

\author{
V.N. SHLEPAKOV, A.S. KOTELCHUK and YU.A. GAVRILYUK \\ E.O. Paton Electric Welding Institute of the NAS of Ukraine \\ 11 Kazimir Malevich Str., 03150, Kiev, Ukraine. E-mail: office@paton.kiev.ua
}

\begin{abstract}
The paper studies the peculiarities of application of flux-cored wires for welding of metal structures of low-alloy steels of increased and high strength. The ways have been proposed for solving the problems existing in this field. The fluxcored wires developed in the recent years at the E.O. Paton Electric Welding Institute for these purposes were described. The directions of increase of quality and efficiency of flux-cored wire welding using modern equipment have been presented. 15 Ref., 2 Tables, 7 Figures.
\end{abstract}

Keywords : electric arc welding, flux-cored wire, low-alloy high-strength steels, heat input, wire melting efficiency, automation and control of welding process

In the world practice the most wide spread among the methods of mechanized or automatic electric arc fusion welding is gas-shielded welding with solid or flux-cored wire. Selection of the reasonable technology of welded structures production includes consideration of such factors as joint preparation for welding, qualification of production staff, determination of the leading welding process, equipment for its realizing and type of welding consumable meeting the requirements of international, national and branch standards. The assortment of welding consumables and equipment has been significantly renewed in the recent years that allows rising a level of welding technology from quality as well as economy point of view.

Application in production of the structural steels with increased service properties has expanded in the last twenty years. This predetermined the need in development of new generation welding consumables for welding of bearing structures with corresponding increase of strength and visco-plastic properties as well as improvement of technological processes of production and application of wires for gas-arc welding [1-4].

High-strength low-alloy steels with more than $550 \mathrm{MPa}$ yield limit are, as a rule, on microstructure referred to ferrite-bainite-martensite or bainite-martensite class with high sensitivity to welding overheating. Taking into account the peculiarities of fluxcored wire application, it is necessary to limit the heat input in product being welded. It can make from 1.0 to $3.0 \mathrm{~kJ} / \mathrm{mm}$ depending on thickness of metal being welded. Necessity of performance and temperature of joint preheating depends on structure rigidity, composition and class of steel strength, expected content of diffusion hydrogen in the weld metal. Following the need of stringent control of heat input in welding of high-strength steels, it is recommended to use solid wires of $0.8-1.2 \mathrm{~mm}$ diameter, flux-cored wires of 1.0-1.4 $\mathrm{mm}$ in combination with shielding gas of reduced oxidizing ability (a mixture based on argon $\left.\mathrm{Ar}+\mathrm{CO}_{2}\right)[5]$.

Welding of low-alloy steels of increased and high strength has been expanded through application of the flux-cored wires having high melting efficiency, technological suitability to automated processes with controlled heat input, providing low content of diffusion hydrogen in the weld metal to prevent cold crack formation. This required significant improvement of the technology of their production.

New generation flux-cored wires for gas-arc welding. During the last decade the E.O. Paton Electric Welding Institute together with State enterprise «Pilot plant of welding consumables of the E.O. Paton Electric Welding Institute» has carried out a complex of works on improvement of technology and quality of production of the flux-cored wires. It allowed significant improvement of quality and application characteristics of wires under production conditions. The improvements concerned all stages of technological production process. Among the main it is necessary to note introduction of a controlled calculation of com- 
position of a powder filler based on real composition of raw materials using special software, permanent control of charge humidity at all stages of the production, improvement of processes of forming and filling of a profile with powder and reducing the wire stock to a finished size using two stage drawing technology. The introduction of indicated procedures in the production technology allowed increasing accuracy of filling and uniformity of wire filler distribution along its whole length, raising the characteristic of wire feed along the feeders' channels of welding semi-automatic and automatic devices, providing reliability of wire contact with a nozzle tip and accuracy of wire feed in a fusion zone to place of welding.

Increase of strength (rigidity) of a wire shell due to deformation strengthening at a two-stage drawing process is neglected by using calcium-sodium stearates and pastes as a lubricant at a calibration stage (which allow getting fine current-conducting protective film on a wire surface).

Winding of the wire on framed spools or plastic bobbins of K300 and BS300 type wind by wind and packaging into polyethylene film or foil for prevention of wire core damping in accordance with the international standards $[6,7]$ were realized. The basic diameter of the flux-cored wires for welding of steels of increased and high strength is $1.2 \mathrm{~mm}$.

The small diameter flux-cored wires of new generation were developed for efficient application of powder core to increase the level of their welding-technological characteristics and process efficiency in automatic and semi-automatic welding. Presence of the powder core allows rising current density that is expressed in melting rate rise, change for spray-drop and spray electrode metal transfer, and allows providing high stability of weld technological quality.

The flux-cored wire with metal core of PP-AN61M grade for welding of steels of common and increased strength is produced in accordance with classification on DSTU ISO 17632 [8] standard. Welding is performed using $\mathrm{CO}_{2}$ shielding medium or mixture of argon with $\mathrm{CO}_{2}$.

The flux-cored wires designed for welding of structures of low-alloy high-strength steels, including heat-strengthened, using rutile and metal-core ones are classified on DSTU ISO 18276 standard [9]. They provide high indices of strength, ductility and impact toughness of the joints being welded applying gas mixture based on argon and $\mathrm{CO}_{2}$. The fields of application include shipbuilding structures, structures of offshore drilling platforms, structures of heavy and transport machine building manufactured of 4-60 mm thickness steels. High application efficiency is achieved using the power sources and feeders with automatic control and feedback. They allow optimizing parameters of a welding mode, static and dynamic characteristics of arcing. High uniformity of the welds, deep and uniform penetration, minimum losses of electrode metal in combination with high penetration efficiency indicate preferability to application of the wires of such type for high-speed and automatic welding.

PP-AN75 flux-cored wire with rutile core type differs by high operating characteristics of welding in different spatial positions. Application of a gas shield based on a mixture of argon with carbon dioxide (M21 on standard ISO 14175 [5]) provides spray transfer of the electrode metal. The wire is designed for wide application in welding of joints of low-alloy highstrength steels with ultimate strength to $590 \mathrm{MPa}$ at more than $4 \mathrm{~mm}$ thickness of welded metal. Uniform shape and smooth weld surface, minimum spattering, easy slag separability and high efficiency allow recommending the wire for welding of the wide range of metal structures of different designation.

PP-AN76 flux-cored wire with metallic core type is designed for semi-automatic welding of low-carbon low-alloy high-strength steels including heat-strengthened ones. High crack resistance and high indices of impact toughness at low temperatures are realized at that. Stable spray transfer of the electrode metal is typical for the wire. Separate slag spots of small thickness, which are easily removed, are formed on the weld surface. Weld surfaces do not require dressing in multilayer welding. The wire is recommended for welding of metal structures including operated under low temperatures, in shipbuilding as well as construction of drilling platforms.

Tables 1 and 2 show data on composition of the deposited metal and indices of mechanical properties of the weld metal and welded joint, respectively, made by flux-cored wires for welding of steels of increased and high strength. The flux-cored wires provide hydrogen content in the weld metal less than $5 \mathrm{ml} / 100 \mathrm{~g}$ according to ANSI/AWS 4.3 standard [10] in keeping with the storage and application rules.

Classification of the flux-cored wires on mechanical properties of the weld metal and welded joint is similar in all national standards. International standards ISO 17632 [8] and ISO 18276 [9] provide 
Table 1. Composition of metal deposited by flux-cored wires of different types*, wt.\%

\begin{tabular}{|c|c|c|c|c|c|c|}
\hline Grade and type of flux-cored wire & C & Mn & Si & Ni & Mo & Zr \\
\hline PP-AN61M type ISO 17632-A-T 50 2 1Ni M M 2 H5 & $0.05-0.08$ & $1.2-1.4$ & $0.3-0.5$ & $1.0-1.2$ & - & - \\
\hline PP-AN75 type ISO 18276-A-T 62 2 Mn2.5NiMo P M 2 H5 & $0.05-0.09$ & $1.4-1.6$ & $0.3-0.6$ & $2.4-2.7$ & $0.10-0.15$ & $0.007-0.010$ \\
\hline PP-AN76 type ISO 18276-B-T 76 4 T1 1 M A N4C1M2 H5 & $0.04-0.07$ & $1.7-1.9$ & $0.4-0.6$ & $2.2-2.6$ & $0.10-0.20$ & $0.005-0.007$ \\
\hline "S and P not more than 0.02 wt.\%.
\end{tabular}

Table 2. Mechanical properties of weld metal and welded joint produced using flux-cored wires of different types in a mixture of shielding gases based on ArM21

\begin{tabular}{|c|c|c|c|c|c|}
\hline Grade and type of flux-cored wire & \multirow{2}{*}{$\sigma_{\mathrm{y}, \mathrm{MPa}}$} & \multirow{2}{*}{$\sigma_{\mathrm{t}}, \mathrm{MPa}$} & \multirow{2}{*}{$\delta, \%$} & $\begin{array}{c}\text { Impact energy } K V \text {, J, at testing } \\
\text { temperature, }{ }^{\circ} \mathrm{C}\end{array}$ \\
\cline { 3 - 6 } & & & & -30 & -40 \\
\hline PP-AN61M type ISO 17632-A-T 50 2 1Ni M M 2 H5 & $500-520$ & $560-710$ & $22-26$ & $50-55^{*}$ & $52-60$ \\
\hline PP-AN75 type ISO 18276-A-T 62 3 Mn2.5NiMo P M 2 H5 & $590-620$ & $650-760$ & $21-24$ & - & $51-56$ \\
\hline PP-AN76 type ISO 18276-B-T 76 4 T1 1 M A N4C1M2 H5 & $680-700$ & $760-920$ & $18-20$ & $54-65$ & $48-55$ \\
\hline${ }^{*}$ In $\mathrm{CO}_{2}$ welding.
\end{tabular}

classification on the guaranteed values of yield limit and minimum temperature, at which value of impact energy on Charpy V-notch specimens is assured. The indices of strength and impact toughness are not rigidly related between each other. This allows classifying virtually any new developments on these indices. At that the mechanical properties in all standards are determined on the all weld metal specimens. Tables 1 and 2 give technical characteristics of the new fluxcored wires, classified in accordance with the requirements of the international standards.

The efficiency indices of solid wire melting are lower than efficiency of welding using flux-cored wires, in particular, with metal-core, that in practice

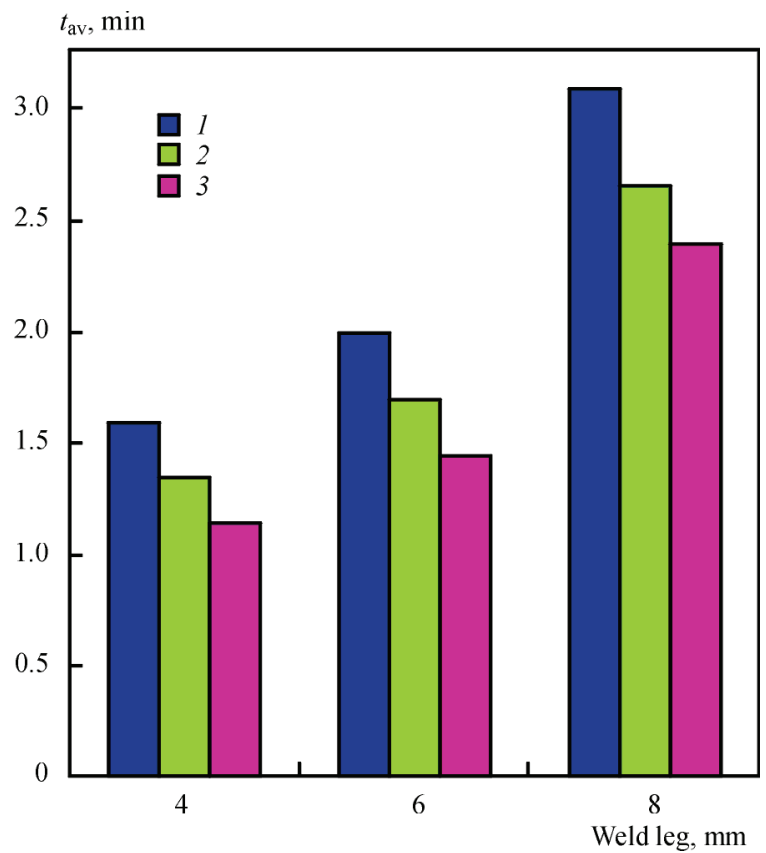

Figure 1. Average time of performance of $1 \mathrm{~m}$ of fillet welds with different leg using solid wire (1), flux-cored wire with rutile type core (2) and metal-cored wire (3) of $1.2 \mathrm{~mm}$ diameter on comparable welding modes $\left(U_{\mathrm{a}} \sim 28-30 \mathrm{~V} ; I_{\mathrm{w}} \sim 290-320 \mathrm{~A}\right)$ can be realized by increase of performance speed of set size welds.

Experimental comparison of the efficiency indices of performance speed of the fillet welds with the similar modes using solid wire and flux-cored wires of equal diameters show that application of flux-cored wires of rutile and metal-cored types of the new generation reduces the time for performance of the fillet welds of the same caliber $(4,6$ and $8 \mathrm{~mm})$ by $15-$ $30 \%$. With automatic process this advantage rises since the process of flux-cored wire welding at spay metal transfer is less sensitive to welding speed variation and provides stable shape of penetration and weld size, guaranteed soft start (Figure 1).

Directions for increase of quality and efficiency of flux-cored wire welding using modern equipment. Significant amount of modern available on the market welding current power sources are based on inverter scheme [11-13]. At that such power sources are inseparably connected to specific type of equipment for electrode wire feed. In the simple design

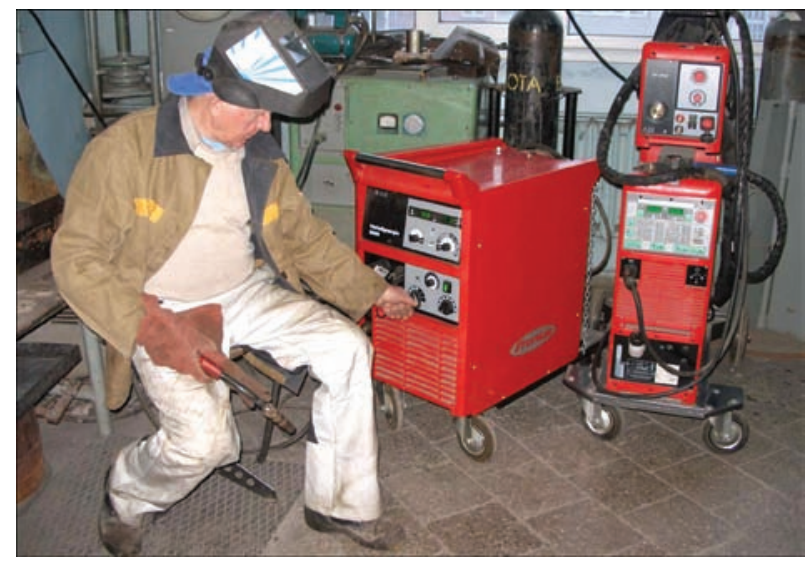

Figure 2. Application of inverter arc power sources with corresponding feeder for flux-cored wire welding 


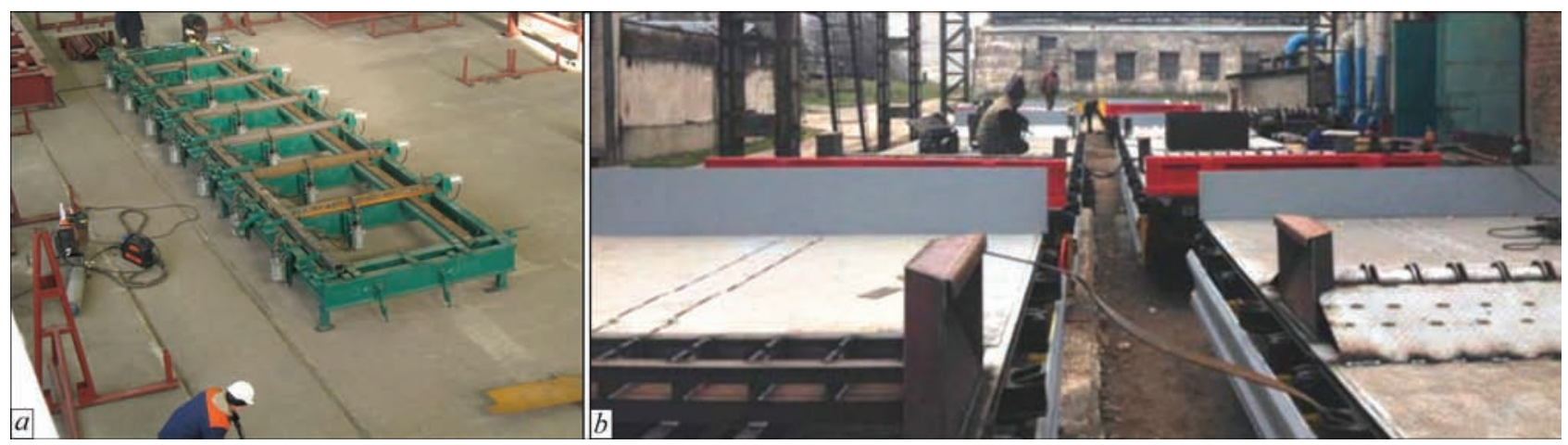

Figure 3. Typical objects of application of flux-cored wire welding: $a$ - assembly-welding of frame of side wall of freight cars («Yugpromtekhmontazh» LLC, Kherson) [15]; $b$ - welding of metal structures of platform for slabs, rails transporting ( «Verkhnedneprovsky machine-building plant» PJCS)

variant such a power source allows performing mechanized gas-shielded electrode welding of low-alloy steels of common and high strength.

The peculiarity of high-frequency inverters is high stability and quality of welding of different materials in a wide range of thickness with minimum metal spattering. Such equipment allows high-quality fluxcored wire welding with all core types.

The basis of a control system is interactive controller of the power source, combined with digital signal processor for acceleration of processing of the converted analogue electric signals of welding process in the digital data. These two blocks together perform all monitoring and regulation functions of welding process (adjustment of welding current and arc voltage on-line). Continuous measurement of the virtual values of welding parameters is carried out during welding and their any change provokes reaction in the control system. For example, control algorithms developed by «Fronius» Company provide support of the necessary set values in welding using wide range of the welding wires. This provides high repeatability of welding process and excellent welding characteristics.

The results of investigations of the indices of arcing stability based on statistical processing of data of the electric signals, analysis of shape of the curves of welding current and arc voltage probability distribution as well as the results of statistical processing of the data of arc welding electric signals showed significant differences of electrode metal mass transfer using the inverter type arc power sources in comparison with the traditional ones. The welding process using inverter power source virtually in all cases is characterized by higher stability indices.

Control of the electrode metal transfer directed on reduction of droplet size is realized in application of the inverter power source. At that electrode metal transfer takes place without rapid changes and variations of process parameters at total power inputs reduction.

To the largest extent it is observed in welding using the metal-cored wire. Software for control of the dynamic characteristics of arc welding process depending on wire type is used in control system of the inverter power source. Regulation of welding parameters is possible only within the limits being determined by the program for each wire type (Figure 2).

Some companies promote technologies for control of electrode metal melting. They program necessary reaction of power source and feeder to controlled changes of welding current and arc voltage that provides a set modified short-circuit electrode metal transfer in mechanized and automated gas-shielded welding. Application of such a process of controlled melting of the electrode wire allows 5-20\% decrease of heat input minimize spattering in comparison with the process having standard short-circuit electrode metal transfer. Mentioned phenomena are reached due to keeping the optimum characteristics of arc and accurate control of welding current during all welding process phases [14].

Application of modern equipment for semi-automatic welding with objective control of the main process indices is, as a rule, the major step to increase the quality stability indices of the welded structures (Figure 3). During semi-automatic welding this reduces effect of a subjective factor, related with performer qualification, but does not cancel the task of staff safety. The experience of automation relating to the welding technologies indicate the need of optimization and increase of quality of the whole complex of technologies of welded structure production including preparation and assembly of the units and structures for welding, determination of the leading welding process, selection of equipment and consumables as 
well as training of qualified personnel on control and methods of testing of quality indices in accordance with acting international standards.

Orientation to application of the process of semi-automatic and automatic gas-shielded flux-cored wire welding is one of the priority directions in the world's practice, in particular, in shipbuilding, power and heavy transport machine building, construction of drilling platforms, pipeline and other objects.

1. Irving, B. (1995) The challenge of welding heat-treatable alloy steels. Welding J., 74(2), 43-48.

2. Keehan, E., Karlsson, L., Andren, H.O., Bhadeshia, H.K.D.H. (2006) New development with C-Mn-Ni high-strength steel weld metals. Pt A. Microstructure. Ibid., 85(9), 200-210.

3. Adonyi, Y. (2002) Welding process effects in hydrogen industrial cracking susceptibility of high-performance steels. Ibid., 61-65.

4. What is the difference between heat input and arc energy? http://www.twi-global.com/technical-knowledge/faqs/material-faqs/faq-what-is-the-difference-between-heat-input-andarc-energy/

5. DSTU EN ISO 14175:2014: Welding consumables. Shielding gases for arc welding and cutting [in Ukrainian].
6. DSTU EN ISO 544: 2015: Welding consumables. Technical delivery conditions for filler materials. Type of product, dimensions, tolerances and markings [in Ukrainian].

7. DSTU ISO 14344:2015: Welding and allied processes. Fluxes and shielding gases for arc welding. Guidelines for delivery of consumables [in Ukrainian].

8. DSTU EN ISO 17632:2015: Welding consumables. Tubular cored electrodes for gas shielded and no-gas shielded metal arc welding of non-alloy and fine grain steels. Classification [in Ukrainian].

9. DSTU EN ISO 18276:2015: Welding consumables. Tubular cored electrodes for gas-shielded metal arc welding of high strength steels. Classification [in Ukrainian].

10. ANSI/AWS A4.3-93 (R2006): An American National Standard. Standard methods for determination of the diffusible hydrogen content of martensitic, bainitic, and ferritic steel weld metal produced by arc welding.

11. Rama, R.S. (2006) Principles of power electronics. Moscow, Tekhnosfera [in Russian].

12. Maleshin, V.I. (2005) Transistor conversion technique. Moscow, Tekhnosfera [in Russian].

13. Mironov, S. (2003) Inverter power sources for arc welding. Svarochn. Proizvodstvo, 4, 41-43.

14. (2007) Trans sinergic MIG/MAG power source 4000/5000/2700. Operating instructions. List of spare parts. Wels, Fronius Intern. GmbH.

15. Designed and put into operation assembly-welding stand of side wall frameworks of freight cars. http://uptm.com.ua/index

Received 17.10.2017 


\title{
RESTORATION REPAIR OF ELEMENTS AND UNITS OF GAS TURBINE ENGINES
}

\author{
V.M. NESTERENKOV ${ }^{1}$, Yu.V. ORSA ${ }^{1}$, K.S. KHRIPKO ${ }^{1}$ and Yu.V. GUSEV ${ }^{2}$ \\ ${ }^{1}$ E.O. Paton Electric Welding Institute of the NAS of Ukraine \\ 11 Kazimir Malevich Str., 03150, Kiev, Ukraine. E-mail: office@paton.kiev.ua \\ ${ }^{2}$ SE Lutsk Repair Plant «LRZ» Motor» \\ 3 Kivertsovskaya Str., 43006, Lutsk, Volyn region, Ukraine. E-mail: info@motor-lutsk.com.ua
}

\begin{abstract}
Restoration of gas turbine engines is very urgent and at the same time difficult task, the solution of which provides significant cost savings. The work reflects the results of developing an efficient and reliable method for repairing gas turbine engine blades using electron beam welding. The technology of repair of three types of blade airfoil defects using welded-in pieces was mastered. It is shown that electron beam welding is ideal for solution of the problem of replacement individual elements of permanently assembled units of gas turbine engines. 4 Ref., 14 Figures.
\end{abstract}

Keywords : electron beam welding, gas turbine engines, restoration repair, replacement of units, technological methods, spot and extended defects, welded-in pieces

Appropriateness of restoration repair of expensive parts of the gas turbine engines (GTE) does not raise doubts [1].

For example, the main reason of early replacement of the aircraft GTE in their operation is damage of titanium blades of the fan and compressor as a result of foreign objects coming in the engine. Usually engine operation is allowed at insignificant defects of leading and trailing edges of the blade airfoil without tears. Part of similar (i.e. without tears), but somewhat larger defects can be repaired directly on the engine. Thus, for example, material rising near the nicks is dressed and bends of the blades are eliminated by flattening. Then, the repaired places are polished. Sometimes, removal of the nicks due to smooth rounding of the edge of up to $10-12 \mathrm{~mm}$ radius is allowed. In contrast, correction of local damages of the blades, exceeding allowable norms, requires dismantling of the damaged blade and repair under production conditions. Usually such a repair lies in mechanical removal of the defective zone till the boundaries of

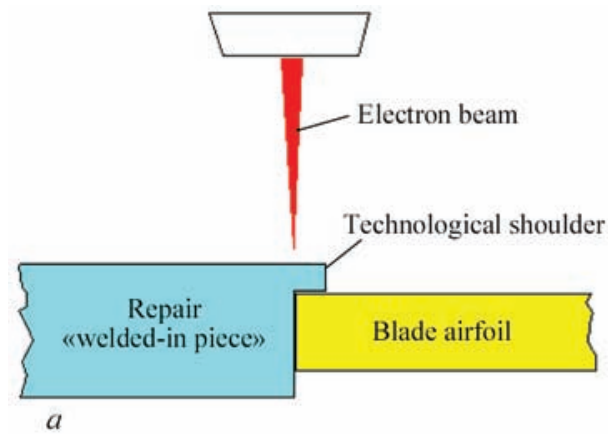

knowingly undamaged blade metal with further connection (welding, brazing) of a welded-in piece of corresponding size instead of it and with technological tolerance on thickness for acquiring a necessary profile of blade repair section using further mechanical treatment [2-4].

Generally, the solution on repair permissibility for each specific defect of the blade is made by the certified repair organization, following the next aspects, i.e. belonging of the blade to low pressure compressor (LPC) or high pressure compressor (HPC), blade type (namely, blade or vane), number of compressor stage, whether it is leading or trailing edge of the airfoil, and at last, evaluating directly the defects sizes, their quantity and location relatively to the places of maximum service stresses (including resonance ones).

Our task lied only in development of an efficient and reliable method, which fundamentally will allow such a repair using electron beam welding (EBW) under domestic production conditions. The technological methods were mastered on the spot and extended de-

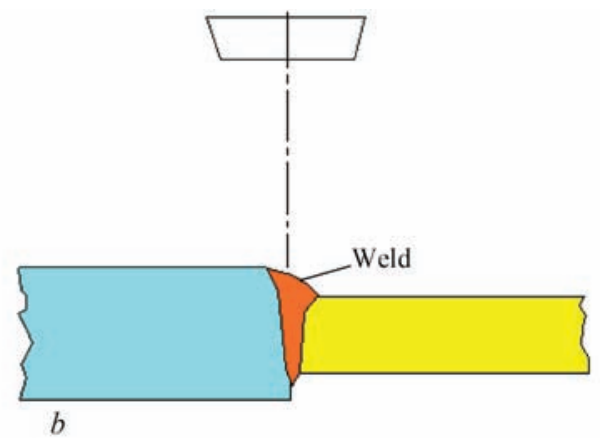

Figure 1. Scheme of repair EBW-joint of «welded-in piece» and blade airfoil: $a$ — before welding; $b$ - after 

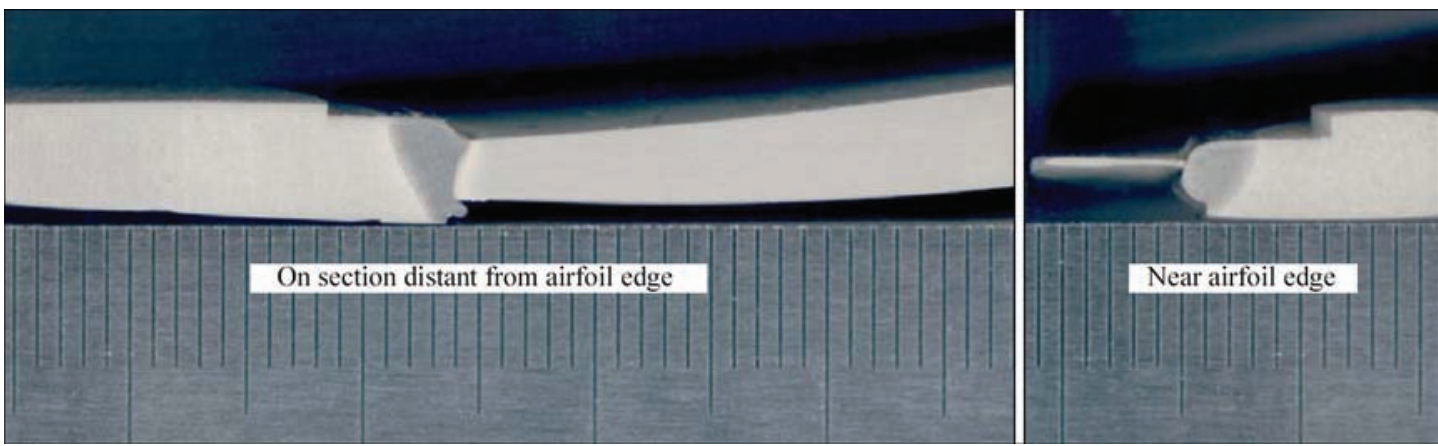

Figure 2. Macrosections of repair EBW-joint of «welded-in piece» and blade airfoil
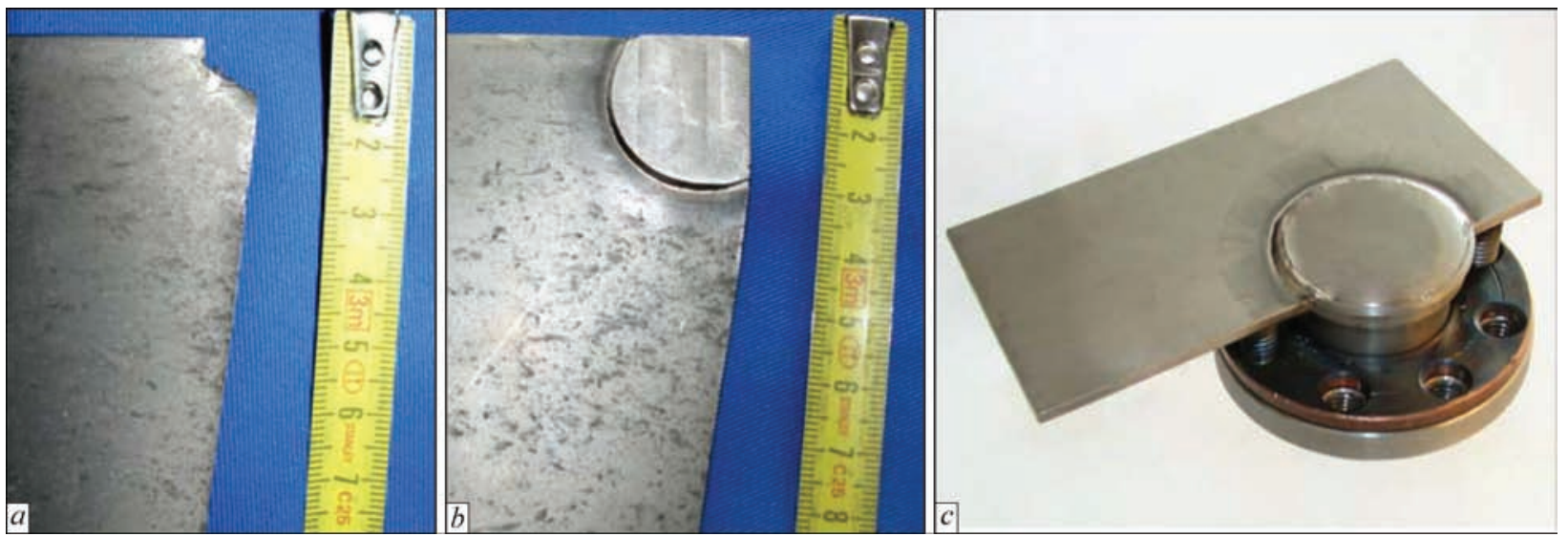

Figure 3. Repair of spot defects of angle of blade airfoil using cylinder repair «welded-in pieces»: $a$ — damaged angle of blade before repair; $b$ - repaired angle (ends of «welded-in piece» after EBW); $c$ - assembly-welding fixture for EBW of cylinder «welded-in pieces» (blade simulator)

fects of airfoil leading edge of different size titanium blades, namely fan blades and blades of GTE LPC.

The following scheme of repair «welded-in piece» and blade airfoil welded joints was developed. It in principle does not depend on the fact whether it is spot or extended defects (Figure 1).

In all cases the joint is carried out by a single-pass EBW, and smooth (without undercuts) transfer from «welded-in piece» surface to base metal is provided by moderate concentration of the electron beam as well as sufficient quantity of additional metal due to applied structure of welded joint with «overhanging shoulder». Moreover, such a smooth transfer can be reached in the areas with sufficiently larger airfoil thickness as well as in the thinnest places adjacent to the edge (Figure 2).

The repair technology was mastered for three types of airfoil blade defects, i.e. spot damage of the blade angle, spot damage of the edge of blade airfoil main part as well as extended local defects of the edge starting from blade angle.

Repair of both types of spot defects is carried out using cylinder «welded-in pieces» (Figures 3 and 4). There are several dimension types of diameters depending on size of airfoil edge defect.
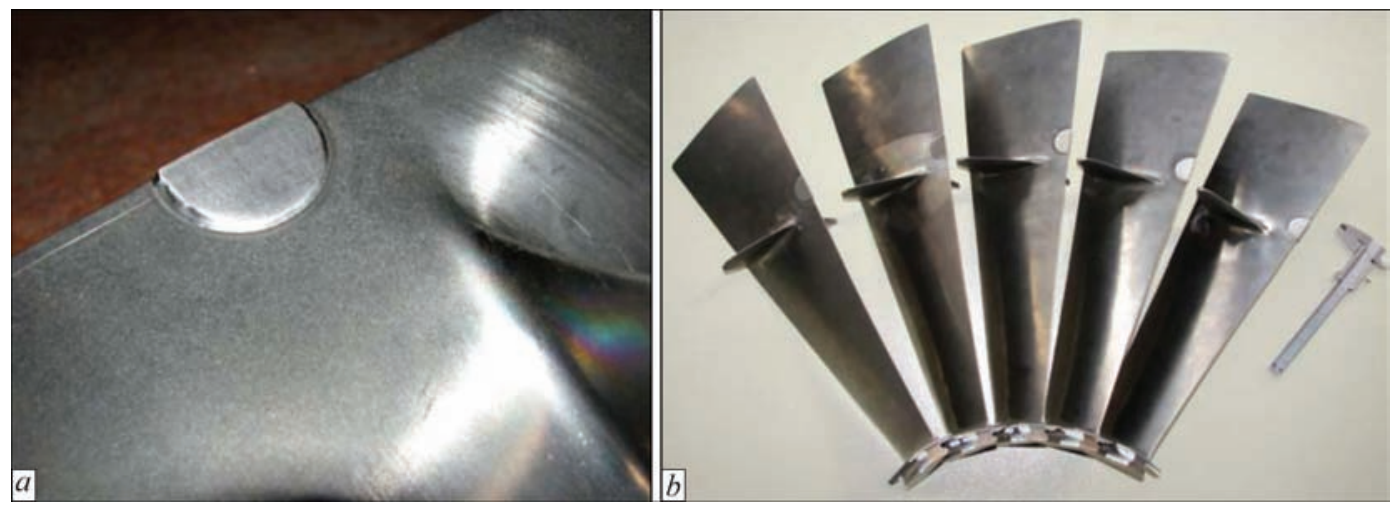

Figure 4. Repair of spot defects of main part of blade airfoil edge using cylinder repair «welded-in pieces»: $a$ - cylinder repair «welded-in piece» at airfoil edge (its edge was cut out at initial mechanical treatment after EBW); $b$ - pilot batch of GTE LPC blades with cylinder «welded-in pieces» on airfoil blade (before final mechanical treatment) 

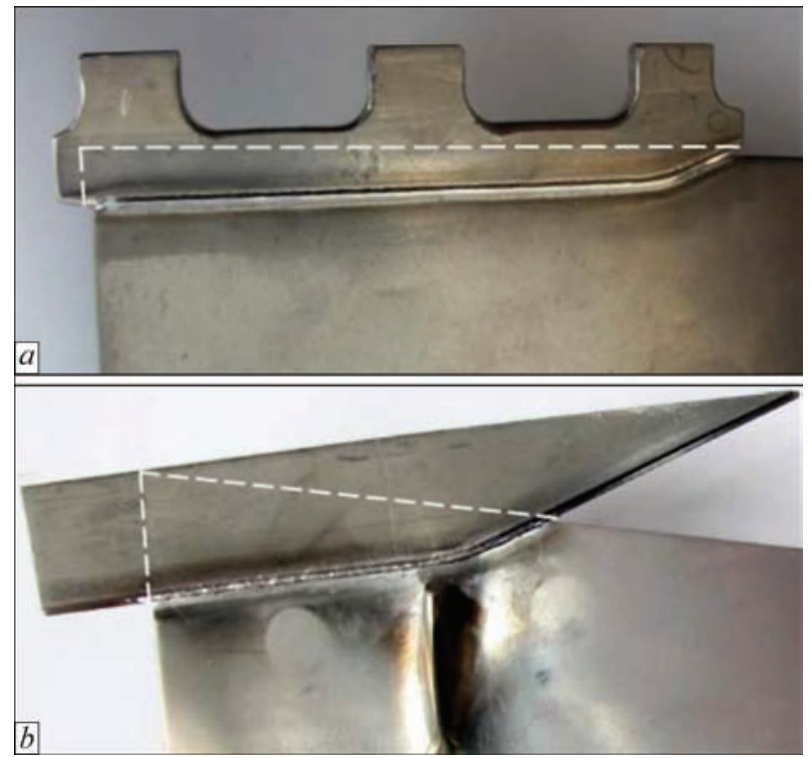

Figure 5. Repair of extended defects of blade airfoil edge: reconstruction of narrow zone adjacent to airfoil edge $(a)$; reconstruction of wider zone with very damaged airfoil angle $(b)$

Such a structure is efficient by the fact that matching of diameters of «window» cut out in the blade and «welded-in piece» itself provides fixing and tight contact of butted parts in radial direction. Therefore, sufficiently simple assembly-welding device (Figure $3, c$ ) should only provide pressing of the edge of the cut out «window» to mentioned above «overhanging shoulder» as well as holding the whole assembly in space during performance of electron beam pass along the arc of corresponding circumference.

At the beginning the works were carried on the samples simulating real parts. Then the results were successfully tested on the pilot batches of defective blades, provided by SE «Ivchenko-Progress» (Figure $4, b$ ).

The corresponding extended «welded-in pieces» are used for the extended defects of different areas of the blade airfoil edge. Their form can be changed depending on width and shape of the damaged zone of blade airfoil edge. In particular, it can be a narrow band replacing only damaged part of the airfoil adge (Figure 5,a) as well as «welded-in piece», width of which is very widened to the corner for the case of significant damage of not only the edge, but the angle as well (Figure 5, $b$ ).

Respectively, uniform pressing of such «welded-in pieces» along the whole length of curved joint with the airfoil requires other more complex assembly-welding fixture (Figure 6).

The developed repair technology was tested on the edges of blade airfoil of different sections and, respectively, dimension types in repair of the defects of various size and shape (Figure 7).

In addition to repair of the blade local damages, it is also important task to replace separate elements

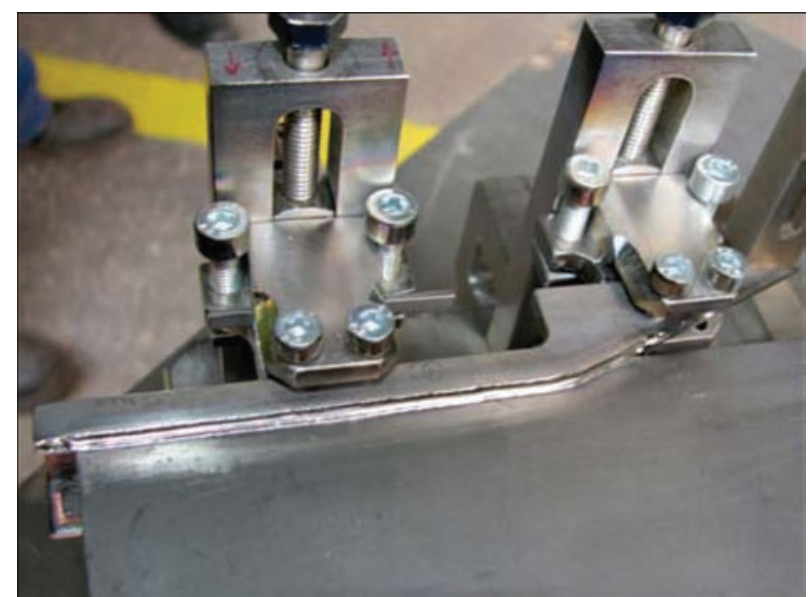

Figure 6. EBW joint of blade airfoil with extended repair «welded-in piece» in assembly-welding fixture

of permanently assembled units of the gas-turbine engine. In particular, such a task was set by Lutsk Repair Plant «Motor».

Guide cases of 3-8 stator stages of high-pressure compressor in gas-turbine engine consist of semirings with a set of brazed in them cantilever blades (Figure 8). The blades of 3-6 stages are made of alloy EP-866 (15Kh16K5N2MFAB-sh), and blades of 7, 8 stages are of alloy EP-718-ID (KhN45MVTYuBR-ID); working temperature of the units makes $300-500{ }^{\circ} \mathrm{C}$.

In operation of such engines there are also the cases of appearance of nicks and cracks on the blades as well as their tear out due to local lack of their brazing with the semi-ring wall.

Replacement of the defective blades is allowed following «Engine overhaul manual». At that the defective blade is removed by milling from semi-ring till its wall, including the brazing filler material holding the blade, and this place is filled with an undamaged donor-blade (Figure 9). In other words a completely cleaned section is prepared in the semi-ring for instal-

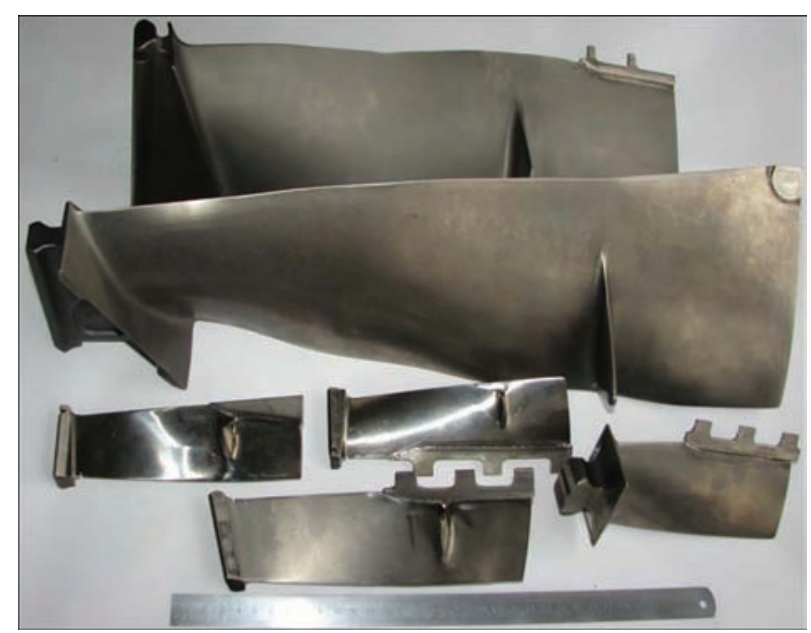

Figure 7. Examples of realization of developed repair technology for different dimension types of the blades (large - fan sections, small - LPC) as well as shapes and extension of airfoil edge defects 


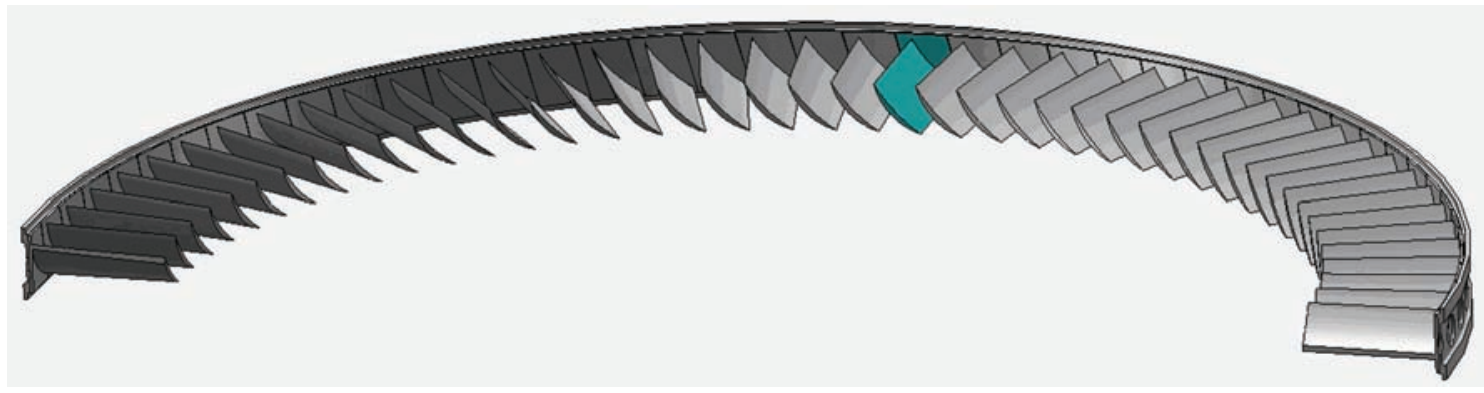

Figure 8. Scheme of semi-ring of stator guide case with set of brazed-in cantilever blades

lation of the donor-blade. It is obviously impossible to repeat initial brazing process without effecting adjacent still suitable blades. Therefore, a fixing method is necessary having local and concentrated temperature effect on the whole assembly unit. Previous technology for donor-blade fixing assumed application of argon-arc welding with the next dressing of weld reinforcement in order to reconstruct the geometry of end of the guide case semi-ring. The disadvantages of such a technology were significant distortion of product shape as well as small penetration depth and, as a result, insufficient area of joint zone, remaining after

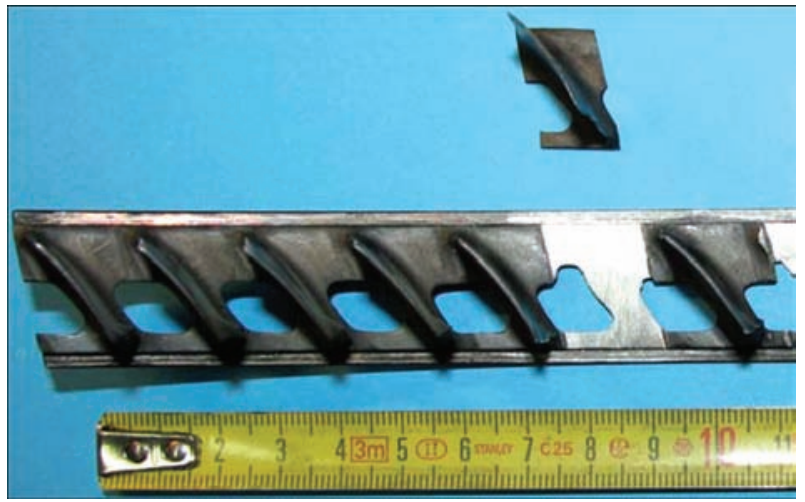

Figure 9. Semi-ring with prepared area for cantilever donor-blade installation

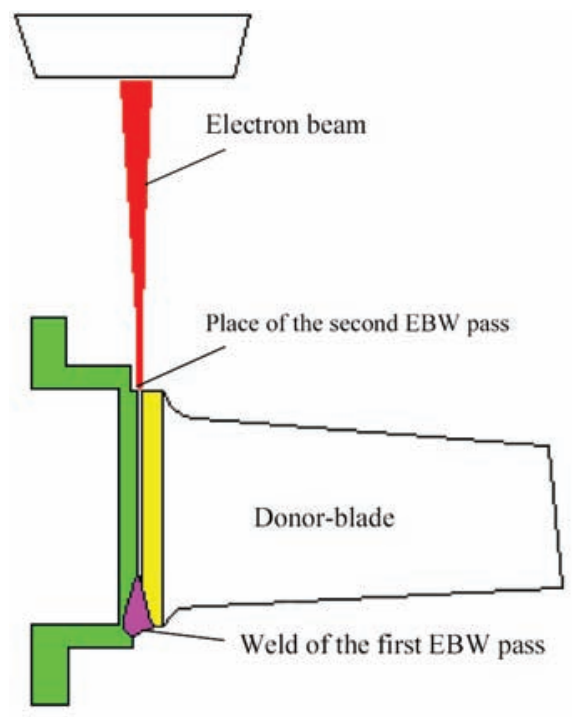

Figure 10. Scheme of double-side EBW of donor-blade with wall of guide case semi-ring weld reinforcement treatment and, thus, high probability of tear of the replaced blade during engine operation.

EBW method is ideal in this case allowing receiving the reliable welded joint of sufficient depth in comparison with small heat input in the product being welded.

The next scheme of welded joint of donor-blade and wall of semi-ring guide case was developed (Figure 10). Joining of the blade with wall is carried out using double-side EBW with intermediate turning of the product by $180^{\circ}$. Structural strength of two similar welds is enough for reliable fixing of the blade, which is not inferior to brazed ones.

Taking into account that this is a stator (i.e. immovable) part of the engine, it is not necessary to use extremely high requirements to geometry accuracy of donor-blade setting. Therefore, it is no need in very complex assembly-welding fixture that is usually the most expensive part when using EBW. Developed laboratory fixture (Figure 11) provided sufficiently accurate regulation of spatial orientation of the donor-blade and its reliable fixing in further welding. Later on the Customer got the design documentation for commercial variant of such a fixture for repair of the semi-rings of guide case installed on EBW machine of KL-188 type.

The main process problem, related, in particular, with the peculiarities of EBW method, was possible gaps in the joint between the semi-ring wall and do-

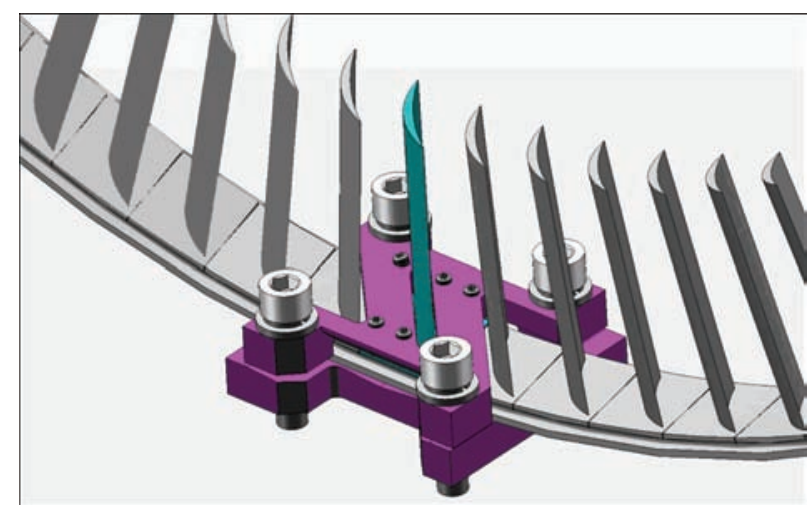

Figure 11. Model of assembly-welding fixture for EBW of cantilever donor-blade with guide case semi-ring 

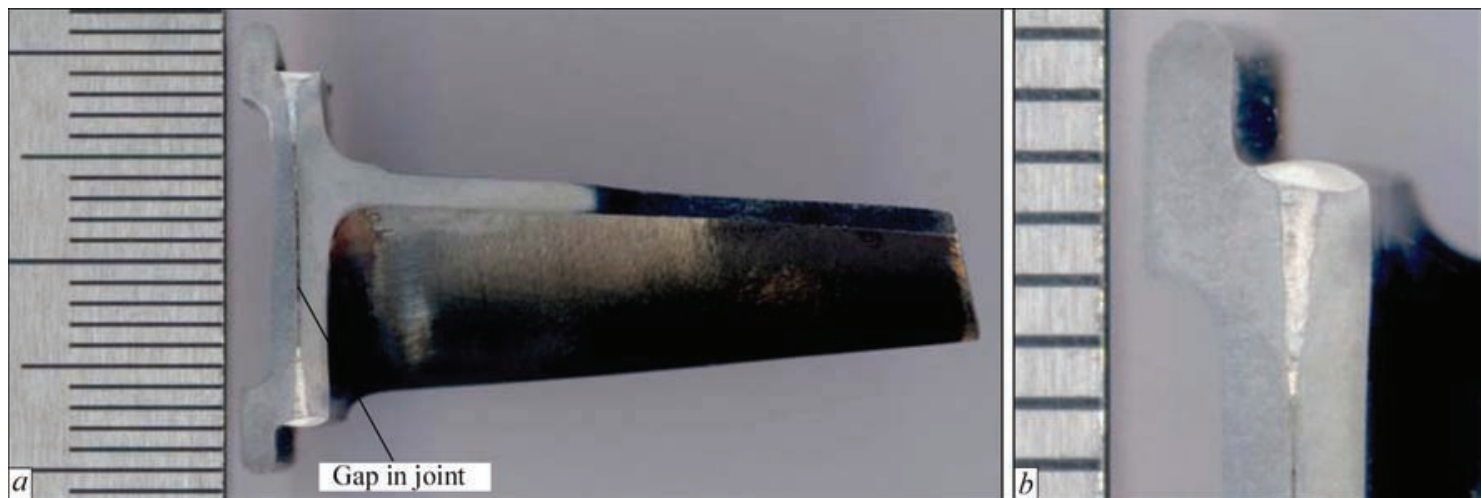

Figure 12. Macrosection of cross section of EB-joint of blade with guide case semi-ring received at up to $0.1 \mathrm{~mm}$ gap in joint (a) and section area containing the weld itself $(b)$

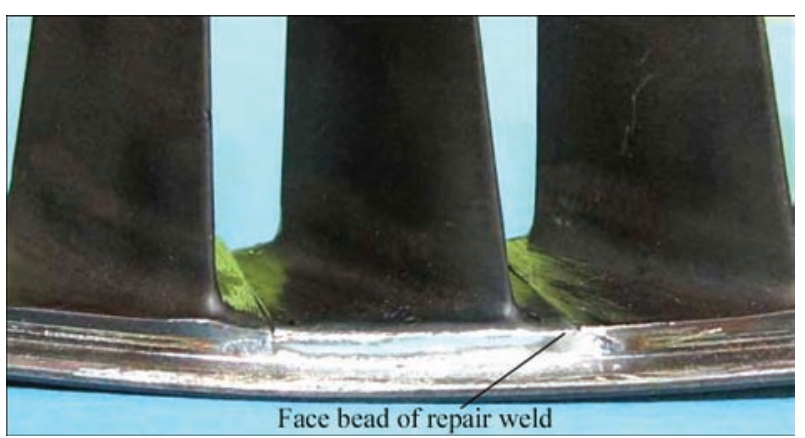

Figure 13. View of repair joint from end of guide case semi-ring nor-blade base. It is a result of difficulty of local mechanical removal of the damaged blade and formation of the area for the donor-blade. Such gaps are very critical, since thickness of the wall, to which the blade is welded, makes only $0.5 \mathrm{~mm}$ in some places.

The results of the experiments, carried out on the sample-simulators, provided the optimum compromise between the power parameters of the electron beam and possibility to form sufficiently deep weld in a thin-wall joint at gap presence in the butt. At that, pulsed EBW mode was used for improvement of weld formation and reduction of total heat input. This allowed getting quality joining of the parts at local gaps in the joint up to $0.1 \mathrm{~mm}$. Then, selected EBW modes were corrected on real joints of the blades with semiring of the guide case (Figures 12 and 13).

The technology has passed successful test in repair of a batch of real guide case semi-rings of differ-

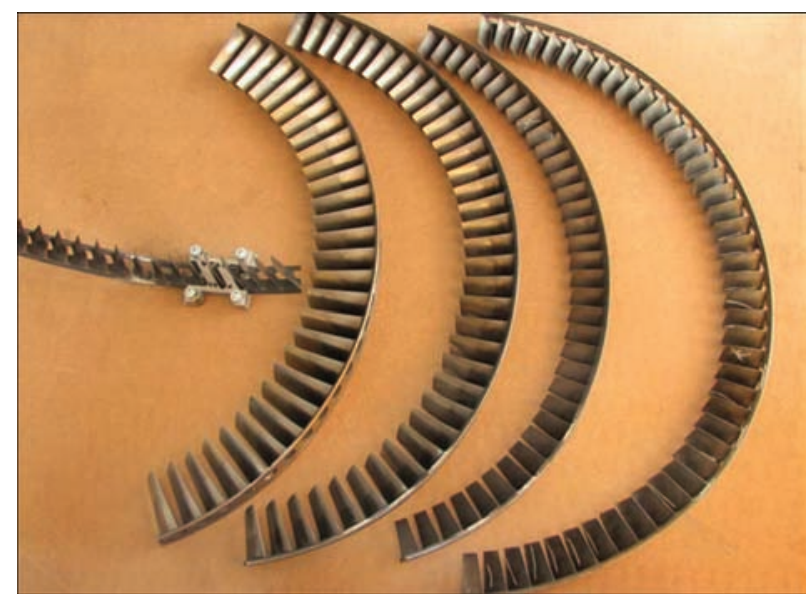

Figure 14. Repaired guide case semi-rings of different stages of LPC stator

ent stages in HPC stator (Figure 14) under laboratory conditions at PWI and later at Lutsk Repair Plant «Motor».

1. Beziyazychny, V.F., Strizhov, A.N. (2010) Increase in efficiency of repair of gas turbine engines on the basis of its localization: Refer. Book. Ingenerny J. s Prilozheniem, 8, 52-56 [in Russian].

2. Eliseev, Yu.S., Krymov, V.V., Malinovsky, K.A. et al. (2002) Technology of service, diagnostics and repair of gas turbine engines. Moscow, Vysshaya Shkola [in Russian].

3. Krymov, V.V., Eliseev, Yu.S., Zudin, K.I. (2002) Production of blades of gas turbine engines. Moscow, Mashinostroenie [in Russian].

4. Moshkin, Yu.B., Eliseev, Yu.S., Poklad, V.A. et al. (2002) Method of restoration of blades of turbomachines. Pat. RF 2185945, Int. Cl. 8 B 23P6/00 [in Russian].

Received 06.10.2017 


\title{
SELECTION OF TECHNOLOGY FOR REPAIR WELDING OF PARTS OF TURBINE UNITS
}

\author{
A.K. TSARYUK ${ }^{1}$, V.P. ELAGIN 1 , G.A. ROZUMENKO ${ }^{2}$, A.I. PASECHNIK ${ }^{3}$ and V.A. PERETYATKO ${ }^{2}$ \\ ${ }^{1}$ E.O. Paton Electric Welding Institute of the NAS of Ukraine \\ 11 Kazimir Malevich Str., 03150, Kiev, Ukraine. E-mail: office@paton.kiev.ua \\ ${ }^{2}$ Zmiyevskaya heat power plant \\ Slobozhanskoye vil., 63460, Zmiyev district, Kharkov region, Ukraine. E-mail: csto_zm.tes@der.com.ua \\ ${ }^{3}$ OJSC «Energoinvest» \\ 19 Geroev truda Str., 84500, Bakhmut, Ukraine. E-mail: a.pasechnik@der.com.ua \\ ${ }^{4} \mathrm{PJSC}$ «Tsentrenergo» \\ 120/4e Kazatskaya Str., 03680, Kiev, Ukraine. E-mail: peretyatkovladimir@ukr.net

\begin{abstract}
The peculiarities of disassembly-free repair of steel grade 15Kh1M1FL body of the control valve of the medium pressure cylinder of the turbine PT-200-130 of the heat power plant, in which a crack was formed after a long-term service, are given. The repair without disassembly of the valve is possible due to the use of technology of repair arc welding by pearlite electrodes with preheating and thermal recovery. 12 Ref, 1 Table, 7 Figures.
\end{abstract}

Keywords : crack, case, steel 15Kh1M1FL, repair welding, thermal metal recovery

During long-term operation of power equipment under the conditions of high-temperature heating and stressed state, the degradation of structure, decrease in properties and crack resistance of metal occur [1]. The cast case parts of turbines are the most vulnerable to this phenomenon, especially such as bodies of high- and medium-pressure cylinders, stop and control valves, whose metal has a significant heterogeneity of control properties, cast defects and increased contamination of metal with non-metallic inclusions. The formation and propagation of cracks are caused both by thermomechanical loads, as well as additional combined action of processes of corrosion fatigue and hydrogen embrittlement of steel [2].

The main method to eliminate defects in the case parts of power equipment is the manual arc welding using pearlite electrodes with local preheating and postweld high-temperature tempering. The purpose of heat treatment is the increase in reliability of welded joint due to bringing the metal structure to equilibrium state, reducing the level of welding stresses and diffusion hydrogen. The local heat treatment of largesized case parts is characterized by a non-uniform heating, appearance of additional temperature stresses, deterioration of structure and properties of welded joint. It is quite possible to prevent that in a certain degree having applied the high-tech thermal equipment, which allows performing all the operations of heating and cooling completely in automatic mode. However, the difficulty in selecting the optimal parameters of local heat treatment mode, especially of large-sized equipment having a different wall thickness, significantly complicates its performance [3]. In addition, the use of heat treatment turns to be impossible, for example, during repair without disassembly of parts when a high-temperature heating can lead to deformation and damage of the power plant entire unit.

For repair of cast case parts of steam turbines and fitting valves, the technologies for rewelding defects without heat treatment were also developed.

One of such technologies is welding by austenitic high-nickel electrodes [4]. It allows preventing the formation of cold cracks in welded joints of hardened steels without preheating and postweld heat treatment. This predetermined its high efficiency during elimination of defects in the parts of power equipment of heat-resistant chromium-molybdenum and chromium-molybdenum-vanadium steels, including also during disassembly-free repair. The disadvantage of such welding technology is the formation and subsequent development of chemical and structural heterogeneity in the fusion zone of austenitic weld metal with pearlite steel, caused by diffusion of carbon. An increase in the nickel content in the austenitic weld is the main method to reduce structural heterogeneity in this zone, however it does not completely eliminate it [5]. This leads to delamination of austenitic metal with the chemical composition based on iron after 4-8 years of service, and with the chemical composition on the base of nickel — after 15-20 years of service. During repair of parts, whose metal worked 
out more than 150 thou h, the reliability of their service with austenitic high-nickel deposition can be reduced to 3-4 years [3]. The technology of repair welding using austenitic electrodes is successfully used at the present time $[3,4]$. However, according to the requirements of modern standard documents, the admissible operation temperature of dissimilar joints is limited to $480^{\circ} \mathrm{C}$ [6].

The relatively new technologies of welding by pearlite electrodes applying technological procedures for control of thermodeformational welding cycle offered an alternative to the technology of rewelding defects by austenitic electrodes without heat treatment. One of them is transverse multilayer hill welding technology. The high resistance of metal against crack formation is achieved not only without heat treatment, but also without preheating. The effect is achieved due to an efficient use of welding heating and reducing the rate of metal cooling to prevent the formation of brittle hardening structures. This method is widely used in welding of thick-sheet metal and being improved at present as-applied to welding during elimination of casting defects in the power equipment of heat-resistant steels $[7,8]$. The disadvantage of this method is, obviously, an increase in metal overheating and grain growth in the near-weld zone. This is particularly undesirable for metal with a degraded structure. The possibility of applying this method for parts with such a metal requires additional investigations.

The technology of welding by pearlite electrodes with preheating and low-temperature tempering (recovery) $[3,4,8,9]$ has found a wide application for repair welding of castings of power equipment. The principle of the technological operation of tempering consists in the fact that after the end of welding the preheating temperature of welded joint is maintained for some time. The recovery belongs to recrystallization process, which is accompanied by removal of lattice distortions, ordering of atomic structure and increase in the ductility of metal. The positive influence of recovery on increase in crack resistance of welded joints is explained also by decrease in diffusion hydrogen content in the deposited metal $[9,10]$. The obligatory component of this technology is the preliminary application of lining, consisting of two layers of deposited metal, on the surface of area of removed metal. Their surfacing is performed at a minimal input energy by narrow annealing beads [6] which are deposited in a certain sequence. Such a technological method of surfacing allows efficiently reducing the hardness and increase in the ductility of heat-affected zone (HAZ) metal due to tempering of hardening structures without a significant grain growth in the near-weld zone [11]. In addition, at the same time, the level of welding stresses is reduced by $21-32 \%$ [12]. This is es- pecially important for metal which worked out its life, has an unfavourable structure and an increased tendency to crack formation. The further decrease in the level of welding stresses occurs during high-temperature operation [9]. Depending on the level and type of alloying of base metal and wall thickness, the recovery temperature is relatively low $\left(120-300{ }^{\circ} \mathrm{C}\right)$ as compared to the temperature of high-temperature tempering $\left(560-750{ }^{\circ} \mathrm{C}\right)$. In this regard, the danger of possible distortion of complex-shaped parts, the formation of cracks and scale, as well as undesirable structural transformations is eliminated. This makes it possible to use such technology for disassembly-free repair. The crack resistance of welded joints is determined by sizes of the defect, by the technique and parameters of the surfacing mode, which are the features of the welding technology.

The aim of this work was the selection of welding technology in disassembly-free repair of cast body of control valve of the medium pressure cylinder (MPC) of a $130 \mathrm{MW}$ power steam turbine (Figure 1) made of steel 15Kh1M1FL.

The valve body represents a large-sized casting of a complex configuration (Figure 2), which is welded-on to the case of MPC (Figure 3). The valve worked out about 300 thou $\mathrm{h}$ at the temperature of $545{ }^{\circ} \mathrm{C}$ and at the vapor pressure of 3.0 MPa. The damage in the form of a small (30-40 mm) crack in the fusion zone of austenitic deposit on its outer surface was detected during preparation of the turbine for major repairs. The deposit was located on the area of variable cross-section, in which the wall thickness varied from 60 to 140 $\mathrm{mm}$. This deposit worked out without remarks about 200 thou hours. It was made by high-nickel electrodes TsT-28 (type 08Kh14N65M15V4G2) during rewelding of removed metal area of $420 \times 155 \mathrm{~mm}$ section and $45 \mathrm{~mm}$ depth, formed during removal of the delaminated metal deposited by austenitic electrodes of

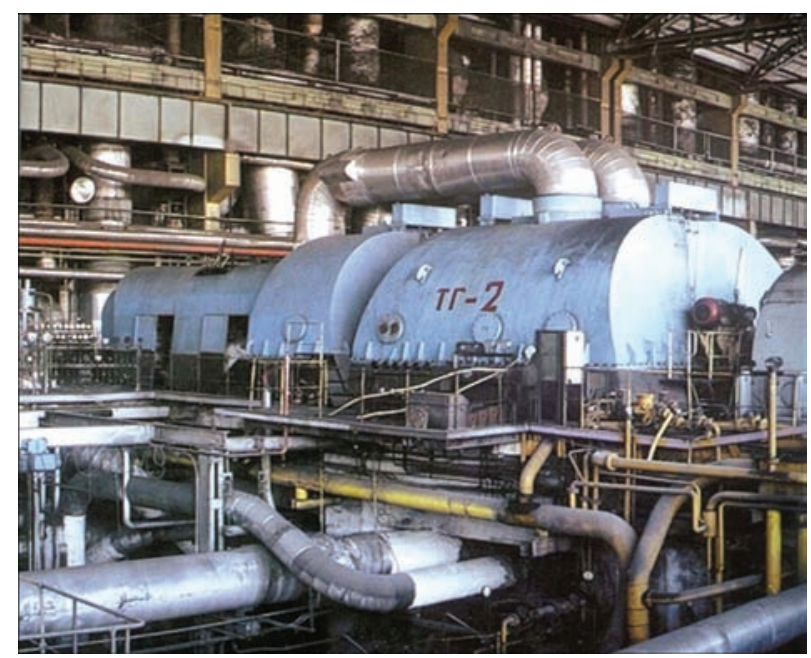

Figure 1. General appearance of turbine PT-200-130 


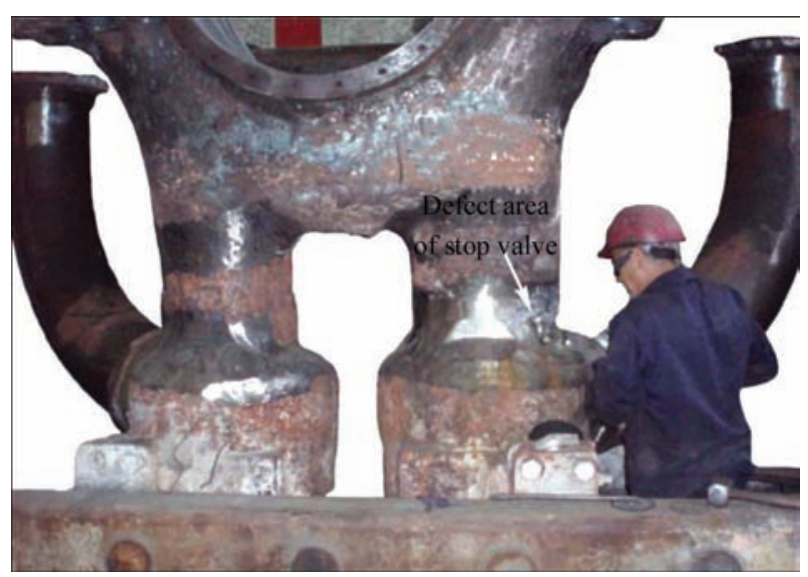

Figure 2. MPC cover with stop valves during preparation for repair

grade EA-395/9 (of type Kh16N25M6). The cause for carrying out initial surfacing was detection of a casting defect in this area in the form of a shrinkage crack of 10-35 mm depth and up to $120 \mathrm{~mm}$ length.

During removal of a defect applying layer-by-layer grinding, the propagation of delamination and separation of austenite metal in small pieces were observed (Figure 4). Moreover, the delamination surface had a relief, typical for deposited metal, and the hardness of its areas had high (HV 480-520) and low (HV 110$150)$ values. It indicates that the fracture occurred in the fusion zone both in the carburized as well as in the decarburized area. The completeness of removal of austenitic metal was controlled by a magnetic powder method and by metallographic etching of surface with $20 \%$ nitric acid. Except of austenitic metal, a layer of base metal of $8-10 \mathrm{~mm}$ thickness was also grinded. This made it possible to remove the HAZ metal having a high degree of defectiveness caused

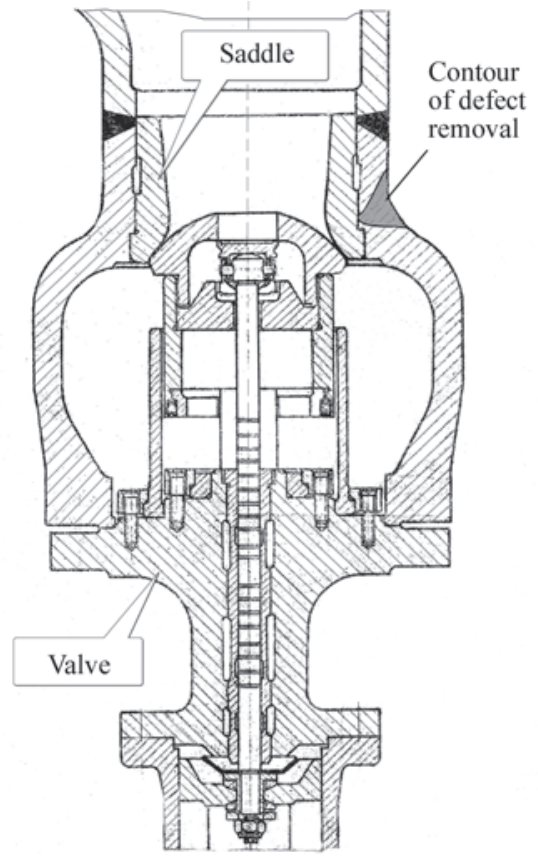

Figure 3. As-assembled control valve

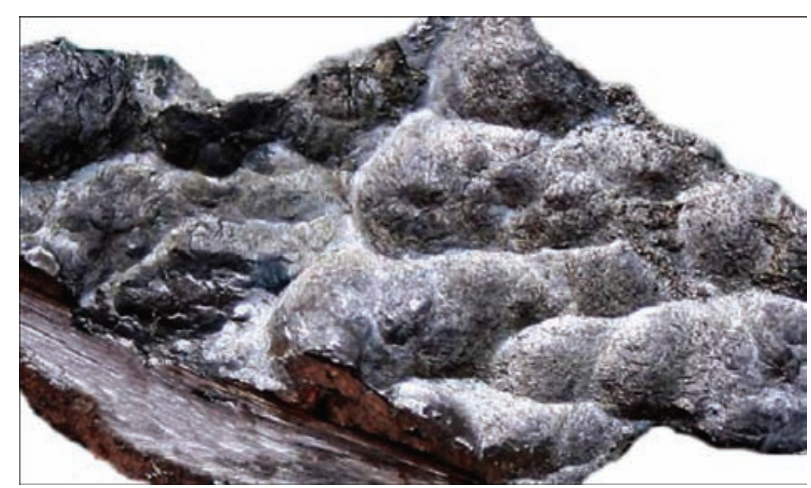

Figure 4. Fragment of austenitic deposit $(\times 3)$. Appearance on the side of delamination surface

by coarse grains, embrittlement of grain boundaries, phase and structural transformations which reduce the mechanical properties. As a result, a removed metal area with dimensions in the plan of $590 \times 185 \mathrm{~mm}$ and the depth within 30-65 mm was obtained. Moreover, in its middle part a through slot of 10-18 mm width and $120 \mathrm{~mm}$ length was formed, in which the surface of the saddle was uncovered (Figures 3 and 5).

The disassembly of the saddle from the valve body turned to be impossible because of the «overgrowing» of the gap with the inner surface of the valve body by strong precipitations in the process of a long service. This predetermined the selection of technology of welding for repair of the body of the MCP valve with preheating and postweld thermal recovery.

To diagnose the metal state on the repair area, to determine the possibility of further operation and its suitability for producing of welded joint, its microstructure and hardness were investigated and the evaluation of microfracture was carried out. For metallographic examination, a fragment of base metal with the size of $20 \times 30 \times 8 \mathrm{~mm}$ was selected at the area to be repaired. The hardness of base metal was measured by the portable durometer of Poldi type, and its microhardness was measured by the device PMT-3A.

The microstructure of base metal represents a fine grained bainite with carbide particles of up to $12 \mu \mathrm{m}$ size and single isolated micropores of up to $2 \mu \mathrm{m}$ size. The ferrite component amounts to not more than $5 \%$. The microfracture of base metal corresponds to point 2 of the scale of the Appendix Zh OST 34-70-690-96 at the admissible one being not higher than point 4 [1]. The microhardness of structural components is given in Table and the microstructure of base metal is given in Figure 6.

The results of investigations of base metal prove its repairability with application of arc welding and its possible further operation.

The preheating of the defect zone to the temperature of $280{ }^{\circ} \mathrm{C}$, maintaining the recovery temperature of $6 \mathrm{~h}$ duration, was performed using the thermal automatic 

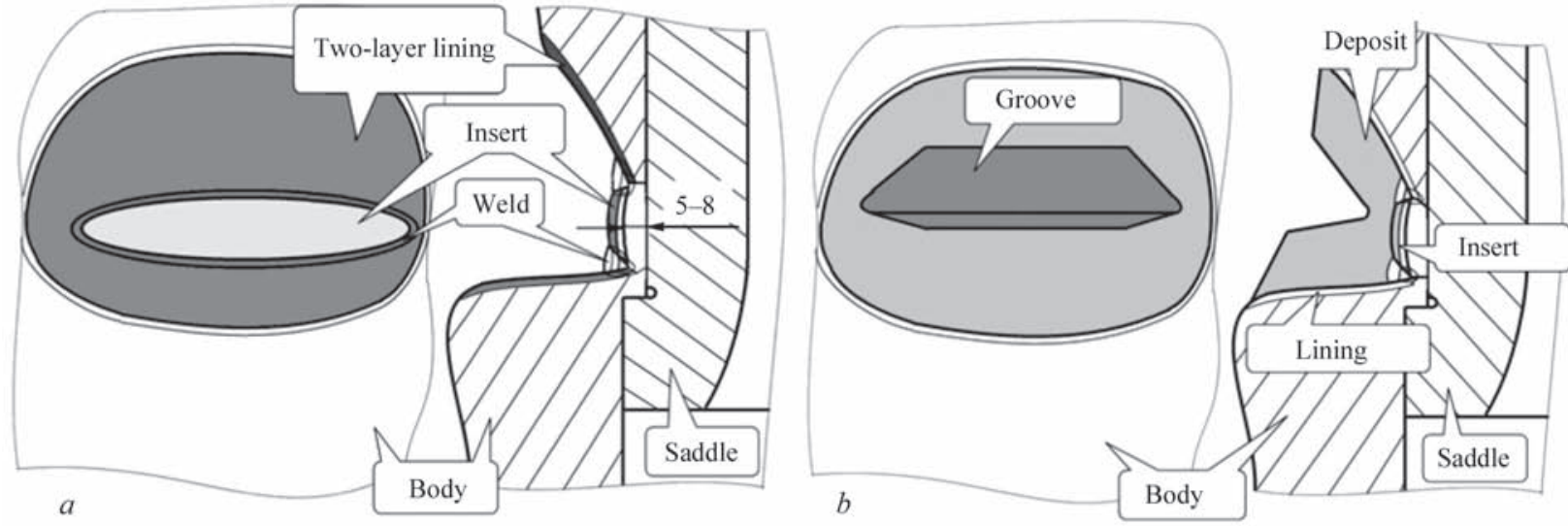

Figure 5. Preparation of a crack in the body of the MCP control valve for welding and the stages of its rewelding

installation «Weldoterm». The adjustment of temperature was performed at 12 controlled points to provide the uniformity of its distribution not only in the repair area but also in the area of $150 \mathrm{~mm}$ adjacent to it.

To eliminate the damage of saddle during rewelding of through slot, a special insert was welded-in to it at the distance of 5-8 $\mathrm{mm}$ from its surface (Figure $5, a)$. The insert was cut out of the section of pipe (steel 15Kh1M1F) deposited by the electrodes TML-5 $(06 \mathrm{Kh} 1 \mathrm{M})$ and subjected to heat treatment: normalization and high-temperature tempering. The profiling of the insert was performed strictly according to the size of slot with the edge bevel for welding at the angle of $45^{\circ}$ on the side of deposit. It was located by 1-2 mm higher than the lower edge of the slot with the formation of gap of $1.0-1.5 \mathrm{~mm}$ size between the edges to be welded. To prevent a possible welding-on to the saddle, its surface was protected with anti-burning coating. The root layer of the weld of the insert was made by argon-arc welding using W-electrode with the filler wire of grade Sv-08KhGSMFA of 1.6-2.0 mm diameter. The value of welding current was 220-240 A and the presence of a gap provided a complete penetration of edges welded. The subsequent weld layers of the insert were made by electrodes TML-5 (06Kh1M). The surface of welded joint of the insert was dressed up to a metallic glittering and controlled for absence of cracks by a visual method.

The surfacing of lening metal on the surface of removed metal area was carried out in two layers by

Microhardness of structural components of base metal

\begin{tabular}{|c|c|}
\hline Structural component & Value of hardness $H V 0.2^{*}$ \\
\hline Ferrite grains & $\frac{114-123}{118.5}$ \\
\hline Grains with bainite substructure & $\frac{143-155}{151}$ \\
\hline $\begin{array}{l}\text { *The denominator indicates the arithmetic mean of hardness from } \\
\text { six measurements. }\end{array}$ \\
\hline
\end{tabular}

electrodes of grade TML-5. The scheme of crack metal removing for welding and stages of its rewelding are shown in Figure 5. The annealing beads during surfacing of the first layer were produced by $3 \mathrm{~mm}$ electrodes and a width of not more than 5-8 mm. They were applied with overlapping by $40-50 \%$ of the width of previous bead. The second layer was made by $4 \mathrm{~mm}$ electrodes. When the base metal was heated to the temperature exceeding $280^{\circ} \mathrm{C}$, the welding was stopped to reduce and equalize the temperature to the preheating level. After surfacing of the second layer, the surface was subjected to peening by $0.5 \mathrm{~kg}$ hammer with a rounded striker. This technological method is an effective way to reduce welding stresses [4]. After dressing the surface of the as-peened metal, its control for absence of defects was carried out. The subsequent filling of the removed metal area was performed in two stages: the first one is a layer-by-layer surfacing on the side and bottom regions of the removed metal area in the direction from edges of the removed area to the centre up to the formation of a longitudinal V-shape groove of 15-20 mm width and the common slot angle of $40-45^{\circ}$ in the middle part of the removed area (Figure 6, $b$ ). The second stage is filling the groove by surfacing using longitudinal

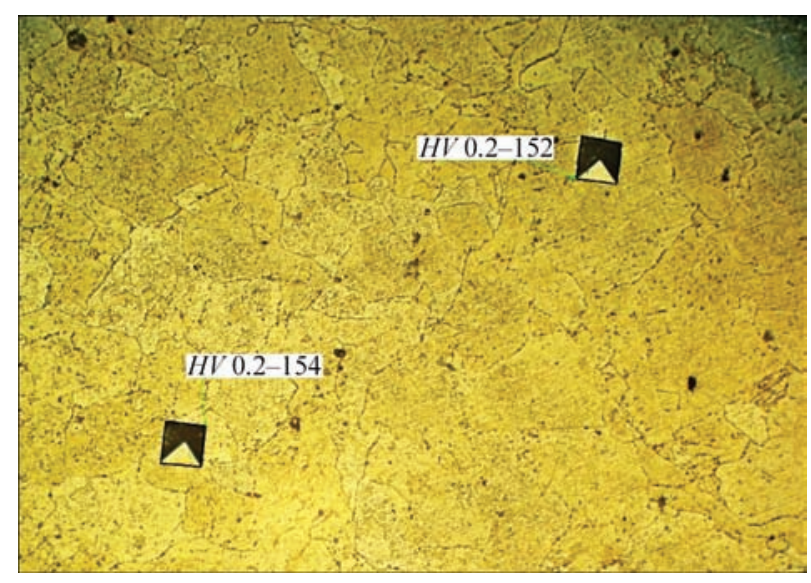

Figure 6. Microstructure $(\times 200)$ of steel $15 \mathrm{Kh} 1 \mathrm{M} 1 \mathrm{~F}$ at the area of repair 


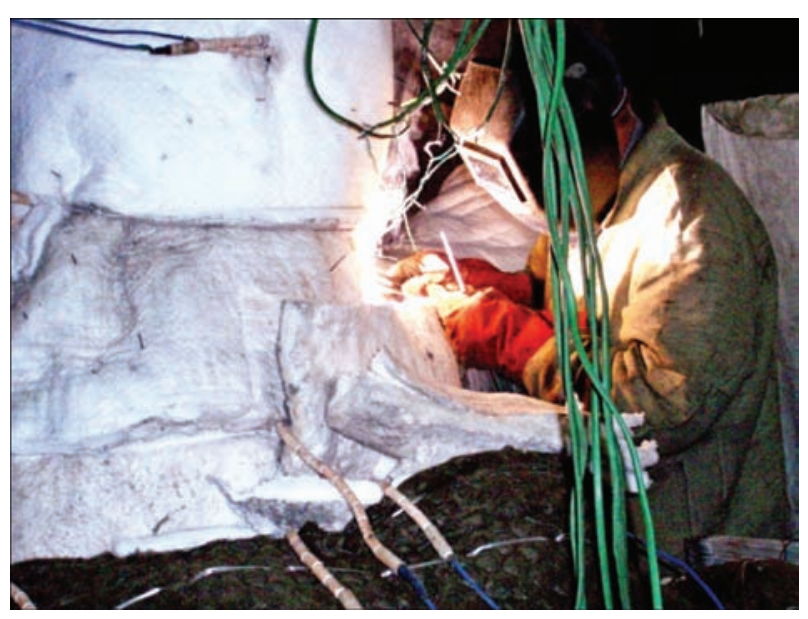

Figure 7. Performing repair welding of a crack in the body of the MCP control valve

beads. The moment of performing repair welding is shown in Figure 7. After end of surfacing, the thermal recovery of metal was carried out by maintaining the temperature of $280{ }^{\circ} \mathrm{C}$ durating $24 \mathrm{~h}$ with the help of the installation «Weldoterm». The cooling of surfacing area was carried out under the layer of thermal insulation at the rate of not more than $25^{\circ} \mathrm{C} / \mathrm{h}$ to the temperature of $70{ }^{\circ} \mathrm{C}$, and at a lower temperature in a calm air with the removed thermal insulation. As a result, the hardness of the deposited metal was obtained within the limits of HB 150-175 and of the base metal in the heat-affected-zone $H B$ 140-240.

The quality control of metal was carried out before, during and after surfacing throughout the whole surface of the deposited metal and beyond its $150 \mathrm{~mm}$ width by visual-measuring, magnetic-powder and ultrasonic methods. The cracks were not revealed. Based on the results of ultrasonic testing, the metal of repair rewelding met the requirements according to the quality level 2 in accordance with EN 126801:2003 and SOU VEA.200.1.1/01-2016.

Due to a low temperature thermal recovery as compared to high-temperature tempering, the widening of the area of application of this repair technology is possible with accumulation of the results of inspection of repair welded joints not only of the parts of power equipment, but also of petrochemical one.

\section{Conclusions}

1. In case when high-temperature tempering is impossible for repair of damages of assemblies and parts of turbine units from heat-resistant steels of operating TPPs, the technology of arc welding using pearlite electrodes with preheating and postweld thermal recovery can be used.

2. The technology of arc welding by pearlite electrodes with preheating and postweld thermal recovery allows:
- increasing the resistance of repair welded joints against crack formation due to improvement of the structure, increase in the ductile properties of metal of the heat-affected-zone and reduction of welding stresses under the influence of the effect of «annealing» beads during two-layer lining, as well as decrease in the content of diffusion hydrogen in the metal under the influence of thermal recovery;

- prolonging the service life of power equipment units;

- reducing the power losses and improvement of operating conditions during repair due to refuse from high-temperature postweld heat treatment.

3. The widening of application of this repair technology is rational while accumulating the results of investigations of properties and reliability of repair welded joints not only of parts of the power equipment, but also of the petrochemical one.

1. Gladshtejn, V.I. (2014) Microdamageability of metal of high-temperature parts of power equipment. Moscow, Mashinostroenie [in Russian].

2. Chernousenko, O.Yu. (2013) Damage and residual life of stop valves of high- and medium-pressure cylinders of steam turbine K-800-240 of Slavyansky thermal power station. Visnyk NTU KhPI. Series: Power and thermotechnical processes and equipment. Kharkiv, 986(12), 100-106 [in Russian].

3. Anokhov, A.E., Korolkov, P.M. (2003) Welding and heat treatment of case power equipment in repair. Kiev, Ekotekhnologiya [in Russian].

4. Khromchenko, F.A. (2005) Welding technologies in repair works. Moscow, Intermet Engineering [in Russian].

5. Lipodaev, V.N., Snisar, V.V., Elagin, V.P. et al. (1991) Peculiarities of brittle fracture of dissimilar welded joint with high-nickel weld metal. Avtomatich. Svarka, 10, 6-9 [in Russian].

6. STO TsKTI 10.049-2013: Removal of defects in cast parts of power equipment using welding without subsequent heat treatment [in Russian].

7. Efimenko, N.G., Atozhenko, O.Yu., Vavilov, A.V. et al. (2014) Structure and properties of welded joints of 15kh1M1FL steel at repair of casting defects by transverse hill method. The Paton Welding J., 2, 42-46.

8. Tsaryuk, A.K., Ivanenko, V.D., Volkov, V.V. et al. (2009) Repair welding of turbine case parts from heat-resistant steels without subsequent heat treatment. Ibid., 12, 32-36.

9. Tsaryuk, A.K., Ivanenko, V.D., Skulsky, V.Yu. et al. (2012) Technology of repair welding of boiler unit assemblies without postweld heat treatment. Ibid., 9, 37-43.

10. Kozlov, R.A. (1969) Hydrogen in welding of hull steels. Leningrad, Sudostroenie [in Russian].

11. Aloraierd, A., Al-Maznoueed, A., Price, J.W.H. et al. (2010) Weld repair practices without post weld heat treatment for ferritic alloys and their consequences on residual stresses. Int. $J$. of Pressure Vessels and Piping, 87, 127-133.

12. Som Dutt Sharma, S.D., Saluja, R., Moeed, K.M. (2013) A review on effect of preheating and/or post weld heat treatment. (PWHT) on hardened steel. Int. J. of Techn. Research and Applications, 1(Issue 2), 5-7. 


\title{
EVALUATION OF TECHNICAL CONDITION AND REPAIR OF CASING OF CATALYTIC CRACKING REGENERATOR R-202
}

\author{
V.N. POZNYAKOV, V.P. DYADIN, E.A. DAVYDOV, A.A. MAKSIMENKO and A.V. KLAPATYUK \\ E.O. Paton Electric Welding Institute of the NAS of Ukraine \\ 11 Kazimir Malevich Str., 03150, Kiev, Ukraine. E-mail: office@paton.kiev.ua
}

\begin{abstract}
The main features of the performed technical diagnostics of damaged petrochemical equipment are considered for evaluation of its reparability. It is noted that in order to detect defects, the nature of their development, and the subsequent possibility of performing repair and restoration works, an individual approach to selection of control means and methods is required in most cases. The work gives an example of development and implementation of repair and welding technologies for restoration of integrity and service characteristics of vessel bodies taking into account the results of technical diagnostics and investigation of mechanical properties. 7 Ref., 3 Tables, 7 Figures.
\end{abstract}

Ke yw or d s : repair of regenerator casing, visual and ultrasonic testing, welded joints, cracks, repair-welding technology

Evaluation of reparability of damaged petrochemical equipment is a rather complicated problem, as it requires not only a thorough assessment of the technical condition of structures, but also of metal properties after long-term service under the conditions of exposure to aggressive process and concomitant media, as well as broadly varied technological parameters.

\section{Regenerator operation conditions}

Working pressure, MPa:

above, not more than $\ldots \ldots \ldots \ldots \ldots \ldots \ldots \ldots \ldots .14$

below, not more than . . . . . . . . . . . . . . . . . 0.17

calculated ........................... 0.35

Working temperature, ${ }^{\circ} \mathrm{C}$ :

medium, not more than . . . . . . . . . . . . . . . 700

wall ................................. 150

calculated . . . . . . . . . . . . . . . . . . 300

Working medium $\ldots \ldots \ldots \ldots \ldots \ldots$ flue gases, air, steam, microspherical zeolyte-containing catalyst

As the nature of defects emergence, their type and nature of their development differ by their variety, an individual approach should be applied for their detection and assessment in each concrete case. This requires:

- clarification of the cause of defect emergence, their type and nature of their development;

- assessment of the level of equipment damage and detection of the main damage sites;

- determination of the properties of base metal and welded joints of equipment in the sites and beyond the affected zones.

Analysis of the results of the above studies can provide a reply to the question of repairability of this structure, and in case of a positive reply, a technical decision on its restoration can be taken, and then de- velopment of the technology of damaged equipment repair can be started. Such an approach will allow avoiding errors in development of the repair technology that may lead to deterioration of technical condition of metal structures, and can make them nonrepairable in some cases.

In this work, the approach to solution of this problem proposed by PWI specialists is shown in the case of preparation for repair-restoration operations for the damaged casing of catalytic cracking regenerator R-202 in PJSC «LINIK» plant (Lisichansk).

The need to perform this work was caused by the fact that through-thickness cracks were revealed in the regenerator casing during routine checkup of its technical condition. The cracks formed exclusively in welded joints and zones adjacent to them. In this connection, engineering services of PJSC «LINIK» Company contacted PWI with a request to look into this problem and provide scientific-technical assistance in restoration of serviceability of the damage apparatus for the period of not less than four years.

At the first stage of the work, the problem associated with determination of technical feasibility of repair-restoration operations was addressed. For this purpose PWI specialists analyzed technical documentation and results of previous diagnostic examinations, performed visual inspection of the affected areas of the regenerator, clarified the reasons, determined the time period of defect initiation and propagation in the form of cracks [1].

Analysis of technical documentation and results of diagnostic examination. When studying the technical documentation, a lot of attention was giv- 


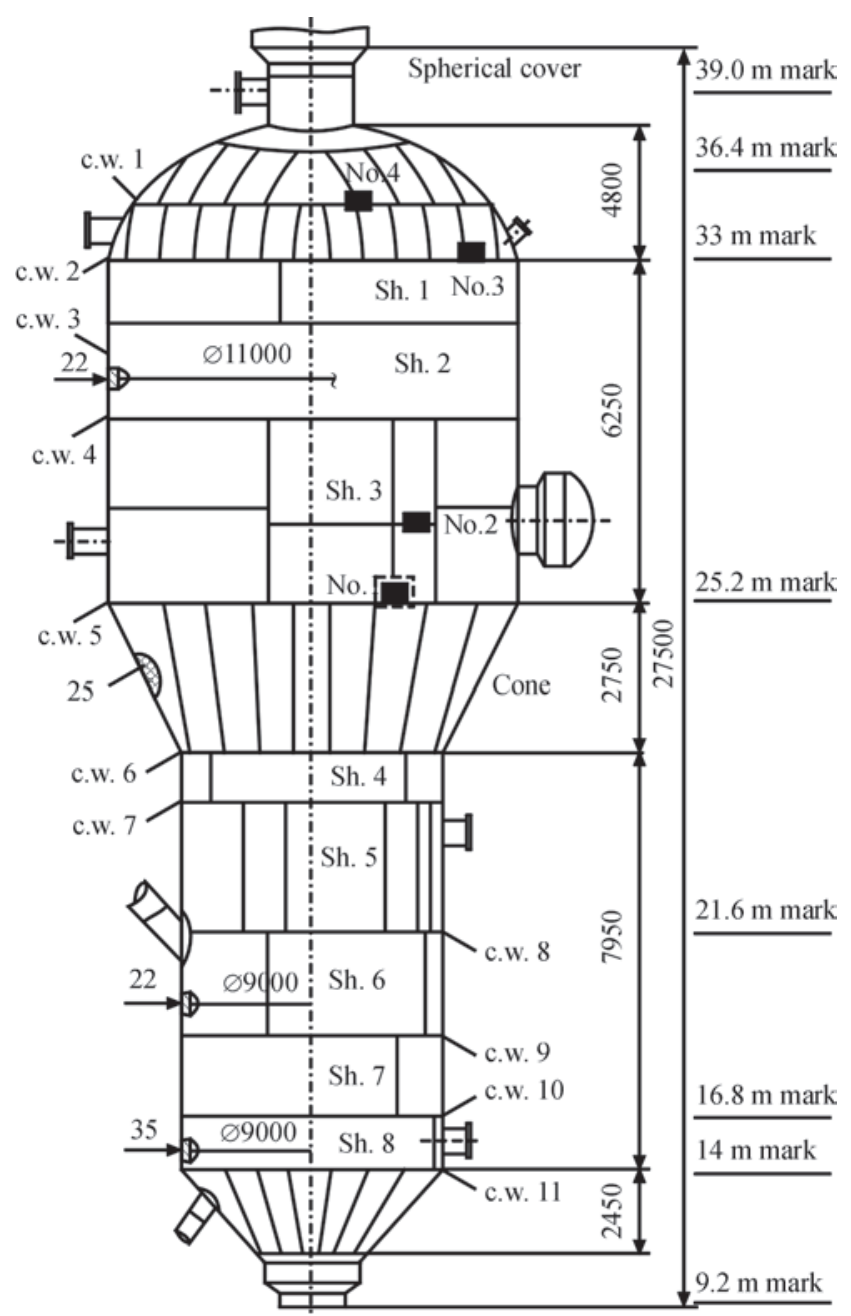

Figure 1. Design of the casing of R-202 regenerator with indication of areas ( $\mathbf{\square})$ of cutting out control samples (characteristic locations where cracks formed)

en to features of mounting assembly and information on routine repairs of the structure. It was found that mounting assembly of the regenerator was performed using enlarged elements, which were manufactured in one of the Russian enterprises. Expansion rolling of the rings and their assembly with application of welding were performed without subsequent heat treatment, either in the manufacturing plant, or in site. The regenerator was commissioned in 1993.

Surveys of service personnel participating in regenerator assembly in the period of its mounting, revealed certain difficulties during abutment of enlarged elements, leading to the need for their pretension before welding. The largest misfits during assembly of enlarged elements were observed in the regenerator upper part, where the casing diameter was equal to 11 thou $\mathrm{mm}$ in the points of its geometric transitions (Figure 1). Considering this fact, as well as casing element thickness being $20-22 \mathrm{~mm}$ in these areas, it is obvious that pretension, as well as generation of welding strains in the joints induced considerable residu-
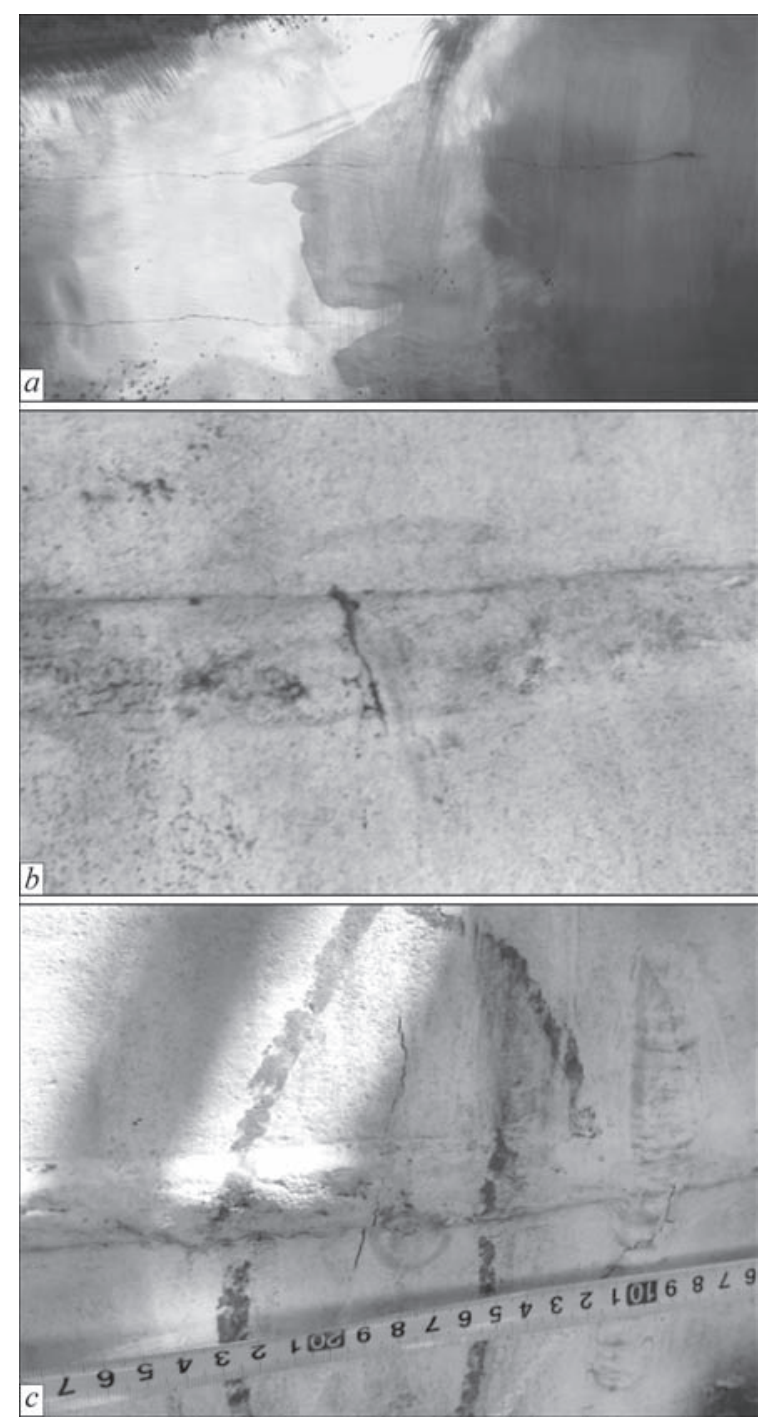

Figure 2. Examples of typical crack formation in welded joints made in shop conditions at enlarging the rings of a shell of 11 thou mm diameter $(a)$; in circumferential welds of assembly joints in regenerator upper part $(b)$ and in areas of repair welding up (c)

al stresses. This accounts for the fact that the largest number of cracks formed in exactly these locations.

Analysis of the results of diagnostic examination of the regenerator casing, performed from 2002 till 2010 with the frequency of once per two years, showed that before 2010, no defects preventing further operation of the regenerator, were revealed in the casing. Massive cracking in the regenerator casing (in the points of welding-in nozzles into the apparatus casing, in circumferential welded joints of 11 thou mm diameter shell and upper cover) started presumably in 2008-2010. This was indicated by the results of monitoring the regenerator technical condition, performed in 2010.

An attempt to perform repair of cracked areas of regenerator casing by the staff and with the technology, developed by the repair service of the company, operating this facility, did not allow solving this problem. After completion of the repair, monitoring the 
condition of the regenerator casing showed that new cracks started initiating and old cracks, covered by patches, began propagating in the locations of welding-on the patches and in welded up defective areas. By 2013 the number and size of the cracks reached a critical value that cast a doubt on the possibility of further safe operation of the apparatus. In this connection, in 2013 PWI experts performed detailed visual inspection and ultrasonic testing of welded joints of regenerator casing. Its results showed the following.

Visual inspection of regenerator casing. Visual inspection of welded joints was conducted, when a considerable part of defects had already been overlaid by patches, that somewhat complicated selection of locations with the most characteristic types of welded joint damage. On the other hand, even in this case, additional cracklike defects were found in plant welded joints made at enlarging of the rings before their expansion rolling (Figure 2, $a$ ).

Absolute majority of the detected defects were located in assembly circumferential joints and on their intersections in the regenerator upper part. The only exceptions were defects in the areas of repair welds or patches, which propagated beyond the heat-affected zone (HAZ) (Figure 2, $b, c$ ).

Detected defects had one characteristic feature, associated with initiation and further propagation of cracks only in the areas of higher residual stresses, formed as a result of site and repair welding. This feature of defect development allowed a certain narrowing of the scope of inspection of the structure surface, and focusing on welded joints in the regenerator upper part, where higher residual stresses are present after welding and straightening of the abutted elements.

Determination of boundaries of damaged areas in welded joint near-weld zones prone to cracking with application of ultrasonic testing. In order to detect and assess the discontinuities, ultrasonic testing of welded joints was performed and the following approaches were used:

- pulse-echo method for relatively fast detection of cracks and their approximate localization [2-4];

- time-of-flight diffraction method (TOFD) for quantitative evaluation of crack height [5-7].

Ultrasonic testing performed with application of standard pulse-echo method revealed that there is no delamination in base metal of regenerator casing.

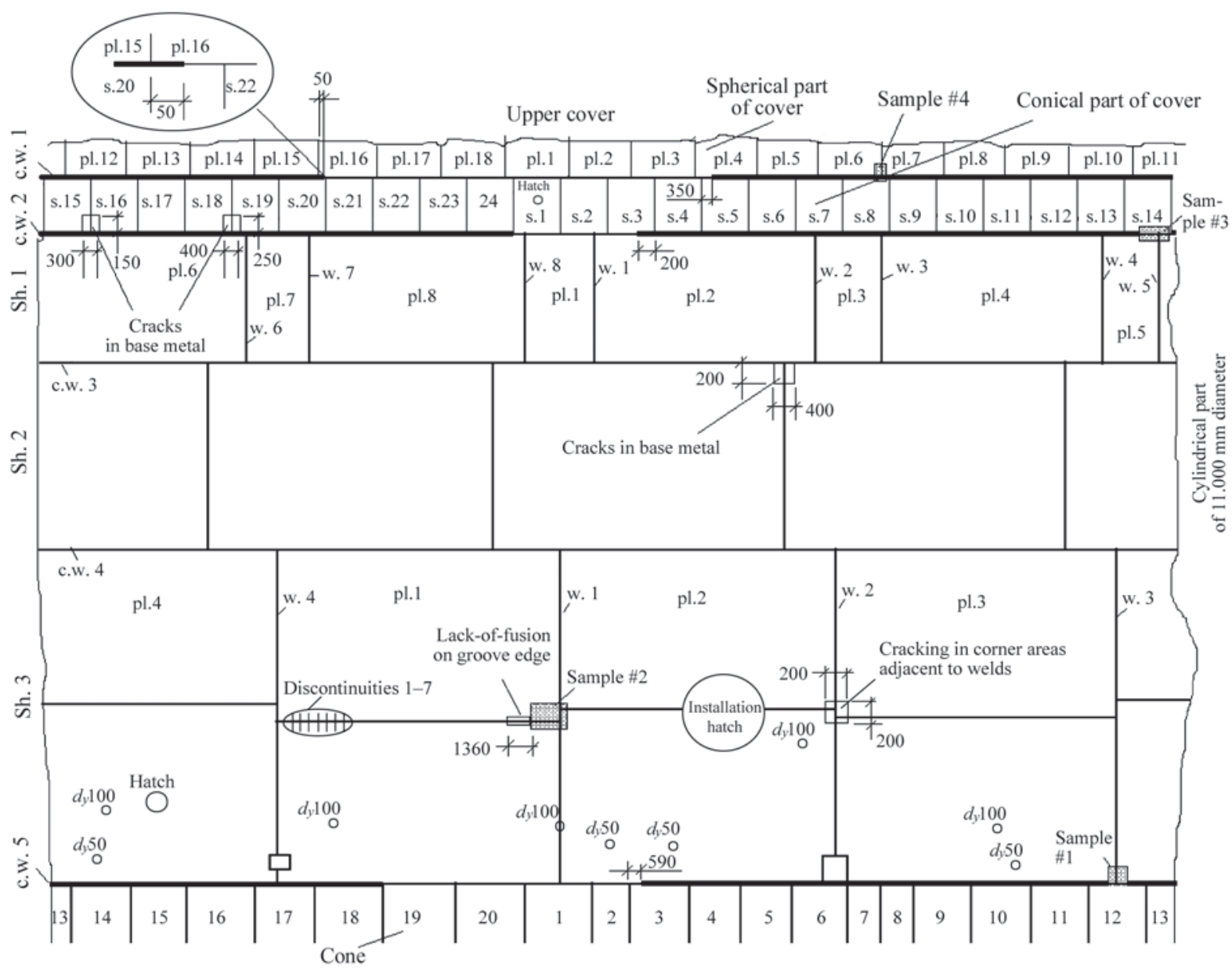

Figure 3. Fragment of regenerator casing with indication of locations of concentration of cracklike discontinuities: circumferential weld areas marked by bold lines have discontinuity density of 30-50 discontinuities per one meter 
Table 1. Chemical composition of metal samples Nos 1-4

\begin{tabular}{|c|c|c|c|c|c|c|c|c|}
\hline Sample number & $\mathrm{C}$ & $\mathrm{Si}$ & $\mathrm{S}$ & $\mathrm{P}$ & $\mathrm{Mn}$ & $\mathrm{Cu}$ & $\mathrm{Cr}$ & $\mathrm{Ni}$ \\
\hline 1 & 0.058 & 0.573 & 0.020 & 0.021 & 1.50 & 0.188 & 0.090 & 0.112 \\
\hline 2 & 0.072 & 0.573 & 0.023 & 0.024 & 1.60 & 0.197 & 0.094 & 0.117 \\
\hline 3 & 0.052 & 0.548 & 0.023 & 0.021 & 1.47 & 0.179 & 0.095 & 0.109 \\
\hline 4 & 0.074 & 0.629 & 0.032 & 0.027 & 1.44 & 0.099 & 0.099 & 0.094 \\
\hline GOST 19281-89 & $\leq 0.12$ & $0.5-0.8$ & $\leq 0.035$ & $\leq 0.030$ & $1.3-1.7$ & $\leq 0.30$ & $\leq 0.30$ & $\leq 0.30$ \\
\hline
\end{tabular}

Table 2. Mechanical characteristics of metal samples Nos 1-4

\begin{tabular}{|c|c|c|c|c|}
\hline Sample number & $\sigma_{\mathrm{y}}, \mathrm{MPa}$ & $\sigma_{\mathrm{t}}, \mathrm{MPa}$ & $\delta_{5}, \%$ & $\psi, \%$ \\
\hline 1 & $359-363$ & $494-495$ & $33.4-35.2$ & $68.3-70.7$ \\
\hline 2 & $426-426$ & $564-564$ & $29.6-31.2$ & $68.4-68.5$ \\
\hline 3 & $444-464$ & $582-594$ & $28.6-31.6$ & $67.0-68.5$ \\
\hline 4 & $408-409$ & $526-529$ & $30.9-34.2$ & $58.9-61.2$ \\
\hline Initial state & $387-398$ & $540-578$ & $30.0-33.5$ & $55.7-55.3$ \\
\hline GOST 19281-89 & 345 & 480 & 21 & - \\
\hline
\end{tabular}

On the other hand, systemic cracklike discontinuities were detected in welded joints with circumferential welds c.w.1, c.w.2, c.w.5 (Figure 3). Density of cracks in some areas of welds was more than 20-30 discontinuities per one meter. Cracklike discontinuities were also found in the other areas of the above-mentioned joints, but not with such a high density. The largest dimensions of cracklike discontinuities were assessed by the value of $100-120 \mathrm{~mm}$ from the circumferential weld towards the base metal. Circumferential weld c.w.5 has predominant cracking towards shell Sh.3 for not more than $100 \mathrm{~mm}$ distance in the weld, and not more than $50 \mathrm{~mm}$ in the base metal. Crack propagation towards the conic part is insignificant and equal to about 20-35 $\mathrm{mm}$.

In welded joints c.w.3, c.w.4, where numerous cracklike discontinuities were also detected, the dimensions and nature of crack propagation were somewhat different. In such joints discontinuities develop from inside the casing, and the length of the largest discontinuities is equal to about $50-60 \mathrm{~mm}$ to each side of the weld.

In the regenerator lower cylindrical part, c.w.6c.w.11, no cracklike discontinuities were detected.

The following stage of work performance involved assessment of the actual state of metal (structure, mechanical properties) in welded joints after long, more than 131 thou h., operating time in service. For this purpose metal samples were taken from regenerator

Table 3. Impact toughness of metal samples Nos 1-4 casing in those locations, where cracking is most often found (see Figure 1). These were further on used to prepare samples for metallographic examinations and mechanical testing (static rupture and impact bending test). Results of testing metal samples showed the following:

- it was confirmed that regenerator metal structures are made from 09G2S steel (Table 1);

- during operation no noticeable changes occurred in the metal structure at more than $150 \mathrm{~mm}$ distance from the present welds;

- metal preserved its static strength, ductility and impact toughness on the level of requirements made to steel 09G2S (Tables 2, 3);

- during operation micro- and macrocracks formed in the weld metal and in the base metal located at up to $150 \mathrm{~mm}$ distance from weld axis, on the inner and outer surfaces of the welded joints (Figure 4);

- intergranular nature of crack propagation (Figure 5) is indicative of the fact that these are stress corrosion cracks;

- at $150 \mathrm{~mm}$ and greater distance from the weld metal 09G2S steel preserved good ability to resist cold cracking.

These studies led to the conclusion that regenerator casing metal in the zones, where damaged welded joints are located, has accumulated local damage during operation. The width of these zones does not exceed $150 \mathrm{~mm}$ from weld axis. Thus, it becomes ob-

\begin{tabular}{|c|c|c|c|}
\hline \multirow{2}{*}{ Sample number } & \multicolumn{3}{|c|}{ KCU, J/cm ${ }^{2}$ at temperature, ${ }^{\circ} \mathrm{C}$} \\
\cline { 2 - 4 } & 20 & -20 & -40 \\
\hline 1 & $255-333$ & $188-304$ & $234-346$ \\
\hline 2 & $160-176$ & $116-120$ & $83-111$ \\
\hline 3 & $150-156$ & $92-110$ & $59-61$ \\
\hline 4 & $90-93$ & $78-84$ & $63-105$ \\
\hline Initial state & $191-196$ & $120-136$ & 34 \\
\hline
\end{tabular}


vious that the technical decision to repair the regenerator casing should envisage mandatory removal of metal located at not less than $150 \mathrm{~mm}$ distance from weld axis. In view of that, repair of circumferential welds with massive cracking was performed by the method of step-by-step cutting out and replacement of defective areas of the casing by plate inserts. This technology was used to perform repair of welded joints c.w.5, c.w.2 and c.w.1 in regenerator casing areas marked in Figure 6.

In areas with isolated short cracks, they were removed by grinding with subsequent welding up of the formed groove.

At step-by-step method of defective area replacement, plates of $09 \mathrm{G} 2 \mathrm{~S}$ steel, pre-expanded to fit the shell radius, were placed and welded in the openings cut out and prepared by mechanical methods. Considering that the defective shells had considerable damage on a length equal to not less that $3 / 4$ of their total length, they were divided into an equal number of areas.

The length of the cut-out areas was commensurate with the length of plates, making up the shell, and it was corrected proceeding from the requirements, that the locations of vertical welds in the points of joining of the inserts, should be shifted to $150-200 \mathrm{~mm}$ distance relative to plant welds present on the shell. Numbers of areas, into which the repaired shells were divided, was précised proceeding from the results of their control from the inside of the regenerator. The width of plate inserts was $300 \mathrm{~mm}$. The sequence of welding-in the plate inserts into the regenerator casing is shown in Figure 7.

The work started as follows: after removal of the lining, the inner and outer surfaces of the casing, where metal was replaced, was cleaned from contamination, then scraped on not less than $50 \mathrm{~mm}$ width to each side from the boundaries of the anticipated opening to conduct nondestructive testing. Scraping was performed to metallic luster by mechanical method using sanding machines fitted with abrasive wheels and disc wire brushes.

Nondestructive testing to determine the boundaries of cracked area was performed using visual-optical, penetrant and ultrasonic techniques.

Results of nondestructive testing were used for marking the repaired area of regenerator casing for cutting out.

Cutting out of the area damaged by cracks was conducted by air-plasma cutting. As the work was performed in winter time, before cutting out the defective area, it was preheated by gas torches up to the temperature of $50-70{ }^{\circ} \mathrm{C}$.
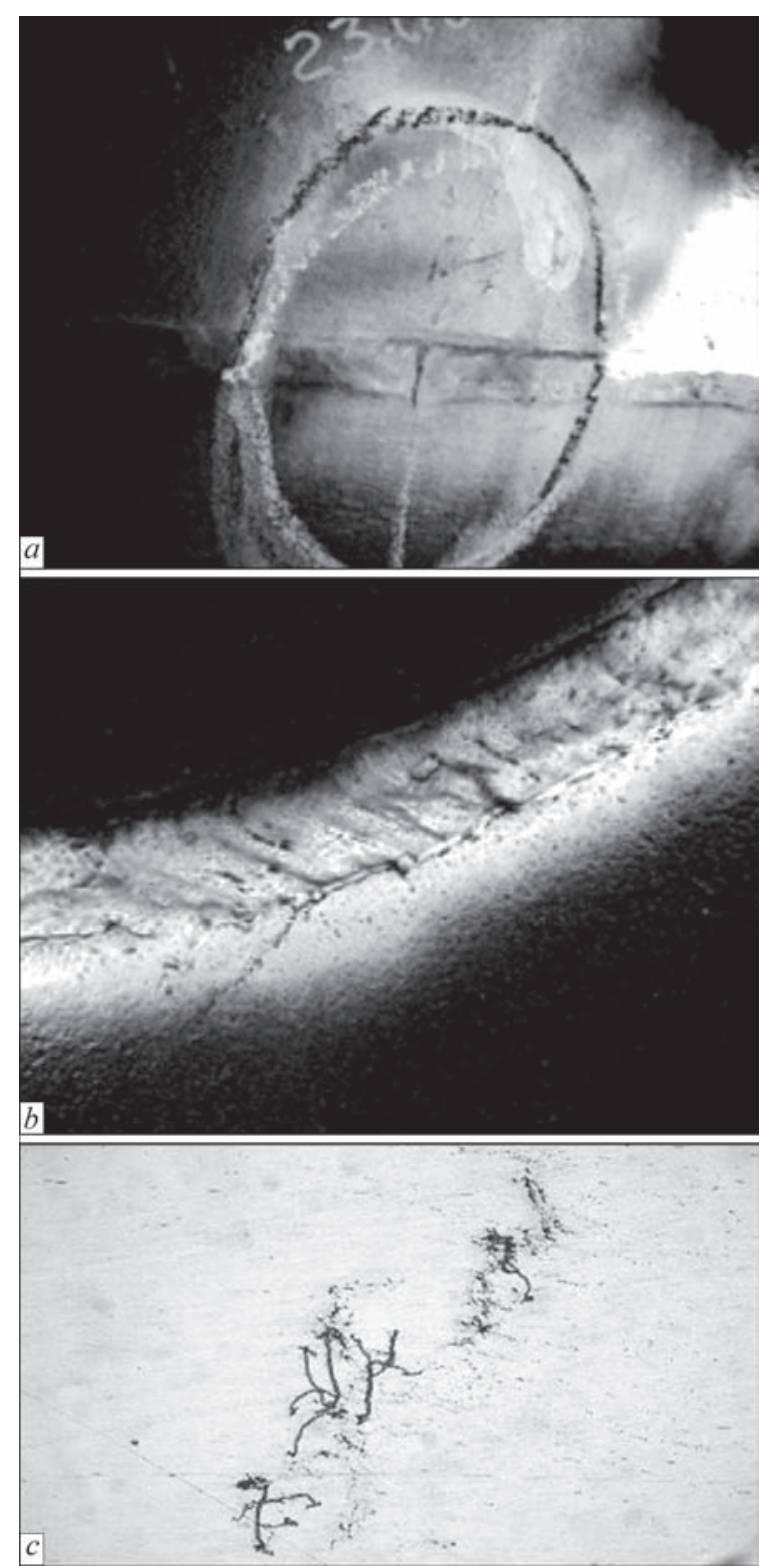

Figure 4. Macro- $(a, b)$ and microcracks $(c)$ formed on inner $(a)$ and outer $(b)$ surfaces of welded joints

Technological openings were cut out in such a way that their length was by $300 \mathrm{~mm}$, and width — by 6-10 mm greater than the dimensions of plates to be welded in.

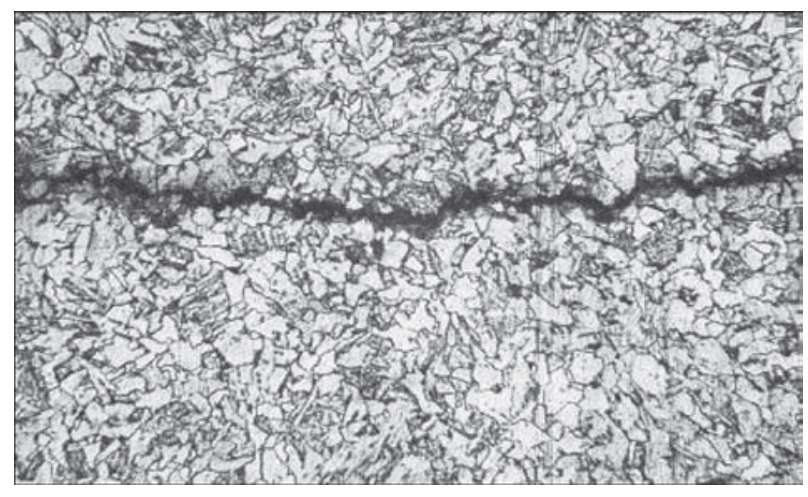

Figure 5. Microstructure $(\times 320)$ of metal of sample No.1 in the crack formation zone 


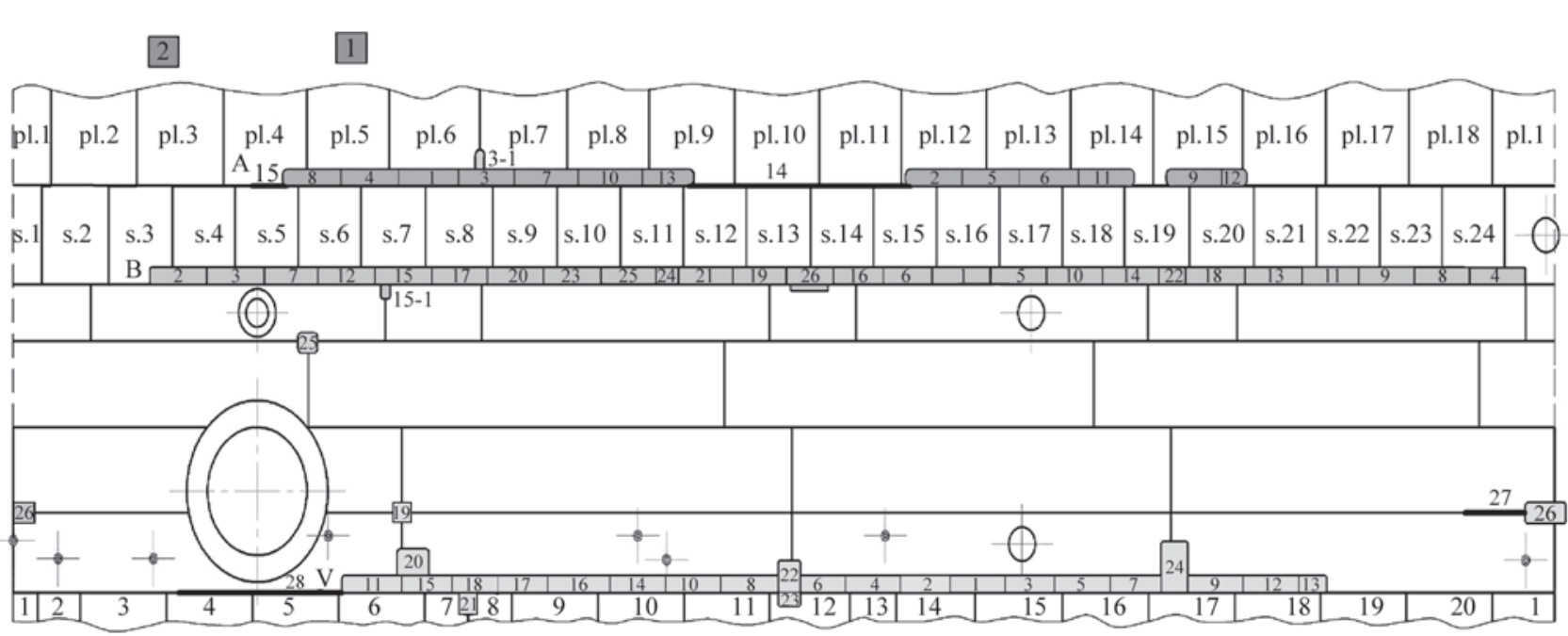

Symbols: 11 Numbering of inserts of lower shell (C) in the order of mounting (25 m mark);

10 Numbering of inserts of middle shell (B) in the order of mounting (33 m mark);

9 Numbering of inserts of upper shell (A) in the order of mounting (35 m mark);

1 Numbering of cupola inserts in the order of mounting (38 m mark);

28 Areas of weld repair by crack cutting-out method.

Figure 6. Schematic of placing the inserts

After cutting out the technological opening, mechanical method was used to scrape the cut surface to the depth of $0.5-1.0 \mathrm{~mm}$, and then the completeness of defect removal was controlled visually and by dye penetrant technique.

If remaining cracks were revealed during inspection, they were mechanically cut out and nondestructive testing was repeated. After complete removal of the defects, the formed grooves were welded up, using the following procedures.

Before welding, each of the areas where remaining cracks were cut out, was heated to the temperature of $120-150{ }^{\circ} \mathrm{C}$. The welding process proper was conduct-
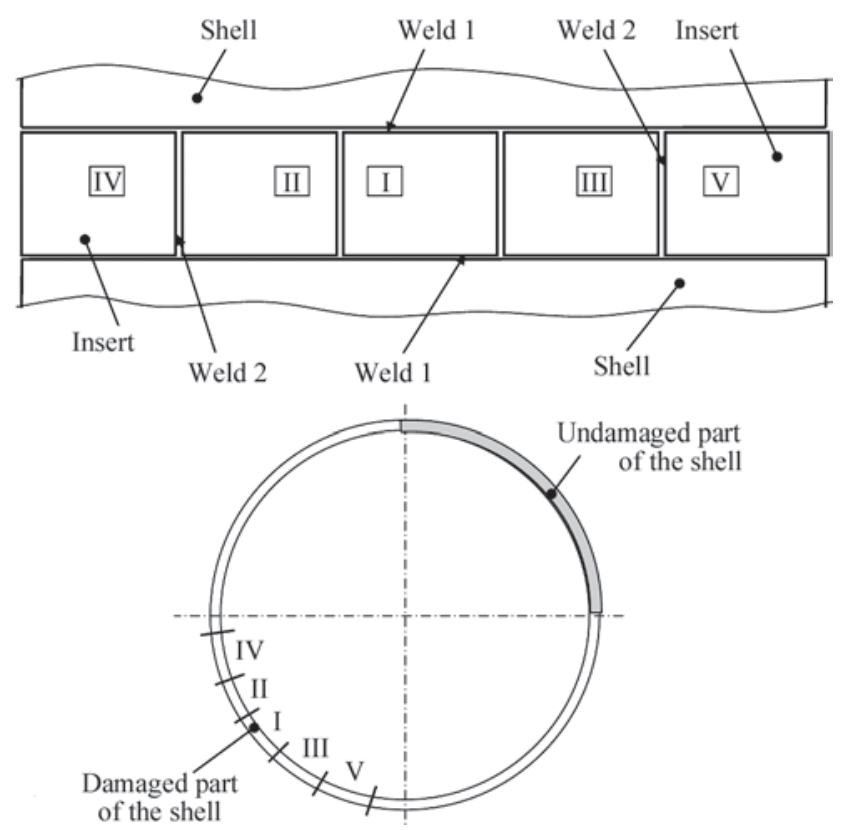

Figure 7. Sequence of welding-in the inserts at repair of regenerator R-202 ed by manual arc method with $3.2 \mathrm{~mm}$ electrodes of LB-52U grade, when making the weld root layer, and with $4.0 \mathrm{~mm}$ electrodes of OK 48.00 grade, when making the filling and face layers of the weld. Reverse polarity direct current (RPDC) welding was performed in the following modes: $I_{\mathrm{w}}=90-120 \mathrm{~A} ; U_{\mathrm{a}}=24-28 \mathrm{~V}$ in welding with $3.2 \mathrm{~mm}$ electrodes and $I_{\mathrm{w}}=140-170$ A; $U_{\mathrm{a}}=24-28 \mathrm{~V}$ - with $4.0 \mathrm{~mm}$ electrodes.

After restoration of the integrity of technological opening edges, air-plasma cutting was used to make a groove on them for welding the plate inserts to the regenerator casing. Then the edges were mechanically scraped to the depth of 0.5-1.0 from the edge surface. The surface of the elements to be welded was also scraped to metallic luster both from the casing outside and inside. Scraping was performed with a sanding machine to not less than $20 \mathrm{~mm}$ distance from each edge. At the final stage of preparation of regenerator casing and plate inserts for assembly and welding the groove geometry and quality of edge preparation were checked. The design elements of welded joints connecting the plate insert to regenerator casing and of the two adjacent plate inserts corresponded to joints C12 and C21, specified in GOST 14771-76.

During assembly, the plate inserts were mounted in the openings prepared for welding in the regenerator casing and tack-welded. Prior to tack welding and during welding the joints were heated up to the temperature of $120-150{ }^{\circ} \mathrm{C}$. Such a preheating temperature was accepted proceeding from the fact that welding was performed in winter time, when air temperature dropped below $-20^{\circ} \mathrm{C}$. 
Welding was performed without interruption. Interpass temperature was regularly monitored and maintained within $100-180{ }^{\circ} \mathrm{C}$ during filling of the groove. In the case of forced interruptions, welded joint temperature was kept at the level of $100^{\circ} \mathrm{C}$.

The welding process was conducted in the following sequence.

First stick electrodes were used to perform from inside of the regenerator manual arc welding of root layers of the weld in the upper and lower horizontal butt joints. The ends of plate insert 150-200 mm long were left unwelded. Welding was conducted from the insert middle to its ends by back-step method in 100$150 \mathrm{~mm}$ sections, shifting the start and end of the second pass steps by $25-40 \mathrm{~mm}$ relative to the first pass. Weld root was made by «double-layer» method.

After making complete inside horizontal welds, the roots of horizontal welds were treated with a sanding machine from the outside to clean sound metal. Then welding of horizontal welds from the outside of regenerator casing was performed. The sequence of making the weld outside part was the same, as when welding it from the inside of the regenerator casing.

The root beads were made with $3.2 \mathrm{~mm}$ LB-52U electrodes. Welding was performed in the following mode: $I_{\mathrm{w}}=100-130 \mathrm{~A}, v_{\mathrm{w}}=6-7 \mathrm{~m} / \mathrm{h}$. The second and subsequent layers of outer weld were performed by mechanized welding in a gas mixture of $80 \% \mathrm{Ar}+$ $20 \% \mathrm{CO}_{2}$ with $1.2 \mathrm{~mm}$ wire of OK Aristorod 12.50 grade in the following mode: $I_{\mathrm{w}}=160-190 \mathrm{~A}, U_{\mathrm{a}}=$ $=24-28 \mathrm{~V}, v_{\mathrm{w}}=10-14 \mathrm{~m} / \mathrm{h}$. In areas difficult-of-access for mechanized welding, the groove was filled by manual arc welding with $4.0 \mathrm{~mm}$ stick electrodes $\mathrm{OK}$ 53.70 (48.00) in the following mode: $I_{w}=150-160$ A, $v_{\mathrm{w}}=7-9 \mathrm{~m} / \mathrm{h}$.

After completion of welding of the upper and lower horizontal welds, the welded joints were heated up to the temperature of $200-220^{\circ} \mathrm{C}$ (temperature of low-temperature tempering), soaked at this temperature for $1 \mathrm{~h}$, then covered by a heat-insulating belt, under which they were kept up to complete cooling.

Then air-plasma cutting was used to cut out the defective part of regenerator casing to the left and right from insert 1 to place plate inserts (coupons) II and III. Edge grooving and their scraping to metallic luster were performed from outside and inside to not less than $20 \mathrm{~mm}$ distance from each edge. Inserts II and III were placed into design position and fastened by welding assembly tacks. From the inside horizontal welds were made, leaving 200-300 mm unwelded sections at the edges of abutment of plates II and III to plates I, IV and V.

After welding inserts I, II and III into regenerator casing, welding of vertical welds, joining inserts
I and II, I and III to each other, was started. Welding of vertical welds began to be performed, mainly, from the inside of regenerator casing. In some cases, the sequence of welding the vertical weld was purposefully used to adjust the position of plate insert relative to regenerator casing. These were exactly the considerations, proceeding from which the welding sequence was changed, when it became necessary to «draw-in» the ends of plate insert inside the regenerator casing, and the vertical weld began to be made from outside of the casing.

The root and near-root layers of vertical welds (from the first to the third one), were made with $3.2 \mathrm{~mm}$ electrodes of LB-52U grade in the following mode: $I_{\mathrm{w}}=90-120 \mathrm{~A}, U_{\mathrm{a}}=22-24 \mathrm{~V}, v_{\mathrm{w}}=6-7 \mathrm{~m} / \mathrm{h}$. After deposition of these weld layers, scraping of weld root layer to clean (defectfree) metal was performed by mechanical method from the weld face side. Filling of the groove was started after visual inspection of the condition of the scraped weld surface. The groove was filled by a combined method: fourth, fifth, and sixth layers were made by manual arc welding with $4.0 \mathrm{~mm}$ electrodes of OK 53.70 (48.00) grade; welding of subsequent layers of the weld was performed by mechanized process in shielding gas mixture with $1.2 \mathrm{~mm}$ solid wire of OK Aristorod 12.50 grade. The following modes were used: $I_{\mathrm{w}}=150-160 \mathrm{~A}, U_{\mathrm{a}}=$ $=24-26 \mathrm{~V}, v_{\mathrm{w}}=7-9 \mathrm{~m} / \mathrm{h}-$ for manual arc welding; $I_{\mathrm{w}}=140-150 \mathrm{~A}, U_{\mathrm{a}}=23-24 \mathrm{~V}, v_{\mathrm{w}}=7-9 \mathrm{~m} / \mathrm{h}-$ for mechanized welding in a gas mixture.

After making the vertical weld, «closing» of the horizontal welds (in the unwelded sections) was performed, i.e. in that part, which was left unwelded before making the vertical welds. The procedure of making the horizontal welds in the «closing» locations was conducted with the same welding materials in the same sequence and modes as the main horizontal welds, which joined the plate inserts and regenerator casing to each other.

After welding the vertical welds and "closing" sections, the area of regenerator casing, where this work was performed, was heated up to the temperature of $200-220^{\circ} \mathrm{C}$, and kept at this temperature for $1 \mathrm{~h}$ with subsequent covering with heat-insulating belt up to complete cooling. After complete cooling of welded joints, their surface was prepared by mechanical method for nondestructive testing performance. Welded joint quality was controlled by visual-optical and ultrasonic techniques.

The above operations, methods and sequence of their performance were realized in repair of the other areas of regenerator casing, requiring replacement of damaged metal. Alongside application of this method, replacement of the following shell assembly welds 
was performed c.w5 of $23 \mathrm{~m}$ length (18 plate inserts were welded in, ), c.w. 2 of $30 \mathrm{~m}$ length ( 24 plate inserts were welded-in) and c.w. 1 of $16 \mathrm{~m}$ length (13 plate inserts were welded-in).

Performance of repair operations was followed by pneumatic tightness testing of the regenerator casing. During such testing no leaks or visible deformations were observed in the zone of structural element repair. This is an indication of the high quality and reliability of repair welded joints.

\section{Conclusions}

1. To detect and assess the discontinuities in welded joints of casings of petroleum-processing equipment it is rational to apply UT, using pulse-echo method for relatively rapid detection of cracks and their approximate localizing, as well as TOFD method for quantitative assessment of crack height.

2. Program of performance of diagnostic examination, which, by NDT requirements is developed before the start of operations, should allow correction, depending on current examination results.

3. Before taking the technical decision on repair of petroleum-processing equipment, metallographic studies of welded joint metal and adjacent base metal areas should be performed that will allow assessment of the level of their damage, as well as establishing the nature and scope of damage beyond the weld zone.

4. At reconditioning equipment, with damage not only of welded joints, but also of adjacent zones of base metal, it is recommended to perform repair with complete replacement of damaged areas.

5. A necessary condition for further reliable operation is application of welding technologies, providing minimizing of residual stresses in welded joints and the structure as a whole that is achieved by step-bystep cutting out of damaged fragments of the casing and welding-in plate inserts with a certain sequence of making the welds.

1. Poznyakov, V.D., Dyadin, V.P., Davydov, E.A. (2016) Diagnostic examination of damaged regenerator of catalytic cracking unit to determine the repair-reconditioning operations for safe operation. Tekh. Diagnost. i Nerazrush. Kontrol, 1, 45-49 [in Russian].

2. DSTU EN ISO 17640:2014: Non-destructive testing of welds - Ultrasonic testing.Techniques, testing levels, and assessment [in Ukrainian].

3. DSTU EN 10160:2015: Ultrasonic testing of flat steel product of thickness equal or greater than $6 \mathrm{~mm}$ (reflection method) [in Ukrainian].

4. DSTU EN ISO 16826: Non-destructive testing. Ultrasonic testing. Examination for discontinuities perpendicular to the surface [in Ukrainian].

5. DSTU EN ISO 10863:2014: Non-destructive testing of welds. Ultrasonic testing. Use of time-of-flight diffraction technique (TOFD) [in Ukrainian].

6. DSTU EN ISO 16828:2015: Non-destructive testing. Ultrasonic testing. Time-of-flight diffraction technique as a method for detection and sizing of discontinuities [in Ukrainian].

7. DSTU CEN/TS 14751:2008: Welding. Use of time-of-flight diffraction technique (TOFD) for examination of welds [in Ukrainian]. 


\title{
STATE-OF-THE-ART OF WELDING EQUIPMENT AND CONSUMABLES MARKET IN UKRAINE
}

\author{
A. A. MAZUR, V.N. LIPODAEV, S.V. PUSTOVOJT and V.S. PETRUK \\ E.O. Paton Electric Welding Institute of the NAS of Ukraine \\ 11 Kazimir Malevich Str., 03150, Kiev, Ukraine. E-mail: office@paton.kiev.ua
}

\begin{abstract}
Welding as a main technology of materials joining is an integral part of commercial sector of economy, integrated into production process of the basic branches of industry. The paper presents systematic economical-statistical information on state and evolution of market of welding equipment and consumables in Ukraine, indices of volumes of their production and export-import operations. Production capacities of enterprises-manufacturers allow both the satisfying of domestic market demand, as well as delivery products to the foreign market. 9 Ref., 11 Figures.
\end{abstract}

Keywords : welding production, equipment, consumables, technologies, market, state-of-the-art, perspectives

The processes of globalization of the world economy $[1,2]$ influence the domestic market of welding equipment in Ukraine and predetermine the need in investigations of its state to reveal the challenging directions of development of welding production, optimal ways of functioning of Ukrainian enterprises and ensuring a stable demand for products in the conditions of rigid competition at the domestic and foreign markets. The works [3-5] are devoted to economic and statistical analysis of the state of the world market of welding equipment and consumables. The regional peculiarities and prospects of its development are considered in the works [6-9], in which it is shown that the strategies of development of national welding productions in the medium-term perspective almost have no sharp differences and are focused on solution of the most urgent problems, among which the increase in volumes and expansion of fields of application of welding and related technologies, enhacing in efficiency of technological processes at the simultaneous providing the high quality of joints, as well as reducing the energy consumption and total production costs for welding and related technologies. The aim of the work is the investigation of the state and tendencies in the development of market of welding equipment and consumables in Ukraine. Such an analysis allows determining the necessary solutions for successful functioning of Ukrainian producers and ensuring a steadily growing demand for their products.

The welding production in Ukraine is a complex scientific-technical and production complex of the national economy, in which about 80 thou people are involved. Its main components are scientific centers, leading research and developments of new welding technologies, equipment and consumables; industrial enterprises realizing the production of modern basic and auxiliary equipment, welding consumables, means of protection of production and ambient environment; a network of organizations which provide relation be- tween designers and consumers of welding equipment; system of training of engineering and working personnel, consisting of higher educational establishments of the I-IV accreditation level and vocational schools.

The regional structure of capacities of welding production in Ukraine and the output of welded structures is shown in Figure 1. The greatest number of industrial enterprises, producing more than a half of welded structures manufactured in the country, is concentrated in the Donetsk-Pridneprovsk region, where large industrial associations of different industries are located.

The welding equipment and consumables for welding and brazing are the important components of welding production in Ukraine. The capacities of Ukrainian enterprises as to their production allow meeting the needs of both the domestic market as well as delivering the products to foreign markets. The dynamics of production of welding equipment and welding consumables is shown in Figure 2. It is seen that during crises in the economy, the volumes of production are significantly reduced and during recovery, they are increased to the pre-crisis levels. The unfavourable situation at the world market, political and economic crises in Ukraine caused a reduction in industrial production and, as a consequence, a decrease in the outputs of welding consumables, which is observed in all groups of welding consumables. The production of welding equipment after recession in 2014 gradually recovered and reached a maximum value of 26.7 thou units in 2016. This indicates the fact that enterprises manufacturers of welding equipment adapted to the new conditions of the domestic market.

Welding equipment. A significant segment of the Ukrainian market of welding engineering products is the production of welding equipment. In Ukraine, there are 39 enterprises-manufacturers of welding equipment certified in the system UkrSEPRO [1], whose production capacities provide the total production of 20-25 thou units of equipment per year. 


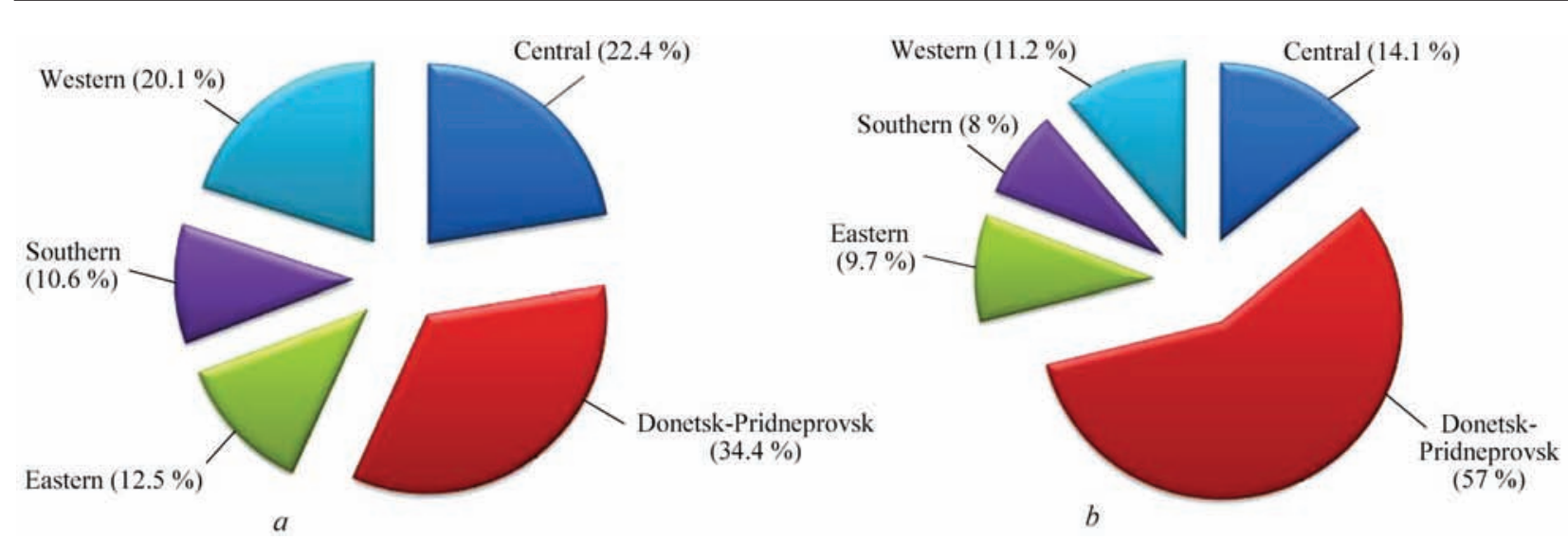

Figure 1. Regional structure of enterprises on output of welded structures (a) and volumes of their production (b) in Ukraine (composition of regions according to classification of State Committee of Statistics of Ukraine)

The output of welding equipment in Ukraine is oriented to consumption both within the country in different branches of industry and construction, as well as to delivery to the foreign markets. The volumes of production depend on the state of the Ukrainian economy and demand in the domestic and global sales markets. The realization of large infrastructure projects (for example, preparation for Euro-2012) facilitates the increase in business activity of enterprises, engaged in performance of works, and growth in demand for welding equipment, and this, in its turn, stimulates the growth of its production volumes and realization. Since 2013, at the main foreign markets, a decrease in demand for many products of Ukrainian industry is observed. This caused a recession of the production in the export-oriented industries and reduction in demand for many industrial products, including welding equipment. The adaptation of enterprises-manufacturers to the new conditions, which arose in the domestic and foreign markets, allowed recovering the pre-crisis production volumes.

Figure 3 presents the structure of production of electric welding equipment in Ukraine in dynamics. In the structure of production of welding equipment, the shares predominate which correspond to the production of automatic and semiautomatic machines for arc welding. The volume of their production since 2013 is constantly growing and in 2016 amounted to 25.2 thou units. The output volume of machines for flash-butt welding for the past three years is at the level of 100 machines per year. Basically, these are rail welding machines, $98 \%$ of which are exported. Whereas, the production of power sources is constantly decreasing from 2012 and in 2016 it amounted to 1.4 thou units, which is almost 7 times less than in 2013. The main cause for such decline is the entry of Ukraine into the WTO and, accordingly, the opening of the domestic market. The volume of imported deliveries of welding equipment to the Ukrainian market has been constantly growing since that time and in the conditions of severe competition the share of domestic manufacturers decreases.

Also, it should be noted that in Ukraine the production of automatic electric welding lines and complexes, as well as specialized equipment for special welding methods, the share of which in the structure of production was several percents, has practically stopped. This equipment is the most science intensive, highly-technological, in which perspective scientific and engineering solutions, as a rule patented, are introduced.

Such unique equipment is competitive and demanded at the market. As a rule, such equipment is created by the enterprises in close and fruitful cooperation with scientific organizations, design bureaus, different innovative organizations. Therefore, the increasing of production of this equipment is one of the tasks put before the enterprises and organizations of welding production.

The dynamics of export and import on the group of products of electric welding equipment is shown in Figure 4. In the foreign trade activity since 2014 the import operations prevail. As compared to the

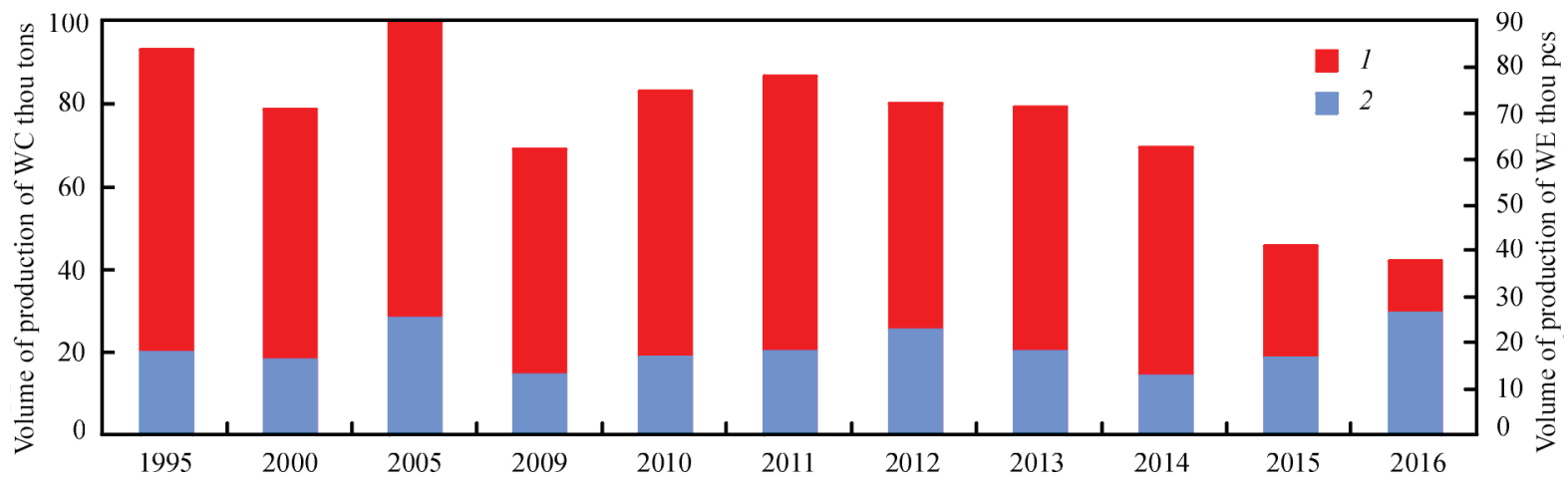

Figure 2. Dynamics of production of welding equipment (WE) and welding consumables (WC) in Ukraine: 1 - WC; 2 - WE 


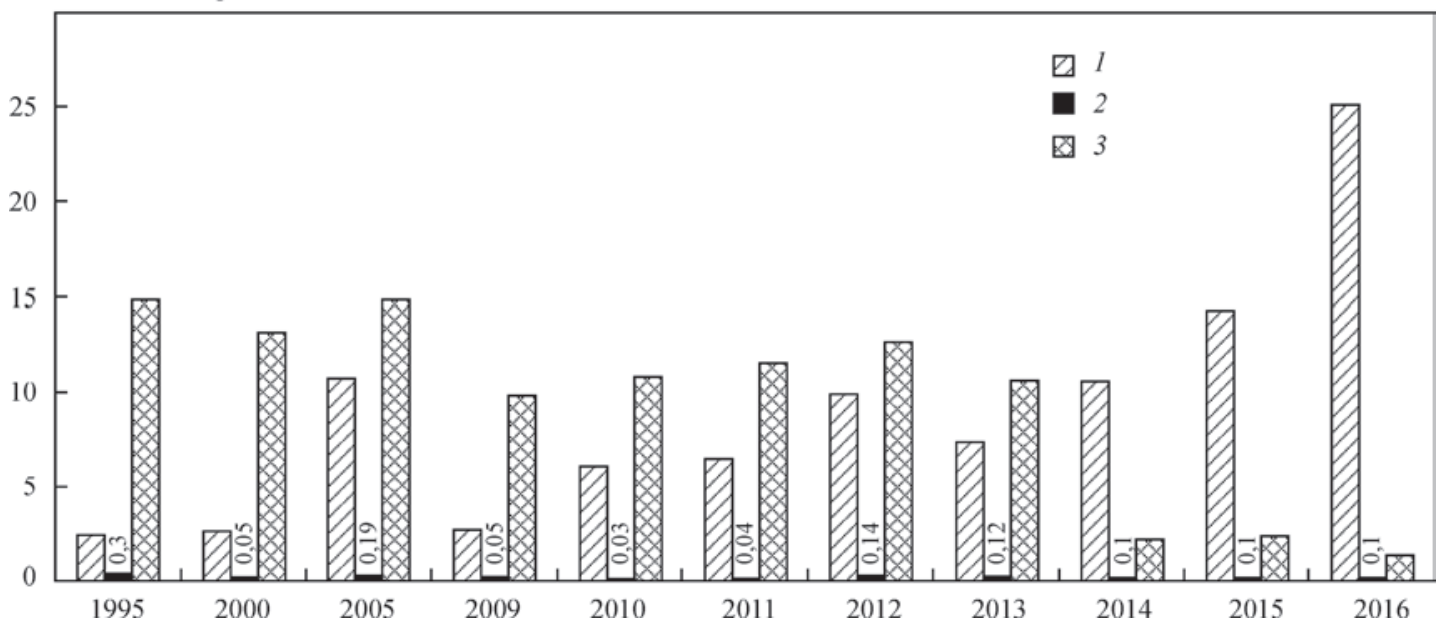

Figure 3. Dynamics and structure of production of electric welding equipment, thou units: 1 - automatic and semi-automatic machines for MAW and ESW; 2 - machines for flash-butt welding; 3 - power sources not included in the set of automatic and semi-automatic machines

base period of 2005, the volume of import in 2016 increased by 1.8 times. The volume of export of electric welding equipment depends on the demand at the foreign markets. During the crises of the world economy, the volumes of product deliveries decrease and during recovery of the market, they increase. The observed ratio of volumes of import and export operations forms a negative balance on the group of products of electric welding equipment.

The export-import operations on the group of products of electric welding equipment cover more than 50 countries. Among them the two major regional associations are distinguished - the EU and the CIS. The CIS countries (mainly Russia, Belarus and Kazakhstan) account for the bulk of export, and import comes mainly from the European Union and China. Since 2008, the volumes of welding equipment from China increased significantly and then annually grew.

Figure 5 shows the export-import data of the main nomenclature of welding equipment for 2016 - machines for flash-butt welding, for arc welding and other welding machines and apparatus for - by the major regional associations. They show a tendency to reduction of volume of export to the CIS countries and to increase in the share of import from the EU countries (exceeds $50 \%$ ).

The analysis of the state of export-import operations by the group of products of electric welding equipment showed that manufacturers of such equipment need diversification of sales directions for their products. A big dependence on deliveries of electric welding equipment to the market of CIS countries in today's conditions of mutual relations of the countries conceals a great deal of risks. The restrictions, imposed on this market, can negatively affect the economic status of enterprises-manufacturers of welding equipment.

The welding consumables are manufactured at 64 enterprises, 32 of which are certified in the system UkrSEPRO. Among them, the leading manufacturers are Zaporozhye plant of welding fluxes and glass products, Plazmatek, Vistek, BADM LTD, Pilot Plant of welding consumables, TM. VELTEK, Ganza, Mariupol Metallurgical Plant named after Iliich and Sumy-Electrode. The total share of these enterprises

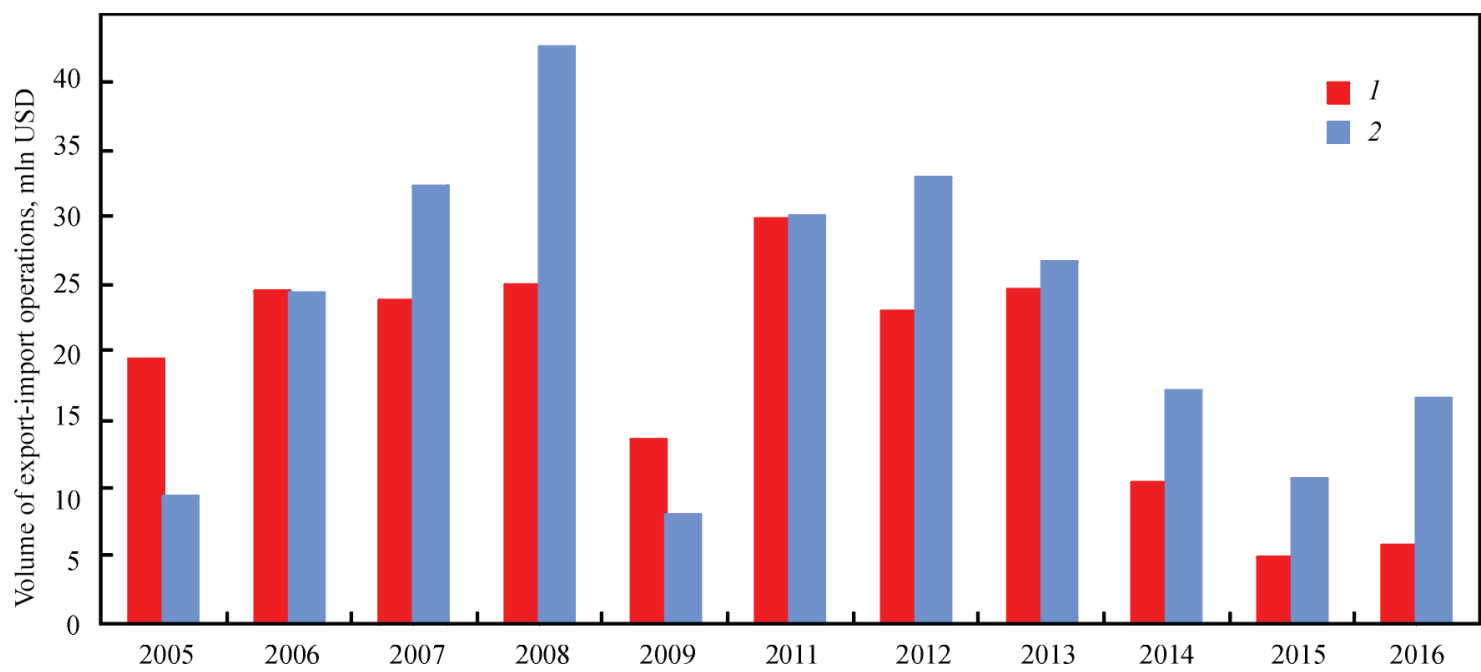

Figure 4. Dynamics of export-import on group of products of electric welding equipment: 1 - export; 2 - import 


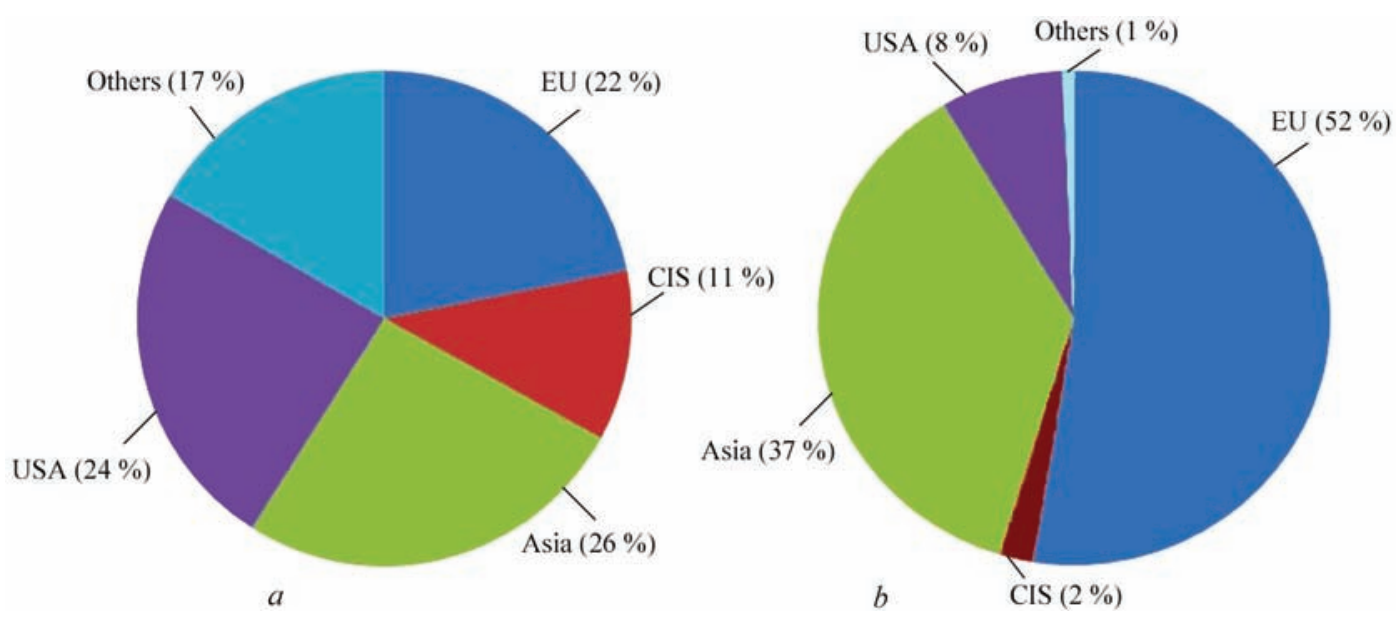

Figure 5. Structure of export (a) and import (b) by major regional associations and countries in 2016

exceeds $90 \%$ of the annual output of welding consumables in Ukraine. Such a high indicator of production and sales of these enterprises at the domestic market evidences about the concentration of production of welding consumables at large enterprises.

The production of welding consumables has been constantly reducing since 2012. In 2015-2016 years the volume of output was 42-46 thou tons, which is almost twice lower than the value of 2012. This is predetermined by restrictions in deliveries of products to the market of CIS countries, which was the main foreign market. A significant cause is also the change in the structure of industrial production in Ukraine. The share of machine building in the total volume of industrial production almost 4 times decreased (to $7.2 \%$ ). Therefore, the output of the main types of industrial products decreased, in the production of which the welding technologies used for joining and treatment of structural materials are basic.

The dynamics of structure of the output of welding consumables is shown in Figure 6. The analysis of data on production and sales of products shows a drop in volumes on all the positions of the nomenclature of the group of products of welding consumables, especially in 2014-2016. The capacities of Ukrainian enterprises-manufacturers of welding consumables are designed to meet the needs of both the domestic market, as well as delivery to the foreign markets.

In the structure, according to 2016, the main part $(65 \%)$ is occupied by production of welding elec- trodes, welding fluxes amount for almost $15 \%$, welding wire of standard quality is $14 \%$, alloyed wire $5 \%$, and the share of flux-cored wire is less than $1 \%$.

The dynamics and structure of export-import operations is shown in Figures 7 and 8 . The export deliveries almost 2 times exceed import ones, which allows ensuring a positive foreign trade balance on the group of welding consumables.

In 2016 the Ukrainian manufacturers mainly exported welding fluxes and electrodes, the share of which is almost $80 \%$ (Figure 7). In the structure of import the main volume (86\%) makes up the alloyed wire, the production of which is only mastered in Ukraine at the leading enterprises.

Since 2014, the volume of export deliveries of welding consumables has been constantly decreasing and in 2016 it amounted to 13 mln USD dollars (2.5 times lower than of the value of 2013), which accounts to almost the one third of the volume of their production in Ukraine. The volume of import for this period also decreased and amounted to $8.47 \mathrm{mln}$ USD.

Such ratio of export-import ensures a positive foreign trade balance on welding consumables during 2002-2016. Thus, in 2016, the foreign trade balance amounted to $4.65 \mathrm{mln}$ USD, i.e., the enterprises which produce welding consumables, are among those, which contribute to entry of foreign currency to Ukraine.

In 2016, the export-import operations on a group of welding consumables covered over 30 countries. Among them the countries are distinguished being a

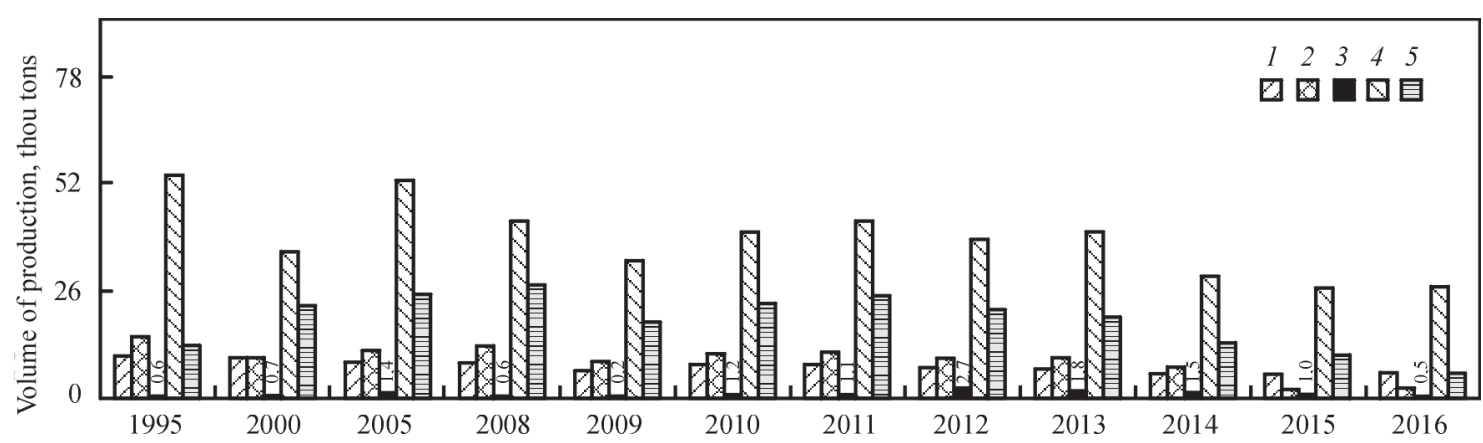

Figure 6. Dynamics of structure of production of welding consumables: 1 — welding wire of standard quality; 2 - alloyed welding wire; 3 - flux-cored welding wire; 4 - welding electrodes; 5 - welding fluxes 


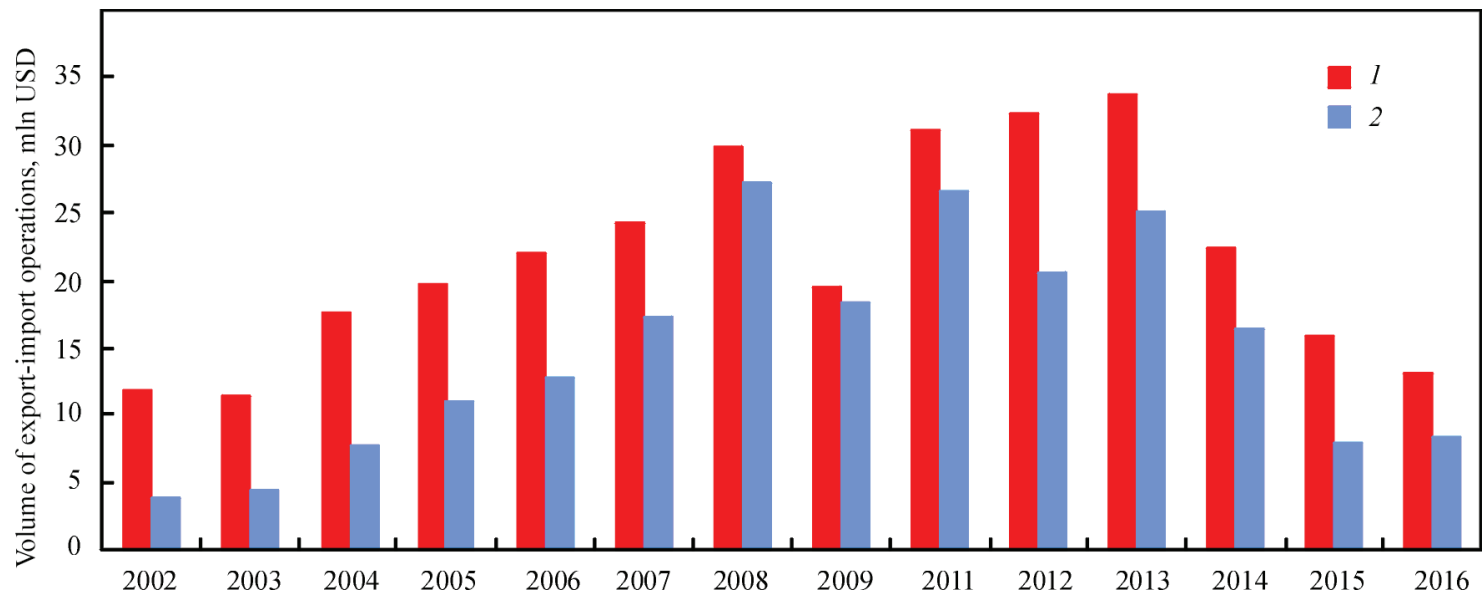

Figure 7. Dynamics of export-import operations on group of products of welding consumables: 1 — export; 2 - import

part of two main regional associations - the EU and the CIS (CU). The CIS countries (CU) account for the major part of export, and import comes mainly from the European Union and China. Figure 9 shows the geography of export-import of welding consumables for the major regional associations.

Foreign trade balance. The export-import operations on a group of products of welding equipment were carried out with organizations from over 60 countries. The data on dynamics of foreign trade

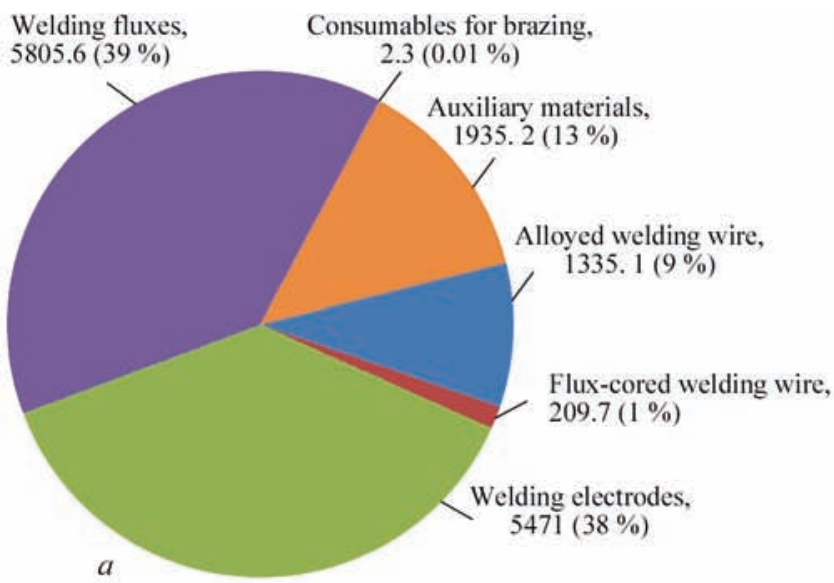

balance are shown in Figure 10. After the entry of Ukraine into the WTO, a negative balance in foreign trade is observed, which is predetermined by a significant prevalence of imported deliveries of equipment, especially electric welding one. During the financial crisis (2009), as a result of the hrivnya devaluation, the volume of import was significantly decreased and the foreign trade balance was positive.

The data on foreign trade balance by the main regions (for 2016) on a group of products of electric

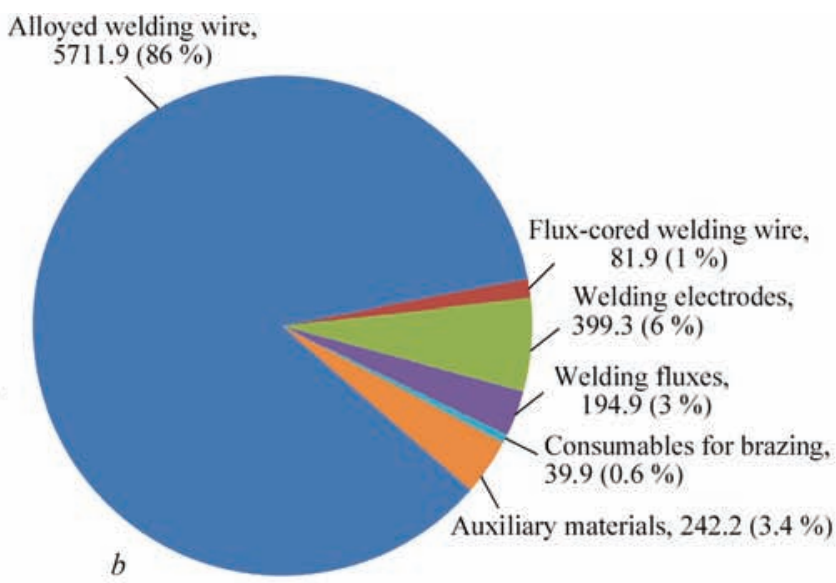

Figure 8. Structure of export (a) and import (b) of welding consumables in 2016, tons

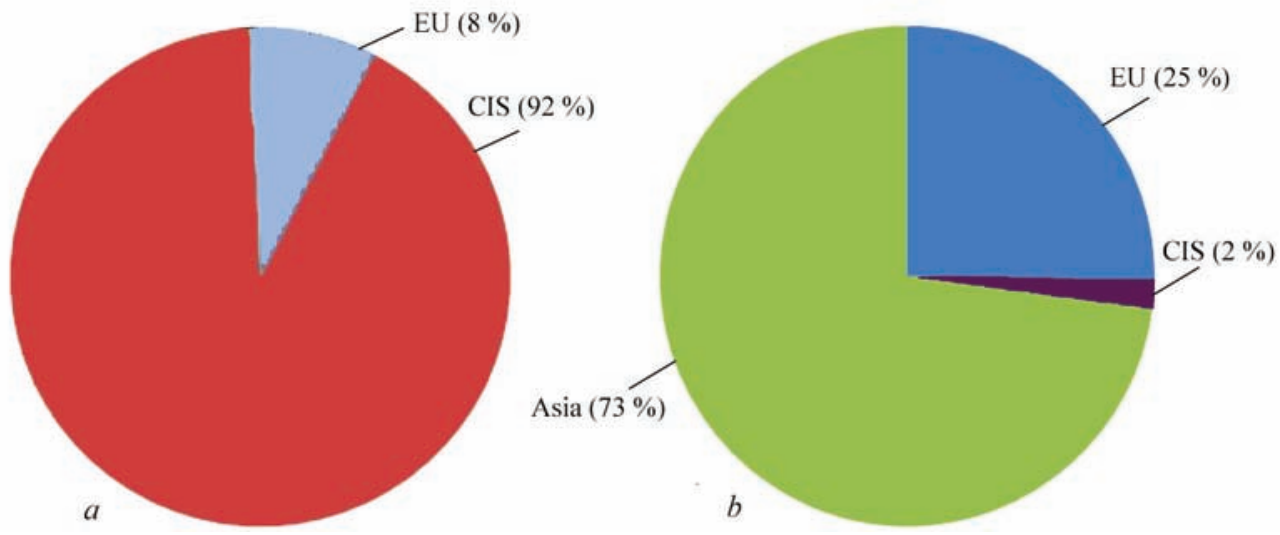

Figure 9. Geography of export ( $a$ ) and import $(b)$ of welding consumables by major regional associations in 2016 


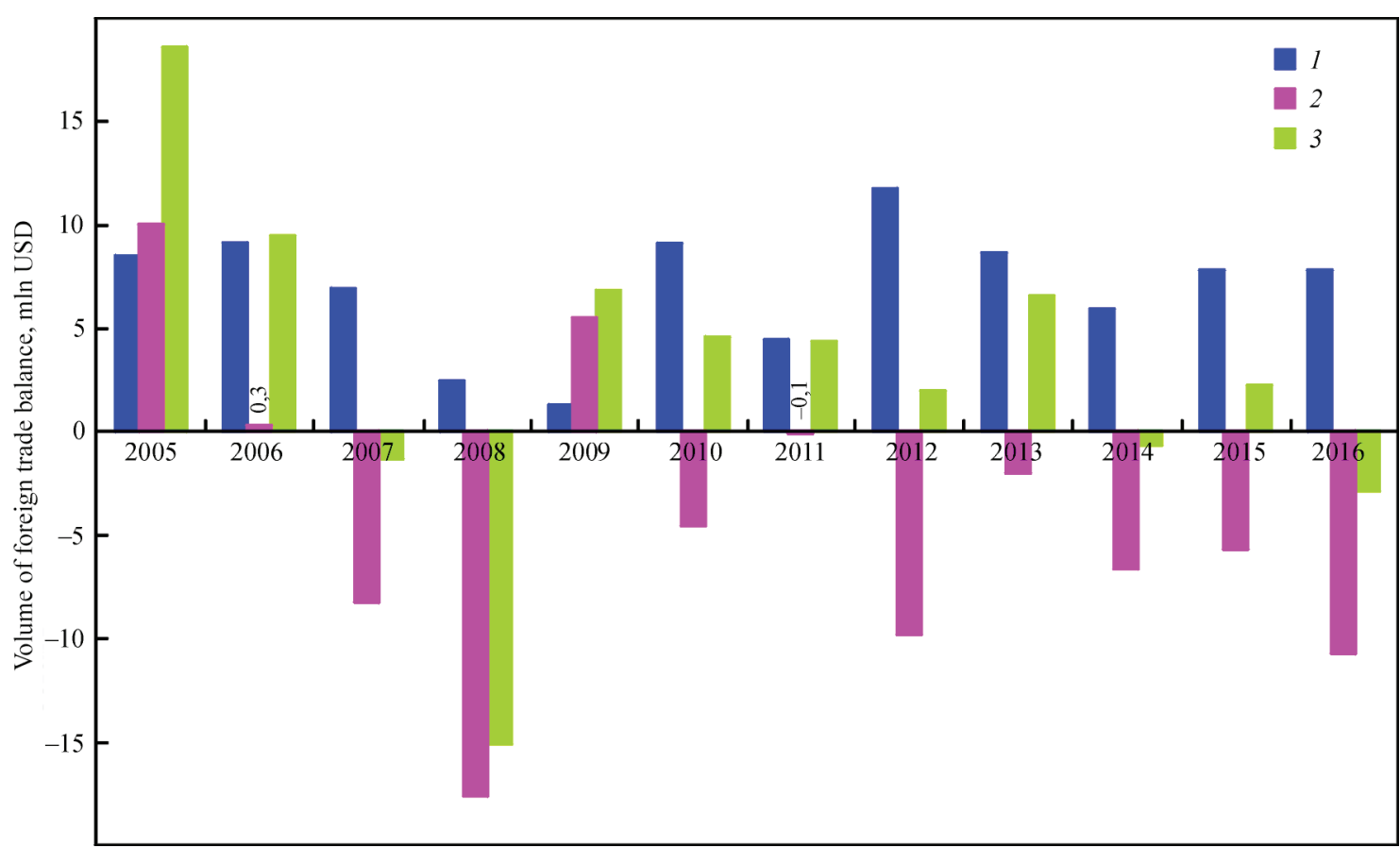

Figure 10. Dynamics of foreign trade balance on the group of products of welding equipment and consumables for 2005-2016: 1 welding consumables; 2 - welding equipment; 3 - foreign trade balance

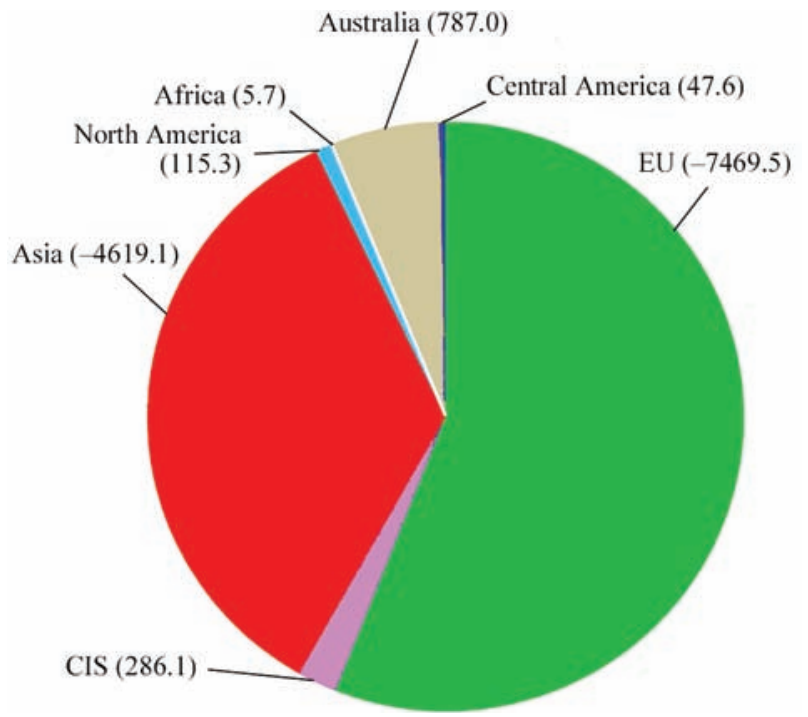

Figure 11. Distribution of foreign trade balance by the group of products of electric welding equipment in 2016, thou USD

welding equipment are shown in Figure 11. A positive balance is observed with the countries of the CIS, Africa, Central and South America, and the negative balance with the countries of EU and Asia (mainly China, Turkey and South Korea).

\section{Conclusions}

The presence of economic, statistical and marketing information about welding production in Ukraine allows enterprises to make grounded decisions on working out a strategy of actions on macro- and microlevels to provide their competitive advantages and grow the demand for their production.
The results of carried out analysis of state-of-theart of the Ukrainian market of welding equipment and consumables allow concluding that the existing production capacities of Ukrainian enterprises-manufacturers allow satisfying the domestic needs on a group of products of electric welding equipment and welding consumables, and also delivering products to the foreign markets.

The further stable and effective development of markets of welding equipment and consumables is possible at the active transfer of advanced welding technologies and other innovations.

1. Kovalenko, V.S. Globalization and laser technology. http:kpi. ua/ru/node/12977 [in Russian].

2. Bernadsky, V.N., Makovetskaya, O.K. (2007) Welding fabrication and welding equipment market in modern economy. The Paton Welding J., 1, 35-39.

3. Bernadsky, V.N., Mazur, A.A. (1999) State-of-the-art and prospects of world welding market. Avtomatich. Svarka, 11, 49-55 [in Russian].

4. Pekkari, B. The future of welding and joining (2006) Svetsaren, 3, 12-16.

5. Middeldorf, K. Hofe, D. fon (2009) Tendencies of development of technologies for joining of materials. Mir Tekhniki $i$ Tekhnologij, 11, 12-16 [in Russian].

6. Makovetskaya, O.K. (2011) Modern market of welding equipment and materials. The Paton Welding J., 6, 18-32.

7. Makovetskaya, O.K. (2012) Main tendencies at the market of welding technologies in 2008-2011 and forecast of its development (Review). Ibid., 6, 32-38.

8. Makovetskaya, O.K. (2012) Technological innovations - basis for increase of competitiveness of the U.S. welding production. Ibid., 11, 48-52.

9. Zadolsky, A.N., Ma Pin (2009) Review of market of welding production of Ukraine. Biznesinform, 5, 33-39 [in Russian]. 


\section{PILOT PLANT \\ oF WELDING CONSUMABLES}

State-owned enterprise «Pilot Plant for Welding Consumables of the E.O. Paton Electric Welding Institute of the National Academy of Sciences of Ukraine» is one of the biggest manufacturers of welding consumables in Ukraine.

The Plant is specialising in manufacture of a wide range of high-quality consumables for different welding processes: general- and special-purpose electrodes for manual arc welding, surfacing and cutting, flux-cored wire

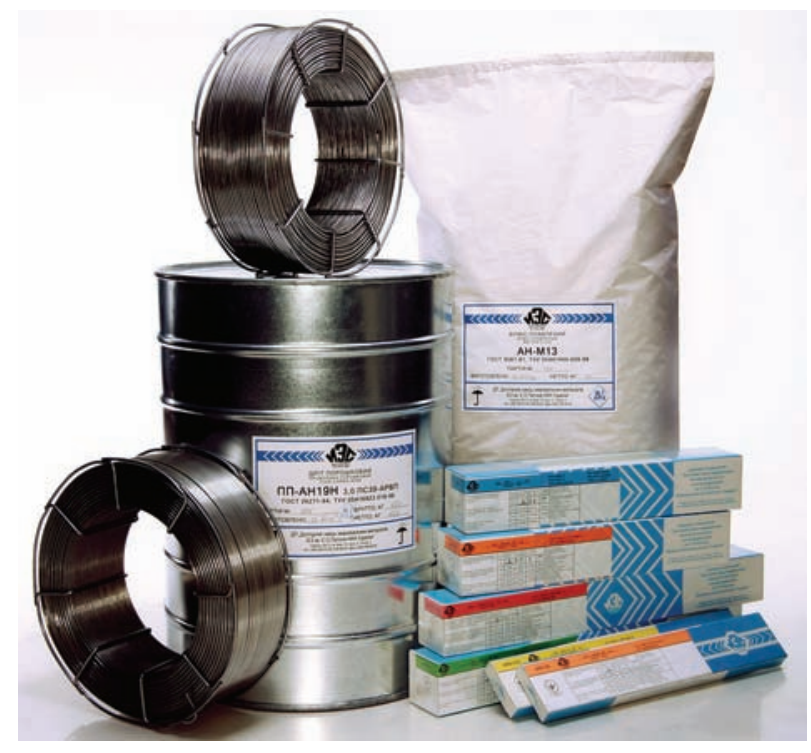
for mechanised and automatic welding and surfacing as well as severing, and fused and ceramic fluxes for automatic welding and surfacing. The Plant manufactures about 35 grades of electrodes, 40 grades of flux-cored wires, and 25 grades of fluxes.

One of the latest achievements of the Plant is upgrading of flux-cored wire production lines, which made it possible to produce small-diameter (1.2-1.6 mm) flux-cored wire.

In its operations the Plant uses the Quality Management System in compliance with ISO 9001:2000. The Plant Testing Laboratory has accreditation for technical competence by the National Accreditation Agency of Ukraine, and for technical competence in compliance with requirements of the Russian Maritime Register of Shipping.

The current production capacities of the Plant allow producing annually $12,000 \mathrm{t}$ of general- and special-purpose electrodes, $500 \mathrm{t}$ of flux-cored wires and $150 \mathrm{t}$ of fused and ceramic fluxes, which makes it one of the leading enterprises for manufacture of welding consumables in Ukraine and other $\mathrm{CIS}$ countries. 


\section{PRODUCTION OF TITANIUM ALLOY INGOTS}

\section{$A T \ll T \mid T A N » C E N T R E$}

At present, industrial production of titanium alloy ingots by the method of electron beam cold-hearth melting (EBM) is organized in the facility of SE «SPC «Titan» of the E.O. Paton Electric Welding Institute of the NAS of Ukraine» with equipment providing 3000 tons total annual capacity. Company specialists continue work on creation of new titanium-based alloys, develop and manufacture locally-produced equipment and technology of ingots melting

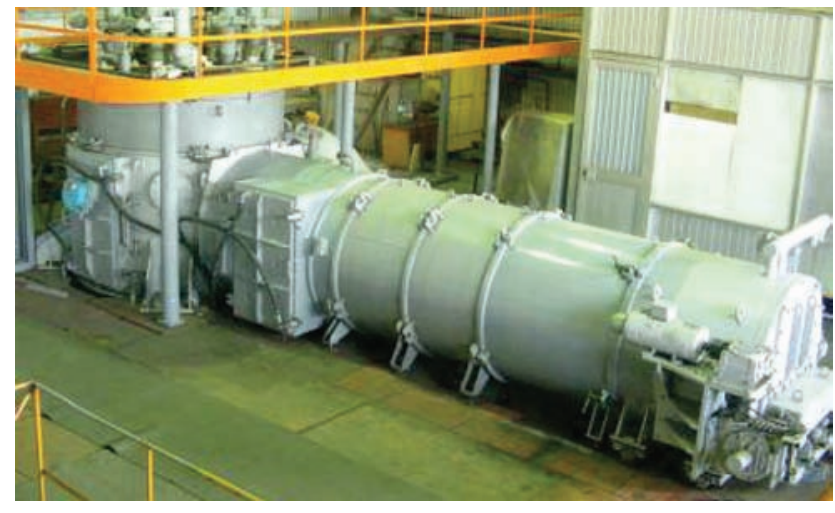

Electron beam unit UE-5812

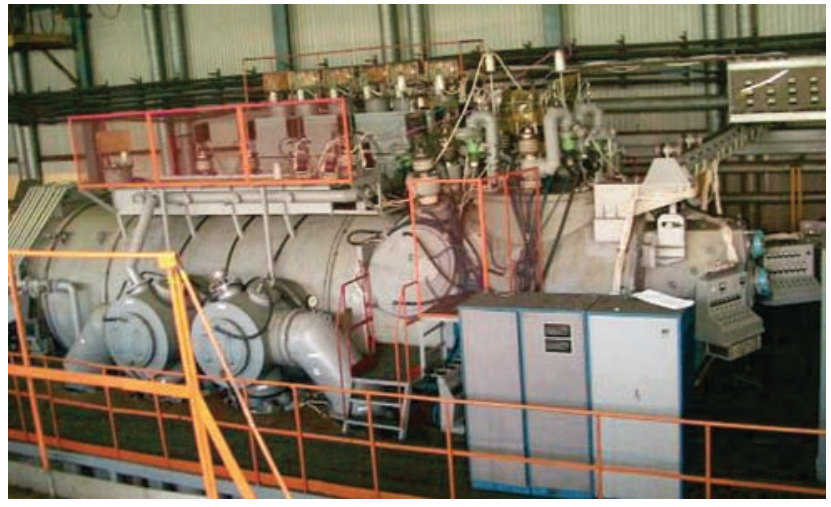

All-purpose electron beam unit UE-5810

based on titanium and other metals by EBM method.

Range of products produced by SE «SPC «Titan» of the E.O. Paton Electric Welding Institute of the NAS of Ukraine» is given in the table:

\section{Size range}

Diameter, mm: 110, 150, 200, 300, 400, 500,600, 830, 1100; of up to $4000 \mathrm{~mm}$ length Width of thickness, $\mathrm{mm}: 165 \times 950,150 \times 530$; of up to $4000 \mathrm{~mm}$ length

Grades*

VT1-00, VT1-0, PT1M, 3M, ET3, VT5, PT7M, PT3V, VT6, VT8, VT9, VT3-1, VT14, VT20, VT22, VT23, T110, Grade 1, Grade 2, Grade 5, Grade 9, Grade 12

*Other alloy grades can be produced by agreement with the Customer.

Chemical composition of the ingots meets the requirements of the local and foreign standards GOST, ASTM, AMS, etc. (ISO 9001 Quality System Certificate).

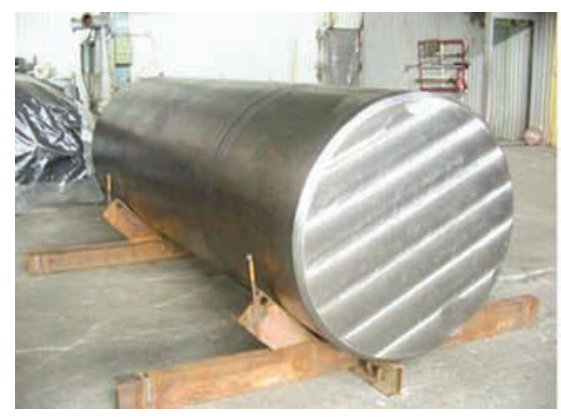

Titanium ingot of $1100 \mathrm{~mm}$ diameter

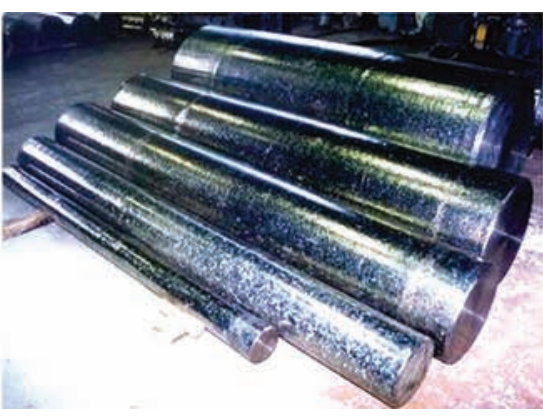

Titanium ingots of 100-600 mm diameter

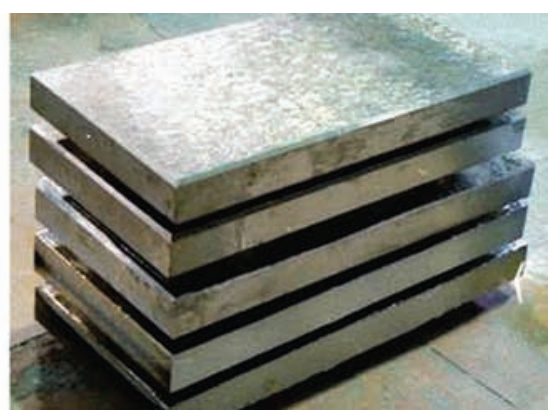

Titanium slabs of $165 \times 950 \times 1500 \mathrm{~mm}$ 


\section{TRAINING AND QUALIFICATION CENTRE}

The Training and Qualification Centre provides continuous multidiscipline vocational training of personnel in the field of welding and allied processes aimed at developing and deepening their professional competence. The Centre has accreditation in the national education system and accreditation of the International Institute of Welding for occupational training with the awarding of International Welding Qualifications.

Special training, advanced training and certification of welding engineers and technicians in accordance with national and international standards:

$>$ Engineers, technologists and foremen;

$>$ Welding supervisors (coordinators);

$>$ Chairmen and members of welder examination boards.

Advanced training and certification of welding instructors in accordance with national and international standards:

$>$ Teachers of special welding disciplines;

$>$ Fusion welding instructors.
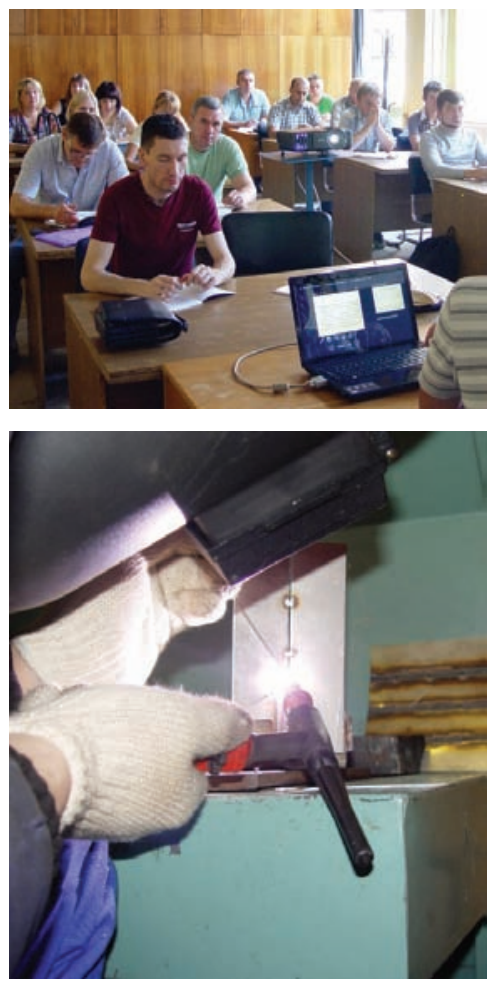

Vocational training, retraining, advanced training and certification of the following personnel in accordance with national and international standards and rules:

$$
\begin{aligned}
& >\text { MMA welders; } \\
& >\text { MIG/MAG welders; } \\
& >\text { FCAW welders; } \\
& >\text { TIG welders. }
\end{aligned}
$$

Modern training facilities, innovative training techniques, highly skilled lecturers and instructors ensure that each student receives a designated qualification level.
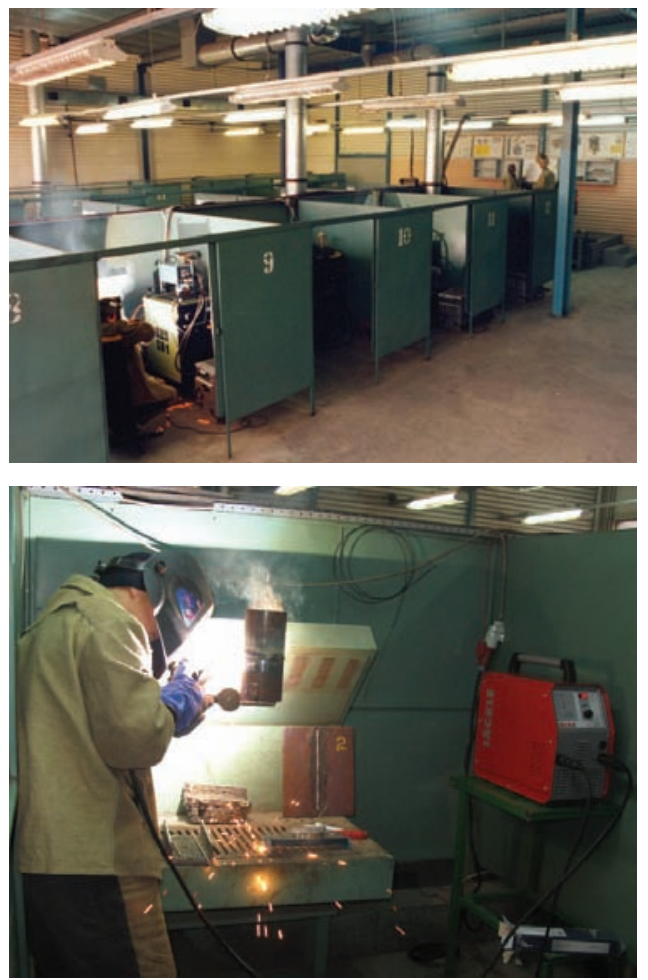


\title{
PATON PUBLISHING HOUSE
}

\author{
www.patonpublishinghouse.com
}

\section{SUBSCRIPTION}

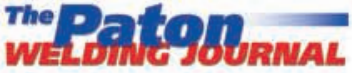 \\ Автоматическия arpang}

«The Paton Welding Journal» is Published Monthly Since 2000 in English, ISSN 0957-798X, doi.org/10.15407/tpwj.

"Avtomaticheskaya Svarka» Journal (Automatic Welding) is Published

Monthly Since 1948 in Russian, ISSN 005-111X, doi.org/10.15407/as.

«The Paton Welding Journal» is Cover-to-Cover Translation of

Avtomaticheskaya Svarka» Journal into English.

If You are interested in making subscription directly via Editorial Board, fill, please, the coupon and send application by Fax or E-mail.

The cost of annual subscription via Editorial Board is $\$ 348$ for «The Paton Welding Journal» and $\$ 180$ for «Avtomaticheskaya Svarka» Journal.

«The Paton Welding Journal» can be also subscribed worldwide from catalogues subscription agency EBSO.

\section{SUBSCRIPTION COUPON \\ Address for journal delivery \\ Term of subscription since \\ Name, initials \\ Affiliation \\ Position \\ Tel., Fax, E-mail}

20

till

20

We offer the subscription all issues of the Journals in pdf format, starting from 2009.

The archives for 2009-2016 are free of charge on www.patonpublishinghouse.com site.
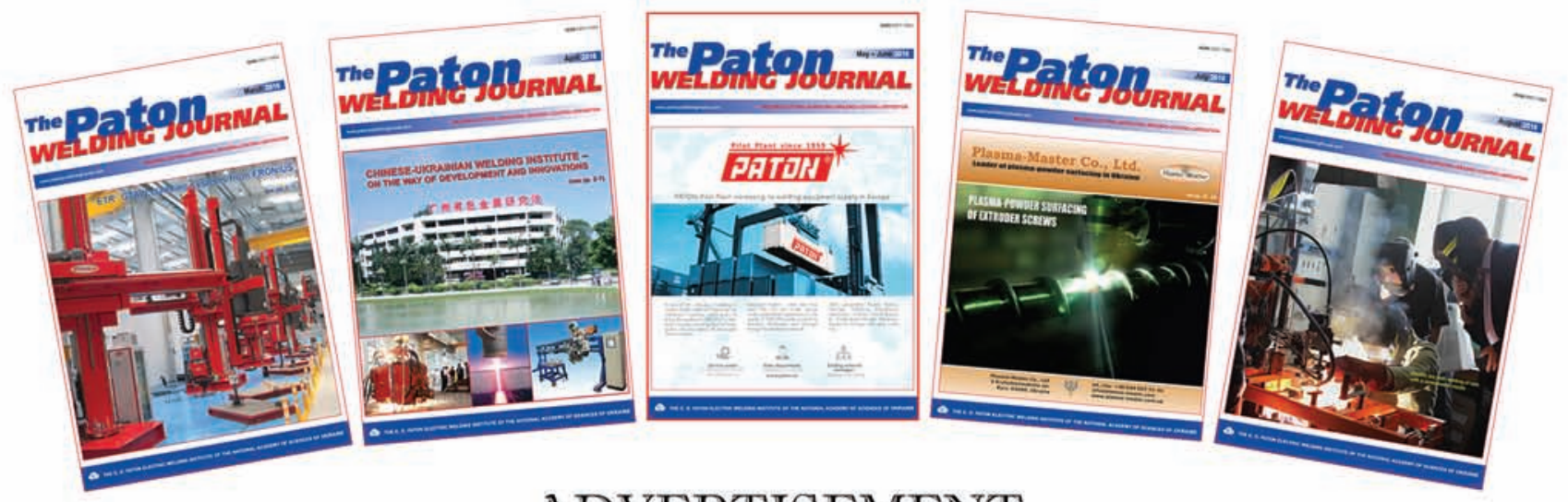

\section{ADVERTISEMENT}

in "Avtomaticheskaya Svarka" and "The Paton Welding Journal"

External cover, fully-colored:

First page of cover $(190 \times 190 \mathrm{~mm})-\$ 700$

Second page of cover $(200 \times 290 \mathrm{~mm})-\$ 550$

Third page of cover

$(200 \times 290 \mathrm{~mm})-\$ 500$

Fourth page of cover

$(200 \times 290 \mathrm{~mm})-\$ 600$
Internal cover, fully-colored: First/second/third/fourth page of cover $(200 \times 290 \mathrm{~mm})-\$ 400$

Internal insert:

Fully-colored $(200 \times 290 \mathrm{~mm})$ $\$ 340$

Fully-colored (double page A3) $(400 \times 290 \mathrm{~mm})-\$ 500$
- Article in the form of advertising is $50 \%$ of the cost of advertising area

- When the sum of advertising contracts exceeds $\$ 1001$, a flexible system of discounts is envisaged

Size of journal after cutting is $200 \times 290 \mathrm{~mm}$

Editorial Board of Journals «Avtomaticheskaya Svarka» and «The Paton Welding Journal» E.O. Paton Electric Welding Institute of the NAS of Ukraine International Association «Welding» 